\title{
Global Assesment of Interparticle Separation Distance on Low Cement Content Paste Mixtures
}

\author{
by \\ Gonzalo Alberto Lozano Rengifo
}

A Thesis submitted to the Faculty of Graduate and Postdoctoral Affairs in partial fulfillment of the requirements for the degree of

\section{Master of Applied Science}

in

Civil Engineering

Carleton University

Ottawa, Ontario

(C) 2020, Gonzalo Alberto Lozano Rengifo 


\begin{abstract}
A variety of research efforts on the concrete industry currently focus on the reduction of its most pollutant constituent, Portland cement (PC). Alternatives to reduce PC content in concrete such as the use of particle packing models (PPMs) and blended systems of PC and limestone fillers (LF) have been proven to be effective. However, the combined response of PPMs and LF at high levels of PC replacement still needs further investigation, particularly in the fresh state. In this work, the concept of Inter-particle Separation distance (IPS) is employed as a criterion to understand the behaviour of cementitious pastes made of PC and designed through continuous PPMs incorporating high LF dosages. Results suggest that IPS is a valuable tool to predict the fresh state behaviour of highly packed systems incorporating LF at low PC content. Moreover, the concept of interparticle

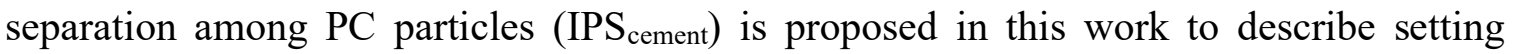
behaviour and compressive strength $\left(f^{\prime} c\right)$ of cementitious systems.
\end{abstract}


Dedications:

To the memory of my father: «Papá, you taught me the sacred value of family and the resilience to endure the toughest circumstances of life - Life is not always easy; it is on us to see the positive side of every experience because a simple smile can light up your day)>

To my beloved wife and son: «Adriana, Ian: you have become my strength and joy of living. My love thanks for your patience >) 


\section{Acknowledgements}

Looking back in time when I just finish my bachelor's degree, I realized my passion for learning and willingness for new challenges, and indeed the pursuit of this Thesis has been one of the most rewarding intellectual journeys I have ever had. However, in every travel story, there are divine forces and great people who guide your path, provide support in difficult time periods and walk alongside you, turning a tough experience into a great pleasure. Thereby, I would like to thank God for the opportunity to pursue my master studies.

I want to express my deepest gratitude to my supervisors, professors Leandro Sanchez and Ted Sherwood, who always advised me throughout my research, helping me to improve in academic and personal aspects. An especial appreciation to Dr. Sanchez who believed in my potential and make me see the beauty of research with his enthusiasm and passion for science.

To my mother and father, I only have thoughts of love and thankfulness for their support and spiritual enlightenment in the moments where I felt exhausted. Also, to my brother who has always pushed me to dream bigger and to think that everything is possible and to my sisters for believing in me

I would also like to thank to Carleton University and the Civil Engineering Department who accept me as graduate scholar and provided me with financial support.

Moreover, I wish to acknowledge my colleagues and friends, especially to Mayra de Grazia who were constantly available to advise me and to Derick Asirvatham for the great discussions that always cheer me up. 
Finally, I like to thank the lab technicians from Carleton and Ottawa University for their help and training in the laboratory. 


\section{Table of Contents}

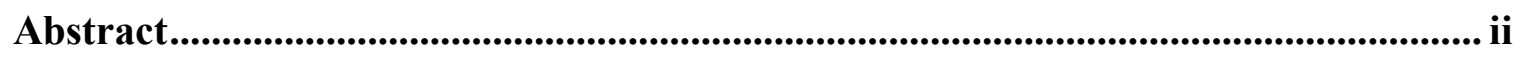

Acknowledgements ..................................................................................................................... iv

Table of Contents ............................................................................................... vi

List of Tables ........................................................................................................................... ix

List of Figures.................................................................................................................................. $\mathrm{x}$

Chapter 1: Introduction .............................................................................................................. 1

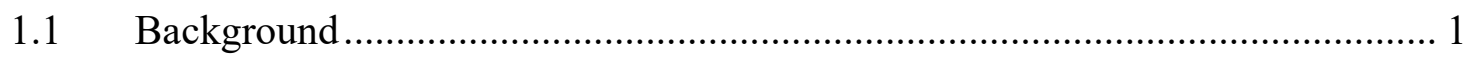

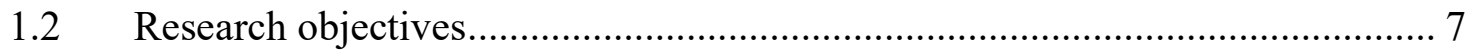

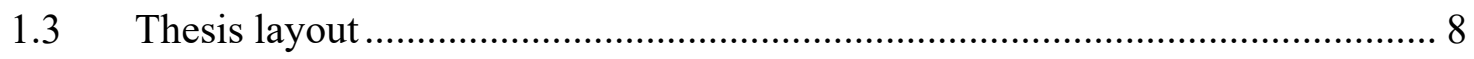

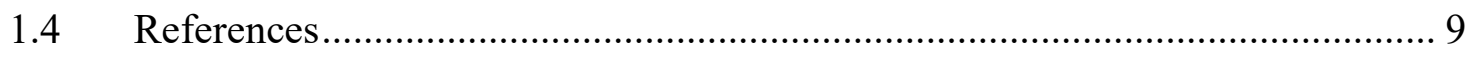

Chapter 2: Literature review .............................................................................................. 12

2.1 Cement paste and concrete mix-proportioning................................................ 12

2.1.1 ACI Method …………………………………..................................... 12

2.2 Advanced mix-design techniques: Particle packing models............................ 13

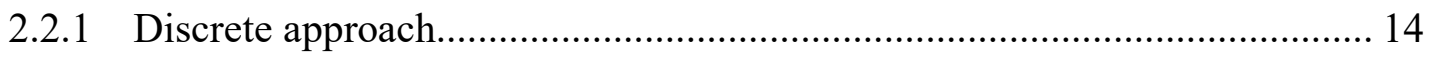

2.2.2 Continuous approach ......................................................................... 18

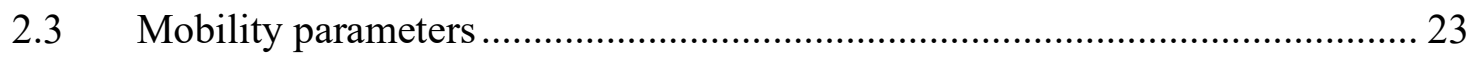

2.3.1 Interparticle Separation Distance (IPS) \& Maximum Paste Thickness (MPT) 23

2.3.2 Water Film Thickness (WFT) \& Paste Film Thickness (PFT) ..................... 26

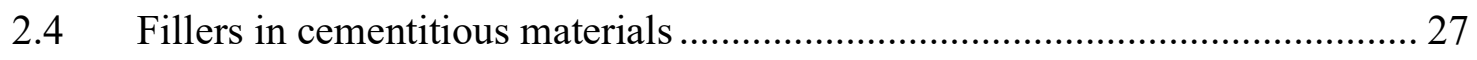

2.4.1 Overview: grindability, reactivity, dilution …………………................. 28 
2.4.2 Limestone filler in the fresh state............................................................... 30

2.4.3 Limestone filler in hydration and setting time ............................................. 31

2.4.4 Limestone filler in strength and packing ................................................... 32

2.4.5 Existing standards limiting filler content..................................................... 33

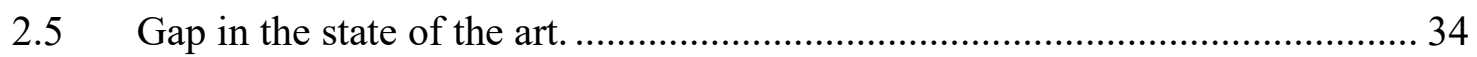

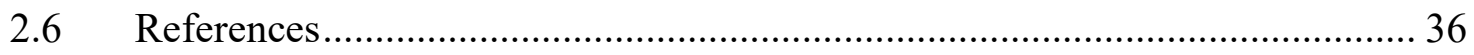

\section{Chapter 3: Assessment of Properties of Low Cement Content Paste Using} Interparticle Separation as an Insight on Fresh State...................................................... 42

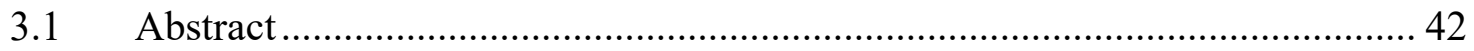

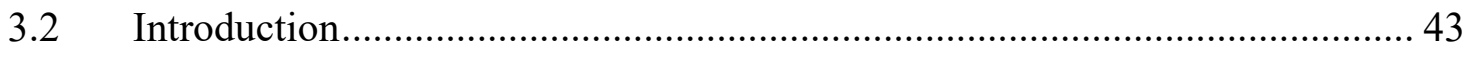

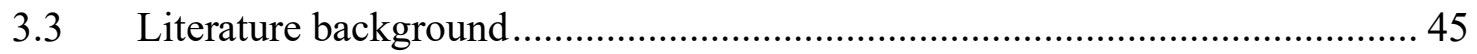

3.3.1 Particle Packing Models (PPM's) ................................................................ 45

3.3.2 Inter-Particle Separation Distance (IPS) ……………................................. 47

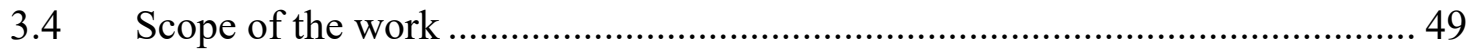

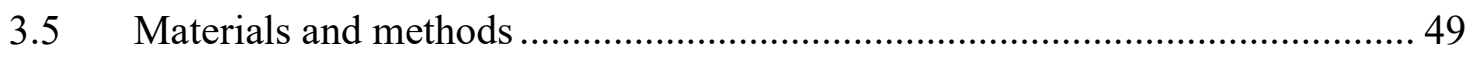

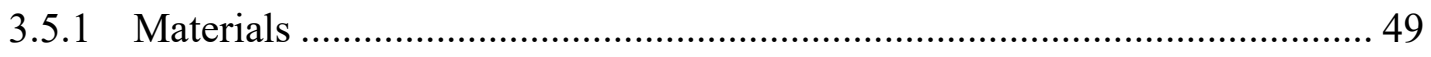

3.5.2 Mix-design and mixing procedure …………………................................. 51

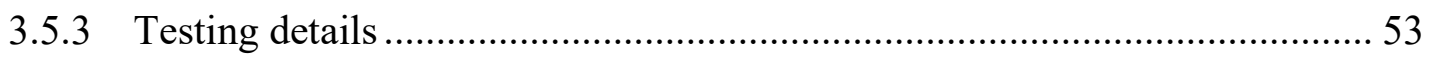

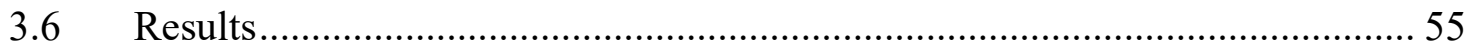

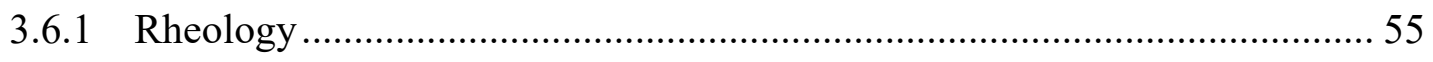

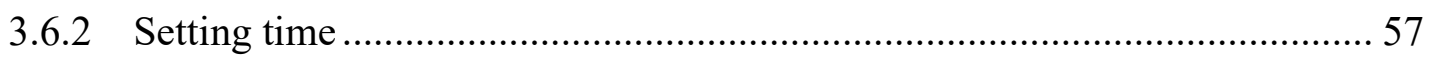

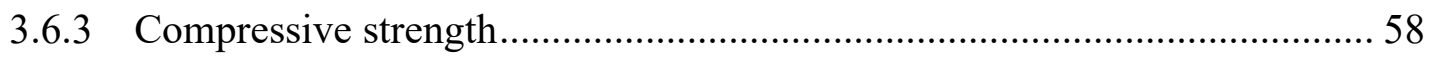

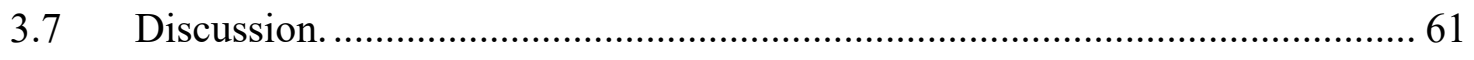

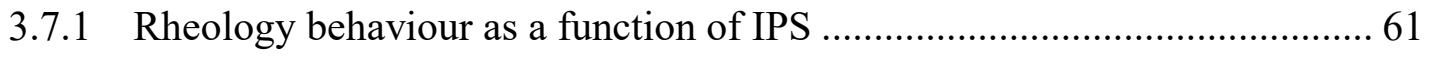




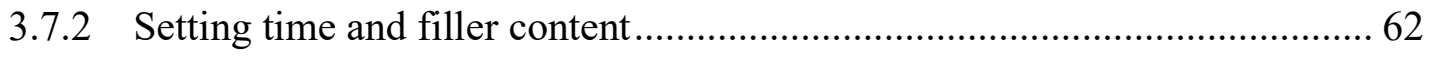

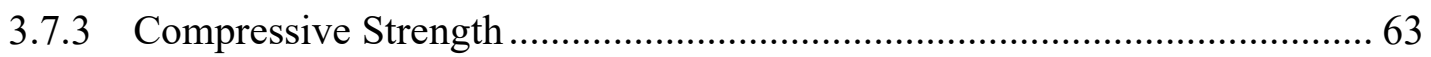

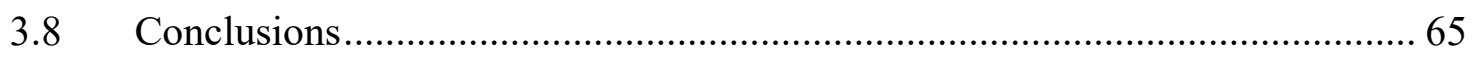

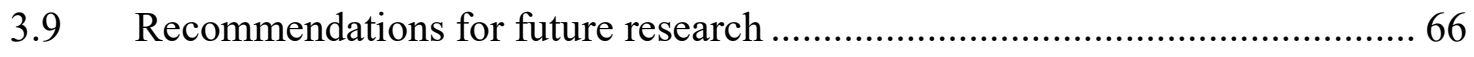

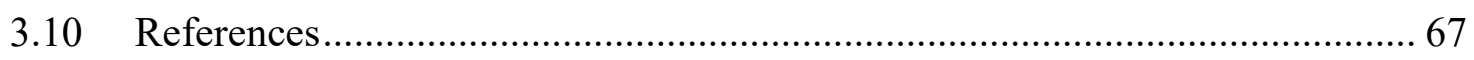

\section{Chapter 4: Influence of Inter-particles Separation Distance on the Properties of}

Low Cement Content Paste................................................................................. 71

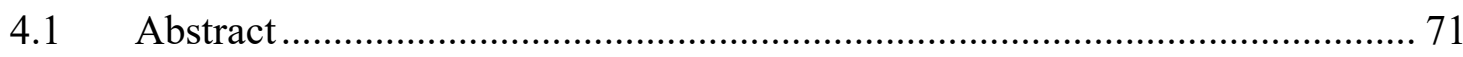

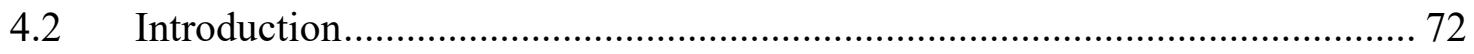

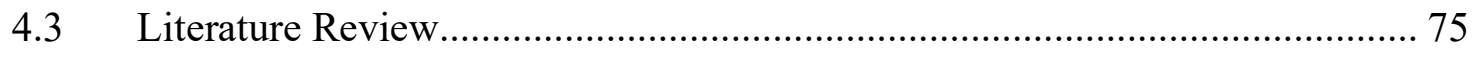

4.3.1 Limestone fillers in cementitious materials ..................................... 75

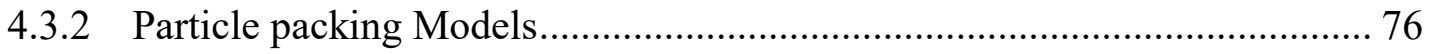

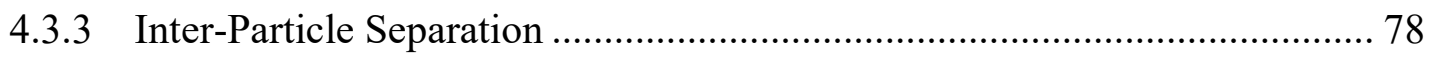

4.3.4 Fresh State behaviour of cementitious materials ................................... 79

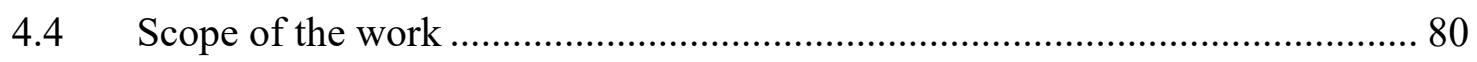

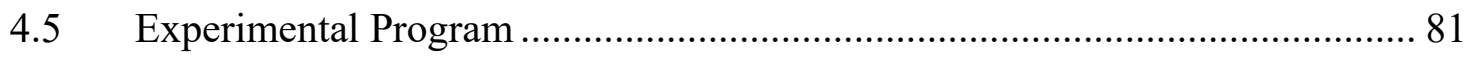

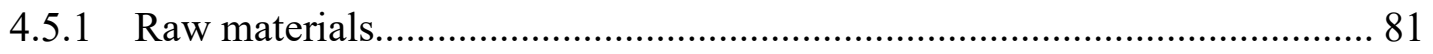

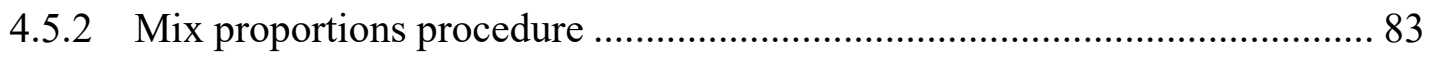

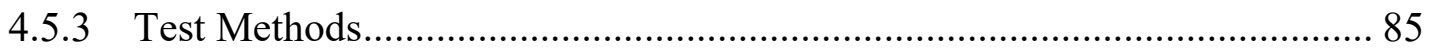

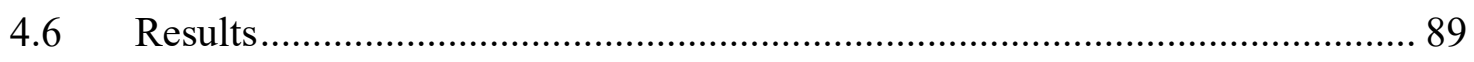

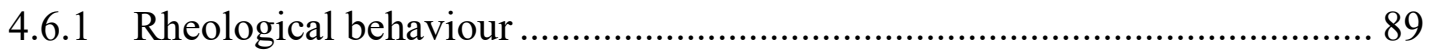

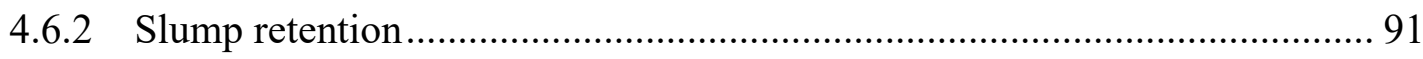

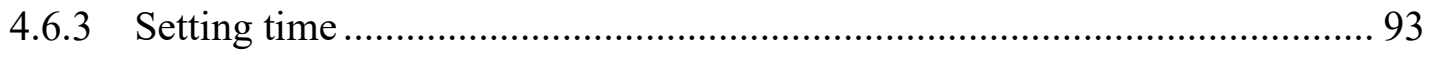

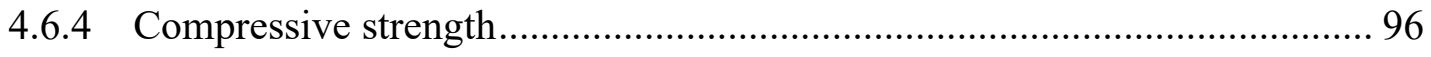


4.7 Discussion

4.7.1 Influence of the IPS on the viscosity behaviour of cementitious systems .... 97

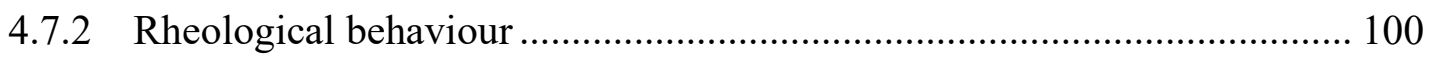

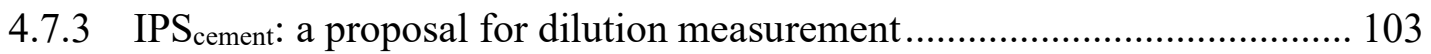

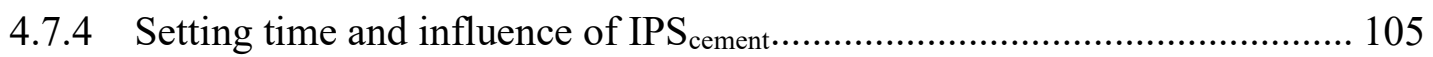

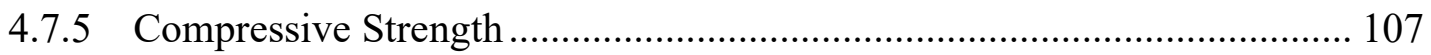

4.8 Conclusions .................................................................................... 111

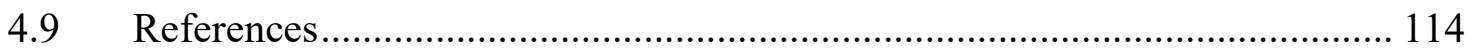

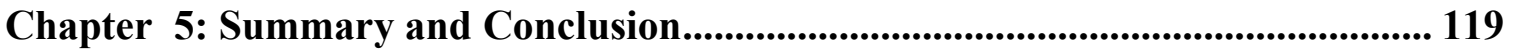

Chapter 6: Recommendations for future research ........................................... 121

\section{List of Tables}

Table 2-1: Properties of the different types of mineral fillers ...................................... 28

Table 2-2: Percentage of limestone fillers (wt.\%) allowed by current cement standard

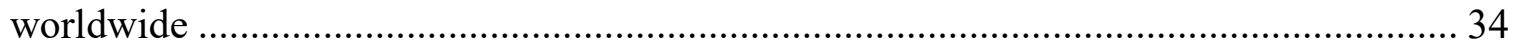

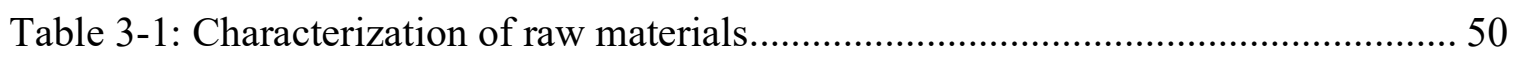

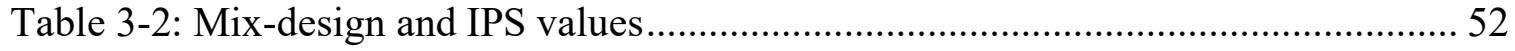

Table 3-3: Maximum value of viscosity reading for each spindle at different torque...... 53

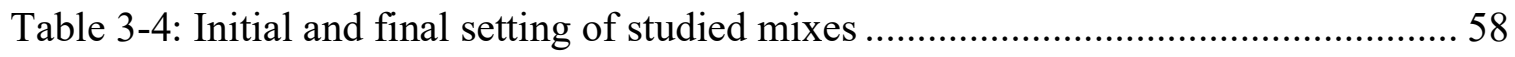

Table 4-1: Chemical composition of the Portland cement Type GU............................. 82

Table 4-2: Physical characterization of the powders ................................................ 82

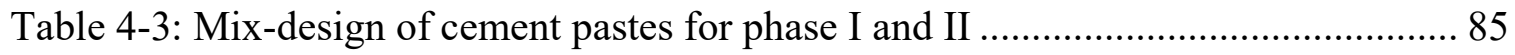

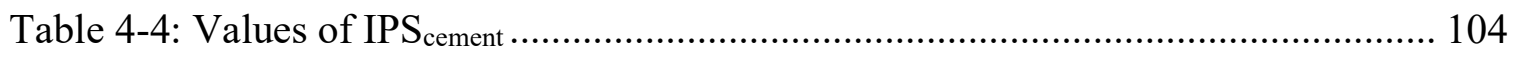




\section{List of Figures}

Figure 1-1: $\mathrm{CO}_{2}$ emmisions breakdown of concrete production supply chain .................. 2

Figure 1-2: Projection of the production rates of portland cement worldwide.................. 3

Figure 1-3: Production availability and use of possible materials substitutes of portland

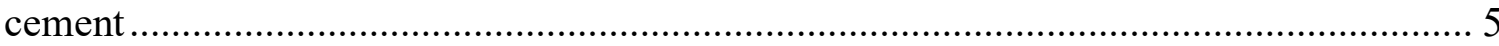

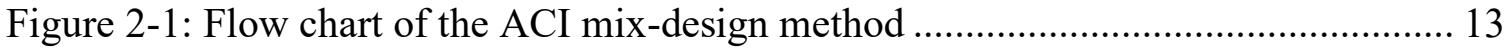

Figure 2-2:Particle packing optimization of a bi-modal suspension ............................ 16

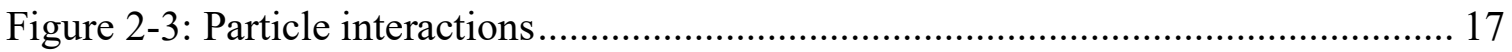

Figure 2-4: Similarity condition in the Andreassen packing model .............................. 19

Figure 2-5: Porosity of continuous distributions at different distribution factors ............ 22

Figure 2-6: Increase of the IPS with water increment ................................................ 24

Figure 2-7: Maximum paste thickness between coarser particles ............................... 25

Figure 2-8: Water film thickness surrounding different particles sizes ........................ 26

Figure 2-9: Water layer theory and packing theory ................................................ 31

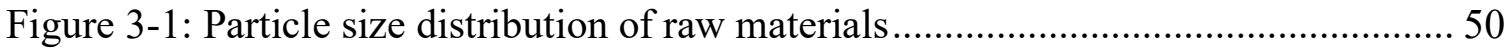

Figure 3-2 Shear history experienced by pastes during viscometer test....................... 54

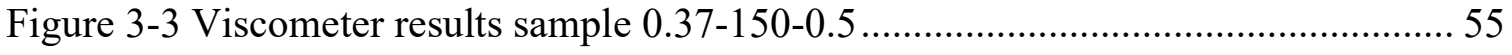

Figure 3-4 Rheological behaviour for all paste families........................................... 57

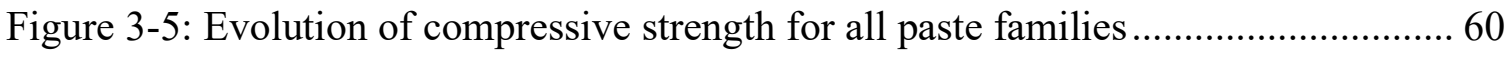

Figure 3-6 Viscosity of cement pastes at two different shear rates vs. Inter-Particle separation 
Figure 3-7 Compressive strength based on: a) water to cement ratio, b) water to fines ratio

Figure 4-1: Particle size distribution of cement GU and limestone fillers....................... 82

Figure 4-2: Equipment used for rheology measurements ....................................... 86

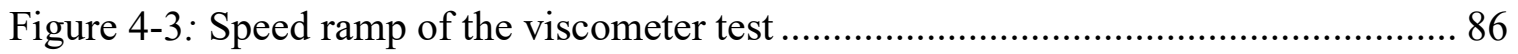

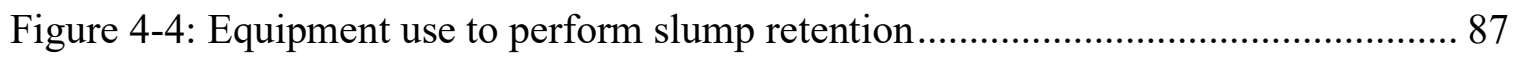

Figure 4-5: Viscosity results of the evaluated mixes at different rotation speeds ........... 90

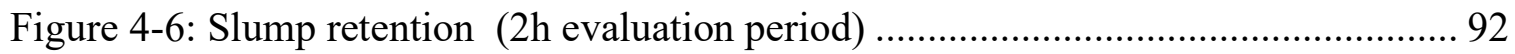

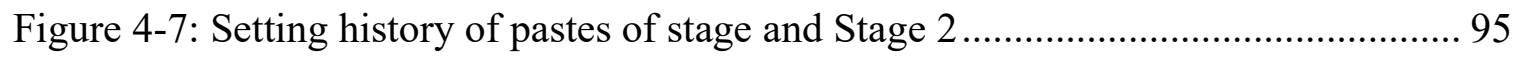

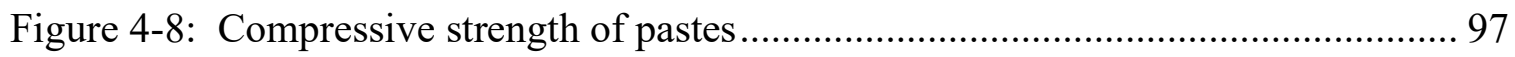

Figure 4-9: Relationship of IPS and viscosity at different shear rates......................... 98

Figure 4-10: Relationship of the IPS/ $\mathrm{d}_{0}$ and viscosity at different torque regimes........ 100

Figure 4-11: Differential viscosity and apparent viscosity determined at a given shear

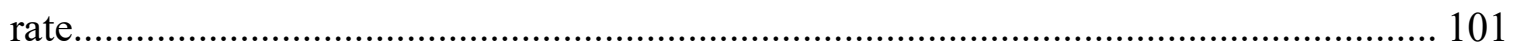

Figure 4-12: Rheological behaviour of pastes proportioned with distinct w/f ............. 102

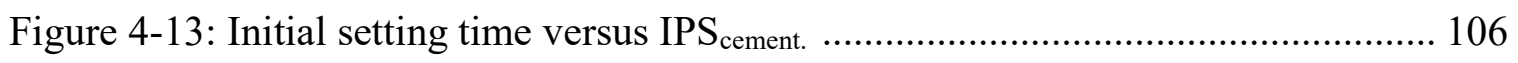

Figure 4-14: Compressive strength as function of water to fines ratio ........................ 108

Figure 4-15: Influence of water to cement and water to fines ratio in compressive strength

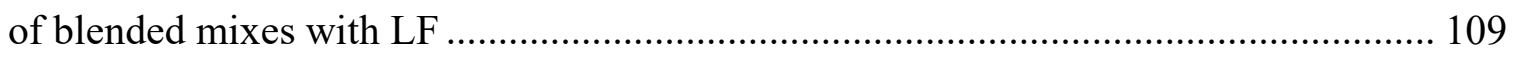

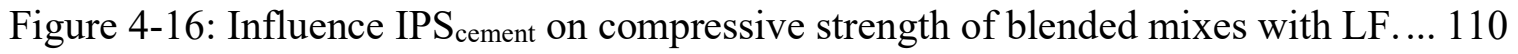




\section{Chapter 1: Introduction}

\subsection{Background}

Humankind has used cementing materials as far back as 6500 B.C. In ancient times, early forms of concrete or "muds" were used to coat surfaces and bind stones together. But it was not until the $19^{\text {th }}$ century, with the patent of Joseph Aspdin, that the name of Portland Cement (PC) appeared (Adrian Forty 2012; Mindess, Young, and Darwin 2003). Ever since, the combination of PC, water, and aggregates, better known as concrete, has been essential in the development of our modern society. Nowadays, concrete is the second most-consumed material on earth after freshwater (Filippo, Karpman, and Deshazo 2019). Its success is attributed to several advantages over other construction materials such as wood or steel. Firstly, properly designed concrete mixes can be water-resistant, enabling its application to multiple infrastructures exposed to water such as reservoirs, dams, aqueducts, offshore structures among others. Secondly, concrete behaves as a viscous fluid in the fresh state, flowing into formworks that allow the material to take almost any shape. Its versatility makes concrete useful for structural and architectural purposes. Third, it is widely available (Imbabi, Carrigan, and Mckenna 2013). Raw materials to produce aggregates and PC are available almost everywhere around the globe. Finally, production costs of conventional concrete are relatively inexpensive compared to other construction materials, besides that it can be designed to be a long-lasting material with low maintenance cost.

Despite the benefits of concrete, its production carries an enormous greenhouse gas (GHG) footprint, primarily related to PC, its main binder. A life cycle assessment cradle-to-gate for a conventional concrete $40 \mathrm{MPa}$ (Figure 1-1) shows that approximately $76 \%$ of concrete 
$\mathrm{CO}_{2}$ is generated in the production of PC (Filippo, Karpman, and Deshazo 2019; Turner and Collins 2013). The industrial process of PC production is highly energy-intensive and polluting. Limestone and clayey materials need to be heated up to $1450^{\circ} \mathrm{C}$ to form clinker, releasing 820 to 980 kilograms of $\mathrm{CO}_{2}$ per ton of clinker produced (Kajaste and Hurme 2016; Ruijven et al. 2016; Imbabi, Carrigan, and Mckenna 2013). Two of the three main sources of $\mathrm{CO}_{2}$ worldwide (i.e. oxidation of fossil fuels, deforestation, and carbonate decomposition) are involved in the process.

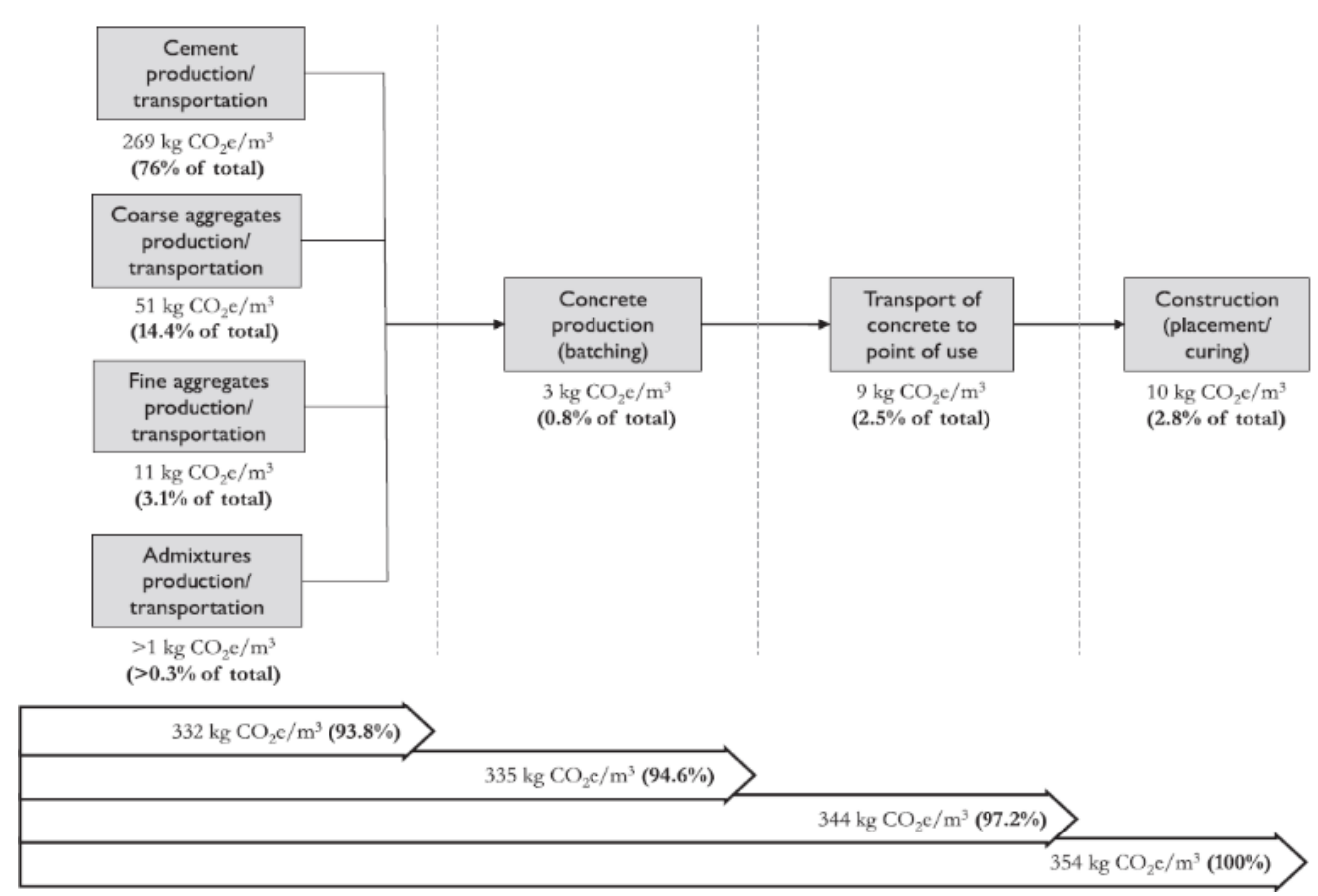

Figure 1-1: $\mathrm{CO}_{2}$ emmisions breakdown of concrete production supply chain (Filippo, Karpman, and Deshazo 2019)

First, calcination of the raw materials of $\mathrm{PC}$, standing as the largest source of $\mathrm{CO}_{2}$ from carbonate decomposition (Andrew 2018), liberates roughly 0.50 tons $\mathrm{CO}_{2} /$ ton PC (Andrew 2018). The chemical reaction is exemplified by the stoichiometry of one of the calcium silicates forming the cement, as shown in Equation 1-1 (Imbabi, Carrigan, and Mckenna 2013). Second, the energy required to heat the raw materials is generally provided by the 
combustion of fossil fuels, which depending on the efficiency of the kilns adds 0.32 to 0.42 tons $\mathrm{CO}_{2} /$ ton PC to the process (Filippo, Karpman, and Deshazo 2019).

$$
3 \mathrm{CaCO}_{3}+\mathrm{SiO}_{2} \stackrel{1450^{\circ} \mathrm{C}}{\longrightarrow} \mathrm{Ca}_{3} \mathrm{SiO}_{2}+3 \mathrm{CO}_{2}
$$

Equation 1-1

Studies suggest that the PC industry currently contributes as much as $8 \%$ of the total $\mathrm{CO}_{2}$ emitted worldwide (Andrew 2018; Filippo, Karpman, and Deshazo 2019; Gartner and Hirao 2015; Imbabi, Carrigan, and Mckenna 2013; Turner and Collins 2013; Kajaste and Hurme 2016; Ruijven et al. 2016). China and India account for two-thirds of the total global emissions, with $59 \%$ and $7 \%$ participation, respectively. $\mathrm{CO}_{2}$ emissions from the $\mathrm{PC}$ industry might increase in the future if no corrective actions are taken. Historical records reveal that cement production is rapidly increasing. According to (Miller et al. 2018) 4500 million tons of PC were produced in 2015 worldwide, a more than 25 -fold increase since 1950 (Andrew 2018; Kajaste and Hurme 2016), as shown in Figure 1-2.

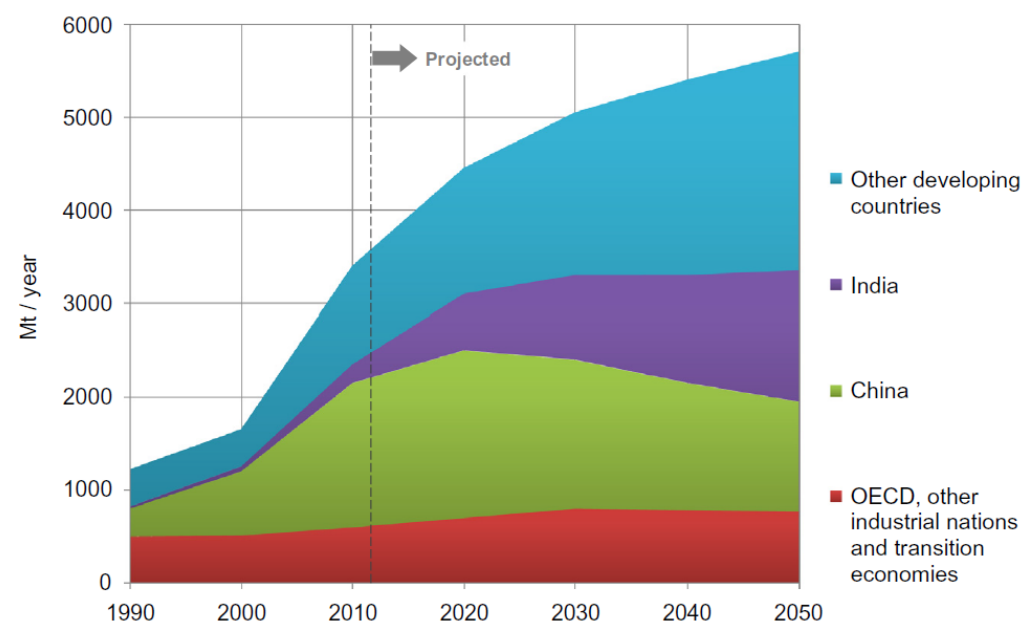

Figure 1-2: Projection of the production rates of portland cement worldwide (Andrew 2018)

Forecasting models predict a $24 \%$ increase by 2050 , reaching 5600 million of tons of PC per year, equivalent to approximately 5000 million tons of $\mathrm{CO}_{2}$ (Imbabi, Carrigan, and Mckenna 2013; C. Zhang et al. 2018). Other models under various socio-economic scenarios predict emission growth until 2050 where reduction or stabilization of the 
emission trends will be seen if sustainable development is achieved, otherwise, $\mathrm{CO}_{2}$ emissions from the PC industry will keep rising at least until 2100 (C. Zhang et al. 2018; Mehta 2002).

Awareness of the previous situation has pushed the scientific community to develop solutions to reduce GHG emissions from the PC industry. Three main paths have been proposed; 1) reducing emissions from the energy spent burning fuels for the calcination process, 2) alternative cement types that avoid carbonate decomposition, and 3) cement reduction or replacement (Haegermann 2002; Scrivener, John, and Gartner 2018). The first one implies technological renovations in the cement plants to improve energy efficiency or even change the source of fuel by renewable energy or alternative fuels with low or zero carbon footprint. This approach requires a medium-term adaptation and an important investment in new technologies. The second approach considers belite - ye'elimite cement, produced in similar conditions as Portland Cement (PC) but with less limestone content. They are normally used for niche applications due to low early strengths (i.e. belite cement) or elevated prices (ye'elimite cement). Another alternative cement is magnesium-based cement from ultramafic rocks (basic magnesium silicates). They may become carbon negative cement, yet this technology is in the early stages of research and it is only expected to be available for large scale in the long term (Filippo, Karpman, and Deshazo 2019; Scrivener, John, and Gartner 2018; Imbabi, Carrigan, and Mckenna 2013). Finally, cement reduction and/or replacement cement is already a well stablished strategy with great potential for improvement in the short term.

Cement reduction refers to lessening PC content in cementitious materials by optimizing their particle size distribution (PSD), reducing inner porosity. This technique is called 
particle packing models (PPMs) and it has proved to effectively reduce up to $50 \%$ of PC content of concrete mixtures (Fennis and Walraven 2012b). On the other hand, PC replacement is commonly performed with traditional supplementary cementitious materials (SCM) such as granulated blast furnace slag (GBFS), fly ash (FA), or silica fume (SF) (Lothenbach, Scrivener, and Hooton 2011a). They can be used to replace PC up to $80 \%$ for GBFS, $70 \%$ for FA and $40 \%$ for SF (Filippo, Karpman, and Deshazo 2019), however conventional concrete mixtures normally use relatively small amounts of SCM's, between 5 to $20 \%$ of PC replacement. The latter is driven by code restrictions (Mehta 2002), economic reasons, and most importantly, local unavailability and shortage of traditional SCM's (Scrivener, John, and Gartner 2018). A very important amount of their current availability is already used in cement and concrete production, yet this is not enough to face the current and future PC demand. Moreover, global decarbonization, promoting the shutdown of coal combustion power plants, steel recycling, and improving steel-making technologies will certainly reduce the source availability of FA and GBFS in the future (Scrivener, John, and Gartner 2018; Snellings 2016).

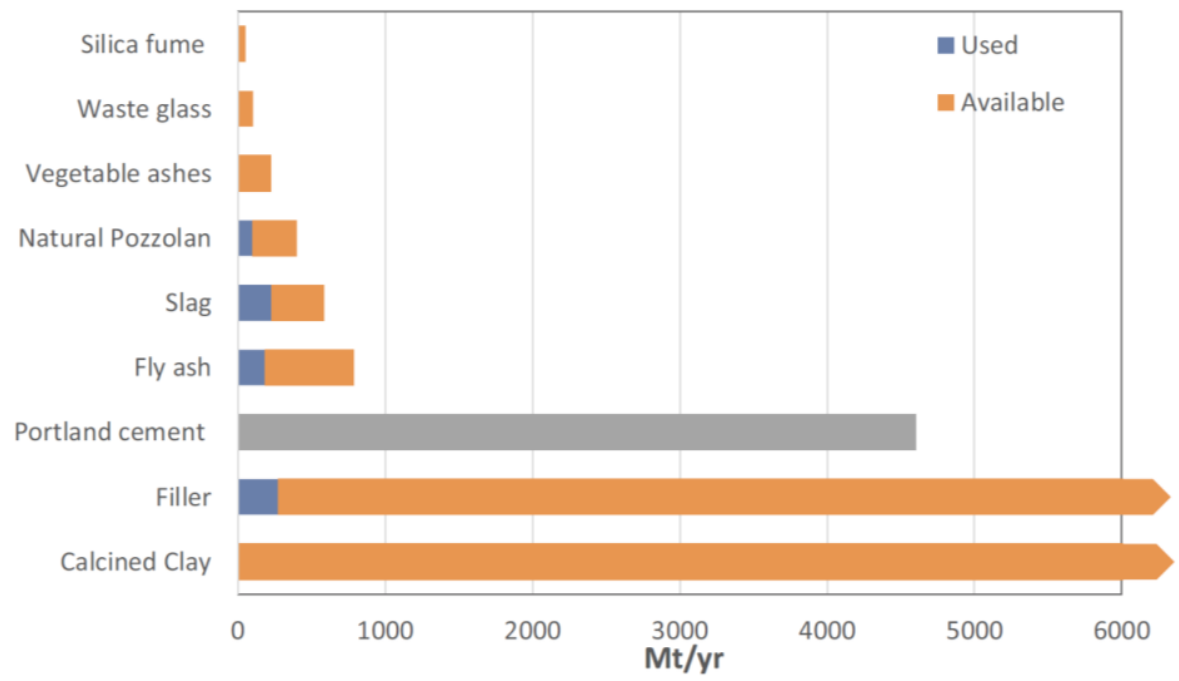

Figure 1-3: Production availability and use of possible materials substitutes of portland cement (Scrivener, John, and Gartner 2018) 
Fortunately, other materials can serve as PC substitutes such as mineral fillers (MF). MFs display an enormous potential to reduce $\mathrm{CO}_{2}$ emissions from the cement industry and overcome the shortages of SCM's, Figure 1-3. Multiple minerals can be used as MFs, therefore they are available everywhere in the world in large quantities and their manufacturing only requires energy for grinding processes, all of which result in low market prices. The most usual and accepted filler comes from limestone rocks, designated hereafter as limestone filler (LF). Current standards allow LF replacement from 5 to $35 \%$ depending on the country (John et al. 2018b). However, higher replacement levels can be achieved with advanced mix-proportioning techniques.

PPMs and LFs can be used simultaneously to develop eco-efficient cementitious materials. Numerous studies suggest that engineered use of fillers and appropriate mix-designs can lead to PC substitutions of $70-75 \%$, achieving compressive strengths $\left(f^{\prime} c\right)$ up to $90 \mathrm{MPa}$ (John et al. 2018a; Proske et al. 2013, 2014, 2018; Palm et al. 2016). However, highly packed systems at high content of LF may face some challenges in the fresh state (Yousuf, Sanchez, and Shammeh 2019; de Grazia et al. 2019; de Grazia, Sanchez, and Pileggi 2018), caused by low free water in the mixtures and the presence of fine particles with elevated specific surface area (SSA) (Ling and Kwan 2016).

Aiming to control and improve the fresh state performance of packed cementitious systems, the concept of mobility parameters was developed. First Funk and Dinger (1994) proposed the Interparticle Separation Distance - IPS as the distance between two adjacent fine particles $(<100 \mu \mathrm{m})$. IPS was scaled up for coarser particles of concrete and was called Maximum paste thickness - MPT (de Oliveira et al. 2000). Viscosity reduction and flow enhancement have been observed for increasing distance between particles (Funk and 
Dinger 1994; F.S. Ortega et al. 2002). Moreover, some studies have demonstrated the potential benefits of coupling PPM and mobility parameters to better describe fresh state behaviour of cementitious mixtures (de Grazia, Sanchez, and Pileggi 2018; de Grazia et al. 2019). However, very few studies have worked on the impact of IPS on the overall fresh state outcomes of highly packed cementitious mixtures with significant LF dosages. Additionally, the range of IPS values to be selected for targeting different fresh state performances, as well as the influence of IPS on hardened state properties (e.g. compressive strength) of cementitious mixtures are still unknown and require further investigation.

\subsection{Research objectives}

This project investigates the influence of IPS as a predictive tool on the fresh (i.e. rheology, slump flow, setting behaviour) and hardened (i.e. compressive strength) state properties of low cement content paste mixtures designed through continuous PPMs and incorporating high LF dosages. Forty-two paste mixtures were developed in two phases of the experimental campaign. The first stage includes 21 mixtures with concrete equivalent cement contents of 250,150 and $100 \mathrm{~kg} / \mathrm{m}^{3}$. Three water to fines ratio (i.e. water/(PC+LF) $-\mathrm{w} / \mathrm{f}$ ) were defined (i.e. $0.32,0.40$, and 0.50 ) to reproduce similar cement paste volumes implemented on pure PC concrete mixtures and to validate the significance of this parameter (i.e. w/f) on hardened properties. Finally, two different packing conditions were evaluated.

The second phase of the research explores the effects of chemical admixtures (plasticizers) on fresh and hardened state properties of packed cementitious systems with low PC 
contents and high LF dosages. A comparison among the outcomes of the different phases is performed.

New insights and equations describing the behaviours observed are proposed aiming to extend the body of knowledge and increase confidence in the use of high amounts of limestone fillers to reduce cement content and further use of this type of binder for structural applications.

\subsection{Thesis layout}

The present thesis comprises five chapters, with the main chapters corresponding to scientific papers that intend to address the research gaps and objectives aforementioned. Chapter 1 shows a brief description of the environmental context of PC and concrete industry and the possible solutions available to produce eco-friendly cementitious materials. The research performed throughout this Thesis focus on the combination of two of the possible methodologies described. Then, the scope of the work and research objectives are presented, followed by the present Thesis layout. Chapter 2 is a brief literature review of the methodologies regarding carbon footprint reduction, particle packing models, and mineral fillers. Moreover, the concepts of rheology and mobility parameters are introduced. Chapter 3 is a conference paper accepted by ACI/RILEM International Conference on Cementitious Materials and Alternative Binders for Sustainable Concrete. The paper focuses on the fresh (i.e. viscosity) and hardened state properties (i.e. compressive strength) of cementitious pastes designed using PPMs and high filler contents. It explores the use of mobility parameters (i.e. Inter-Particle Separation IPS) to predict the fresh state behaviour of 21 mixtures without chemical admixtures. Chapter 4 is a journal paper that provides a comprehensive study on the influence of IPS 
on several properties (i.e. fresh and hardened state properties) of 42 cementitious mixtures with and without chemical admixtures (i.e. superplasticizers + midrange). In this chapter new equations and models, based on the IPS, are proposed to predict the fresh state behaviour (i.e. rheology and setting time) and compressive strength of paste mixtures containing high amount of limestone fillers and low cement content. Finally, Chapter 5 describes the main conclusions gathered over the current research and proposes topics for further investigation.

\subsection{References}

Adrian Forty. 2012. Concrete and Culture-A Material History. London: Reaktion Books. Andrew, Robbie M. 2018. "Global CO2 Emissions from Cement Production, 19282017." Earth System Science Data 10 (4): 2213-39. https://doi.org/10.5194/essd-102213-2018.

F.S. Ortega, R.G. Pileggi, A.R. Studart, and V.C. Pandofelli. 2002. "IPS A Viscosity Predictive Parameter." American Ceramic Society Bulletin 81 (1): 44-52.

Fennis, S.A.A.M., and Joost C. Walraven. 2012. "Using Particle Packing Technology for Sustainable Concrete Mixture Design." Heron 57 (2): 73-101.

Filippo, James Di, Jason Karpman, and J R Deshazo. 2019. "The Impacts of Policies to Reduce CO 2 Emissions within the Concrete Supply Chain." Cement and Concrete Composites 101 (August 2018): 67-82. https://doi.org/10.1016/j.cemconcomp.2018.08.003.

Funk, James E., and Dennis R. Dinger. 1994. Predictive Process Control of Crowded Particulate Suspensions. https://doi.org/10.1007/978-1-4615-3118-0.

Gartner, Ellis, and Hiroshi Hirao. 2015. "A Review of Alternative Approaches to the Reduction of CO 2 Emissions Associated with the Manufacture of the Binder Phase in Concrete." Cement and Concrete Research 78: 126-42. https://doi.org/10.1016/j.cemconres.2015.04.012.

Grazia, M.T. de, L.F.M. Sanchez, R.C.O. Romano, and R.G. Pileggi. 2019. "Investigation of the Use of Continuous Particle Packing Models (PPMs) on the Fresh and Hardened Properties of Low-Cement Concrete (LCC) Systems." Construction and Building Materials 195: 524-36. https://doi.org/10.1016/j.conbuildmat.2018.11.051.

Grazia, M.T. de, Leandro F. M. Sanchez, and Rafael G. Pileggi. 2018. "Evaluation of the Fresh and Hardened State Properties of Low Cement Content Systems." Magazine of Concrete Research 72 (5): 232-45.

Haegermann, Bernd. 2002. "The Cement Industry Sustainability Initiative Within the World Business Council for Sustainable Development." Vdz Congress, 506-13.

Imbabi, Mohammed S, Collette Carrigan, and Sean Mckenna. 2013. "Trends and Developments in Green Cement and Concrete Technology." International Journal 
of Sustainable Built Environment 1 (2): 194-216.

https://doi.org/10.1016/j.ijsbe.2013.05.001.

John, Vanderley M., Bruno L. Damineli, Marco Quattrone, and Rafael G. Pileggi. 2018a.

"Fillers in Cementitious Materials - Experience, Recent Advances and Future

Potential." Cement and Concrete Research 114 (September 2017): 65-78. https://doi.org/10.1016/j.cemconres.2017.09.013.

John, Vanderley M., Bruno L. Damineli, Marco Quattrone, and Rafael G Pileggi. 2018b. "Cement and Concrete Research Fillers in Cementitious Materials - Experience, Recent Advances and Future Potential." Cement and Concrete Research 114 (September 2017): 65-78. https://doi.org/10.1016/j.cemconres.2017.09.013.

Kajaste, Raili, and Markku Hurme. 2016. "Cement Industry Greenhouse Gas Emissions e Management Options and Abatement Cost." Journal of Cleaner Production 112: 4041-52. https://doi.org/10.1016/j.jclepro.2015.07.055.

Ling, S K, and Albert K.H. Kwan. 2016. "Adding Limestone Fines as Cementitious Paste Replacement to Lower Carbon Footprint of SCC." Construction and Building Materials 111: 326-36. https://doi.org/10.1016/j.conbuildmat.2016.02.072.

Lothenbach, Barbara, Karen Scrivener, and R. D. Hooton. 2011. "Cement and Concrete Research Supplementary Cementitious Materials." Cement and Concrete Research 41 (12): 1244-56. https://doi.org/10.1016/j.cemconres.2010.12.001.

Mehta, Kumar P. 2002. "Greening of the Concrete Industry for Sustainable Development." Concrete International 24 (7): 23-28.

Miller, Sabbie A, Vanderley M. John, Sergio A Pacca, and Arpad Horvath. 2018. "Cement and Concrete Research Carbon Dioxide Reduction Potential in the Global Cement Industry by 2050." Cement and Concrete Research 114 (August 2017): 115-24. https://doi.org/10.1016/j.cemconres.2017.08.026.

Mindess, Sidney, Francis J Young, and David Darwin. 2003. Concrete. 2nd Edition. Edited by Inc Pearson Educatioon. New jersey: Prentice Hall.

Oliveira, I.R. de, A.R. Studart, R.G. Pileggi, and V.C. Pandolfelli. 2000. Dispersão e Empacotamento de Partículas: Principios e Aplicações Em Processamento Cerâmico. Sao Paulo: Fazendo Arte.

Palm, Sebastian, Tilo Proske, Moien Rezvani, Stefan Hainer, Christoph Müller, and Carl Alexander Graubner. 2016. "Cements with a High Limestone Content - Mechanical Properties , Durability and Ecological Characteristics of the Concrete." Construction and Building Materials 119: 308-18.

Proske, Tilo, Stefan Hainer, Moien Rezvani, and Carl Alexander Graubner. 2013. "EcoFriendly Concretes with Reduced Water and Cement Contents - Mix Design Principles and Laboratory Tests." Cement and Concrete Research 51: 38-46. https://doi.org/10.1016/j.cemconres.2013.04.011.

_ 2014. "Eco-Friendly Concretes with Reduced Water and Cement Content - Mix Design Principles and Application in Practice." Construction and Building Materials 67 (PART C): 413-21. https://doi.org/10.1016/j.conbuildmat.2013.12.066.

Proske, Tilo, Moien Rezvani, Sebastian Palm, Christoph Müller, and Carl Alexander Graubner. 2018. "Concretes Made of Efficient Multi-Composite Cements with Slag and Limestone." Cement and Concrete Composites 89: 107-19.

https://doi.org/10.1016/j.cemconcomp.2018.02.012.

Ruijven, Bas J Van, Detlef P Van Vuuren, Willem Boskaljon, Maarten L Neelis, Deger 
Saygin, and Martin K Patel. 2016. "Resources, Conservation and Recycling LongTerm Model-Based Projections of Energy Use and CO 2 Emissions from the Global Steel and Cement Industries." "Resources, Conservation \& Recycling" 112: 15-36. https://doi.org/10.1016/j.resconrec.2016.04.016.

Scrivener, Karen L, Vanderley M. John, and Ellis Gartner. 2018. "Eco-Efficient Cements : Potential Economically Viable Solutions for a Low-CO 2 Cement-Based Materials Industry." Cement and Concrete Research 114 (February): 2-26. https://doi.org/10.1016/j.cemconres.2018.03.015.

Snellings, Ruben. 2016. "Assessing, Understanding and Unlocking Supplementary Cementitious Materials.” RILEM Technical Letters 1: 50. https://doi.org/10.21809/rilemtechlett.2016.12.

Turner, Louise K, and Frank G Collins. 2013. "Carbon Dioxide Equivalent ( CO 2 -e ) Emissions : A Comparison between Geopolymer and OPC Cement Concrete" 43: $125-30$.

Yousuf, S., L.F.M. Sanchez, and S.A. Shammeh. 2019. "The Use of Particle Packing Models (PPMs) to Design Structural Low Cement Concrete as an Alternative for Construction Industry." Journal of Building Engineering 25 (October 2018): 100815. https://doi.org/10.1016/j.jobe.2019.100815.

Zhang, Cheng-yao, Rong Han, Biying Yu, and Yi-ming Wei. 2018. “Accounting ProcessRelated CO 2 Emissions from Global Cement Production under Shared Socioeconomic Pathways." Journal of Cleaner Production 184: 451-65. https://doi.org/10.1016/j.jclepro.2018.02.284. 


\section{Chapter 2: Literature review}

\subsection{Cement paste and concrete mix-proportioning.}

Cement paste can be considered as an essential phase of concrete mixtures since most of the concrete properties rely on the paste quality. Adequate mix-proportioning of concretes defines the volume of the cement paste and its flow properties that ultimately will set the rheological behaviour of the fresh concrete. Moreover, parameters such as water to cement ratio, type of mineral additions for the paste, and chemical composition of the fine particles (i.e. $<100 \mu \mathrm{m}$ ), among others are defined during the concrete mix-proportioning. Those variables will influence hardened properties as compressive strength and durability related aspects.

Furthermore, in the mix-proportioning process, one may find potential opportunities to reduce the carbon footprint of concrete materials, by optimizing the paste volume and reducing the PC content, the most pollutant constituent of concrete.

\subsubsection{ACI Method}

ACI method, an absolute volume mix-proportioning method, is a conventional concrete mix-design procedure largely used in North America. Figure 2-1 describes the step by step procedure of ACI. 


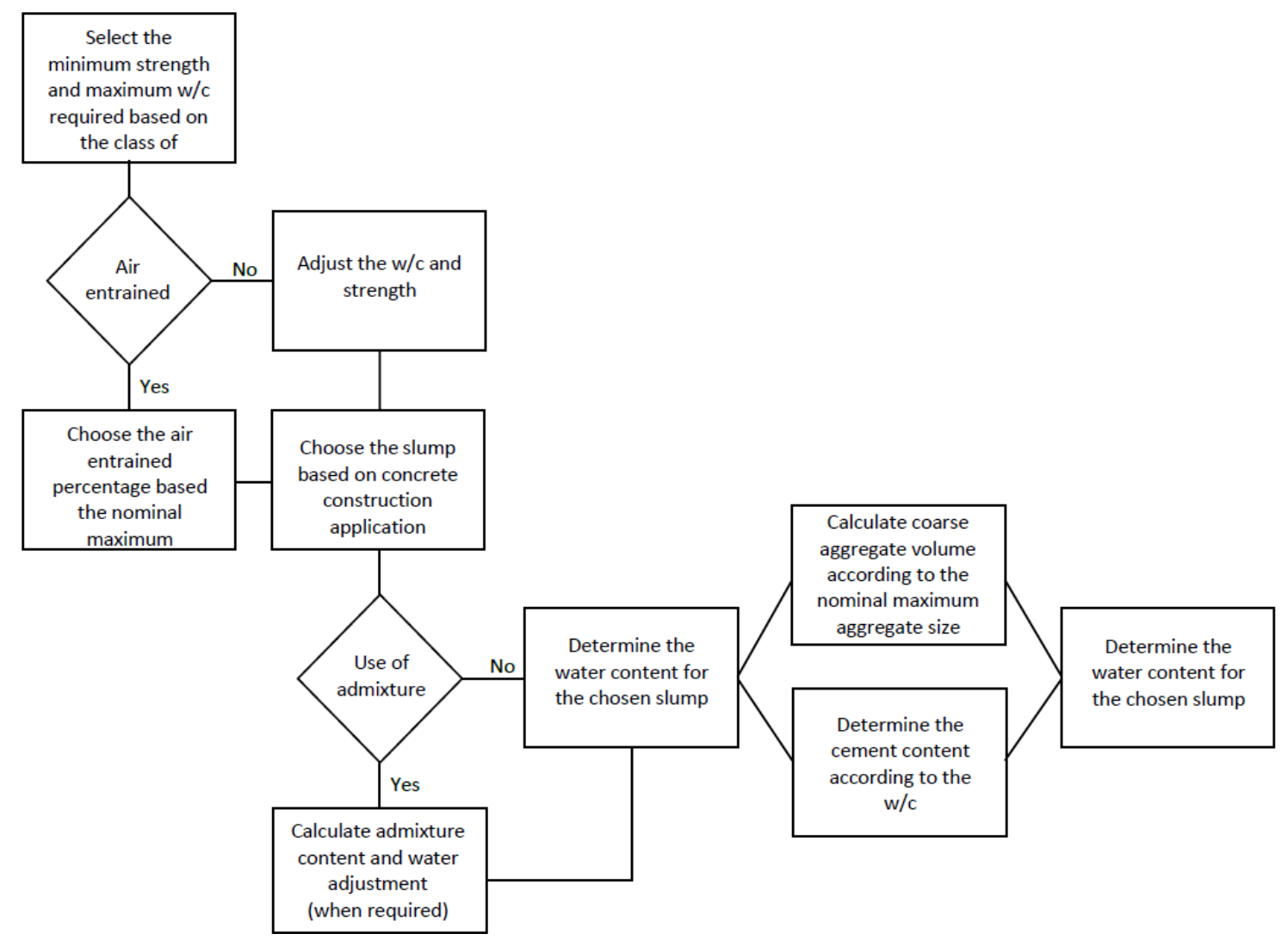

Figure 2-1: Flow chart of the ACI mix-design method (de Grazia 2018)

Exposure conditions and consistency (i.e. slump value) are the main parameters that enable the selection of the water-to-cement ratio and water content, therefore the concrete class or $f^{\prime} c$. The ACI method is commonly used due to its simplicity and straightforward approach. However, concrete mix-proportioning by the ACI method often results in non-eco-friendly mixtures with moderate to high PC contents. In fact, ACI guidelines recommend a minimum PC content of $335 \mathrm{~kg} / \mathrm{m}^{3}$ for concrete mixtures exposed to de-icing salts.

\subsection{Advanced mix-design techniques: Particle packing models}

Manufacturing cementitious mixtures with low cement content (i.e. eco-friendly mixtures) require more engineering techniques rather than empirical approaches. One of the alternatives is the use of Particle Packing Models (PPMs) which is used to improve the granular skeleton (or diminish voids) of cementitious materials by selecting the right 
amounts and sizes of particles within the system (Kumar and Santhanam 2003). Void reduction implies increasing packing density $\left(\Phi_{\mathrm{p}}\right)$, defined as the volume proportion of the solid particles in a bulk unit volume (Equation 2-1). It occurs with the addition of small particles in the voids created among the larger particles. Smaller voids left between small particles can further be filled with even smaller particles and so on (Fennis and Walraven 2012b; Dinger and Funk 1997).

$$
\phi_{p}=\frac{V_{\text {solid }}}{V_{\text {Total }}}
$$

Void reduction in the granular skeleton (i.e. coarse particles $>100 \mu \mathrm{m}$ ) of concrete mixtures implies less space to be filled with cement paste, thus decreasing the overall amount of cement paste required (Moini et al. 2015; Yousuf, Sanchez, and Shammeh 2019). Optimization of the particle size distribution (PSD) of the fine portion of concrete (i.e. powders forming the cement paste $<100 \mu \mathrm{m}$ ) is also possible and can lead to a further reduction in the interparticle porosity. Part of the water previously allocated within the pores is released as free water that could be employed to improve flow (Kwan and Chen 2012) or be removed out of the system by decreasing the w/c (Larrard 1989).

PPMs are studied since the beginning of the $20^{\text {th }}$ century. They are mainly divided in two categories: discrete and continuous models (Dinger and Funk 1997; Kumar and Santhanam 2003; Mangulkar and Jamkar 2013) and they are further explained in the next sections.

\subsubsection{Discrete approach}

Discrete models consider two or more narrow size classes or mono-dispersions (i.e. group of particles of equal size). The fundamental assumption states that all class sizes are packed to their maximum density, starting from the coarsest particles $\left(\mathrm{d}_{1}\right)$ which forms a fixed skeleton ( $\Phi_{\mathrm{p}}=0.60$ for random packing). Then, smaller particles $\left(\mathrm{d}_{2}\right)$ pack within the voids 
left of the first arrangement. If more than two size classes are selected, a third particle $\left(\mathrm{d}_{3}\right)$ needs to be small enough to be packed within the voids left by the first and second arrangements (Kumar and Santhanam 2003; Dinger and Funk 1997). For perfect packing, the size ratio between adjacent size classes was originally set around 1:100 (Funk and Dinger 1994; Dinger and Funk 1997). Recent developments proved that size ratios of 1:7 are adequate to provide high packing in multimodal distributions (i.e. $\geq 3$ class sizes) (Dinger and Funk 1997; Shenoy 1999). These systems are known as gap-graded due to the absence of all the other possible sizes in between the selected class sizes, as visualized in Figure 2-2.

The first discrete PPM was developed by Furnas $(1929,1931)$ who developed the analytical equations to calculate the packing density of bimodal dispersions. Two scenarios are considered: first, coarse-grained dominant (Equation 2-2), where the amount of coarse particles is larger, providing the fixed structure, and the small particles are packed within their voids. Second, fine-grained dominant (Equation 2-3), where the volume proportion of small particles is larger, and the coarse particles are embedded in the fines.

$$
\begin{gathered}
\phi_{p}=\frac{\phi_{1}}{1-r_{2}}=\frac{\phi_{1}}{r} \\
\phi_{p}=\frac{1}{r_{1}+\left(\frac{r_{2}}{\phi_{2}}\right)}
\end{gathered}
$$

Equation 2-2

In the latter equation $\Phi_{\mathrm{p}}, \Phi_{1}$ and $\Phi_{2}$ are the packing densities of the mixture, the larger and the smaller size, respectively. $r_{1}$ and $r_{2}$ are the volume fractions of larger and small class sizes.

A graphical representation of the $\Phi_{\mathrm{p}}$ as a function of the proportions of two size classes is presented in Figure 2-2. The maximum value of $\Phi_{\mathrm{p}}$ occurs when the larger particles are 
dominant, yet a sufficient number of fine particles is present to fill the voids without disturbing the arrangement of the larger ones.

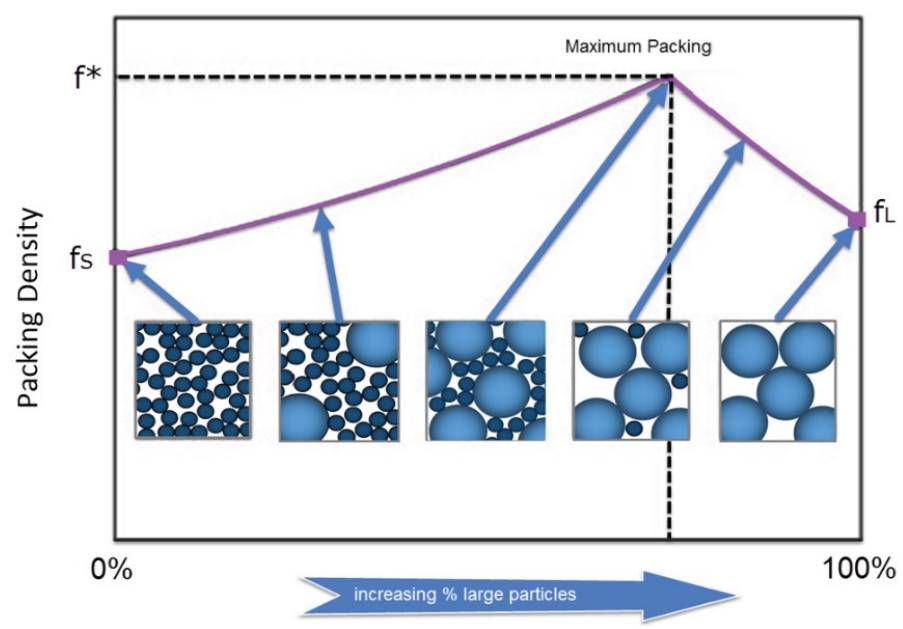

Figure 2-2:Particle packing optimization of a bi-modal suspension (Malvern-Instruments 2016)

Based on Furnas equations, further discrete PPMs were developed such as Toufar Models who study binary mixtures with adjacent size ratios within $0.22<\mathrm{d}_{1} / \mathrm{d}_{2}<1$. Additionally, Toufar models extended the calculation of packing densities to ternary mixtures (Fennis 2011; Fennis and Walraven 2012b; Mangulkar and Jamkar 2013). Dewar (1999) proposed the analysis of multimodal suspensions in an iterative process as follows:

- Calculation of the properties (i.e. $\Phi_{\mathrm{p}}$ and particle size average) of two adjacent size classes.

- A third particle size can be combined with the properties of the first combination.

- All the particles sizes follow the same procedures until all of them are included in the system

The most recent developments in discrete models include the linear packing density model (LPDM) and compressible packing model (CPM) proposed by De Larrard et al (Stovall, Larrard, and Buil 1986; de Larrard and Sedran 1994; Larrard 1999). The LPDM improves the Furnas model by integrating the use of multicomponent systems with geometrical 
interaction between particles, described by the wall and the loosening effect (Figure 2-3) (Mangulkar and Jamkar 2013; de Oliveira et al. 2000; Mehdipour and Khayat 2018). Particle interactions reduce packing density and they are related to border conditions of particles of different sizes.

- Loosening Effect: The presence of fine grains that are too large to fit in the voids of a coarse matrix disturbs the optimal packing of the coarser particles.

- Wall Effect: The presence of isolated coarse grains in a matrix of fine particles disturbs the packing arrangement of the fines, hence, a reduction in packing is observed in the large particle surroundings.
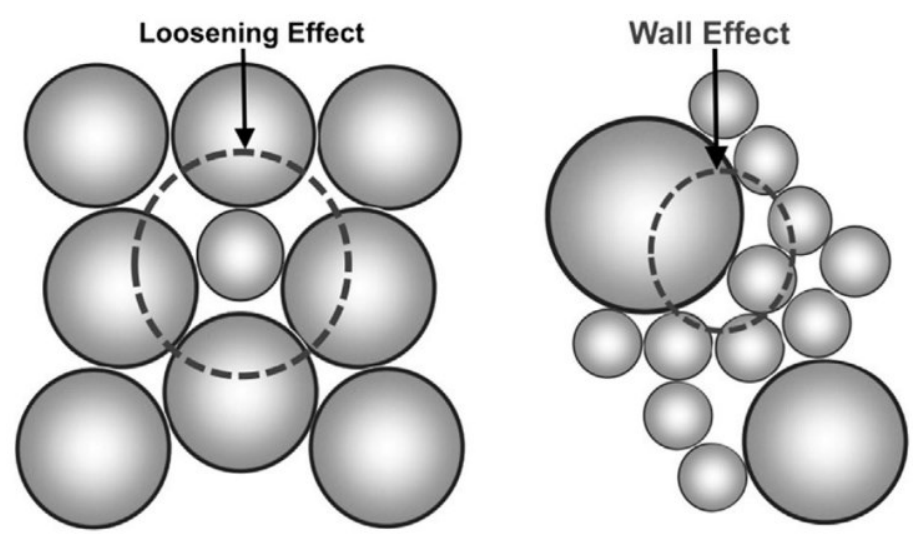

Figure 2-3: Particle interactions (Mehdipour and Khayat 2018)

On the other hand, the CPM considers a maximum possible virtual packing density $\beta$. It is theoretically achieved if the particles were placed one by one in the perfect positions to grant the lowest void ratio. In real applications particles are randomly placed (i.e. real packing density) that depends on the compaction energy of the material placing. Therefore, a factor $\mathrm{K}$ is introduced in the model to account for the type of application of the cementitious material. Low $\mathrm{K}$ values are assigned for applications without external compaction energy (i.e. only gravity forces - pouring) and higher values for compactions 
processes (i.e. vibration + compression, roller compaction) (Larrard 1999; Larrard and Sedran 2002).

\subsubsection{Continuous approach}

Particle size distributions found in nature are commonly known as continuous distributions, that is, no gap-graded system (Dinger and Funk 1997; Vogt 2010). Therefore, continuous distributions can be considered as multi-modal distributions with class size ratio approaching 1:1 and no gaps in between particle sizes (Dinger and Funk 1997; Funk and Dinger 1994; Kumar and Santhanam 2003; Mangulkar and Jamkar 2013). Fuller and Thomson (Fuller and Thompson 1907) proposed in 1907 the "ideal" gradation curve described by Equation 2-4.

$$
\frac{C P F T}{100}=\left(\frac{d}{D}\right)^{q}
$$

where CPFT is the cumulative percentage finer than $d, d$ is the particle diameter, $D$ is the largest particle diameter and $\mathrm{q}$ is the distribution factor coefficient.

Fuller and Thompson (1907) stated that $\mathrm{q}=0.5$ provides the highest packing density for the aggregate arrangement of concrete mixes. Later, Andreasen and J. Andreasen. (1930) after an intensive experimental program suggest a range of distribution factor $\mathrm{q}$ from 0.33 to 0.50 acknowledging that perfect packing requires a similarity condition around particles of two specific and very different sizes. Therefore, the arrangement of particles surrounding a coarse grain should be similar to the array of particles surrounding a small grain, like equal images at a different scale, as shown in Figure 2-4 (de Oliveira et al. 2000; Funk and Dinger 1994; Dinger and Funk 1997; Vogt 2010). 


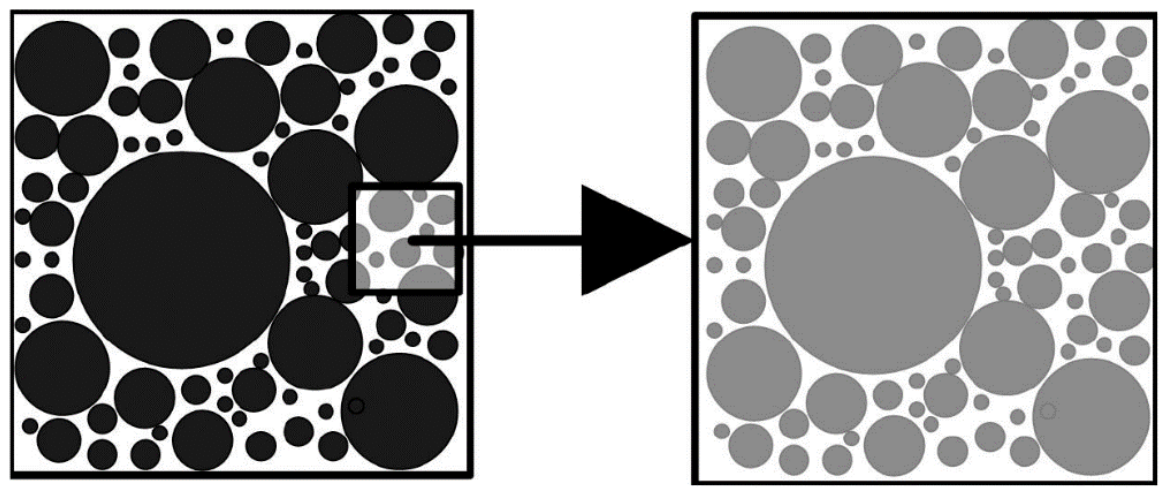

Figure 2-4: Similarity condition in the Andreasen packing model

Funk and dinger in 1980 recognized that particle size distributions (PSD) cannot present infinitesimal small particles, thus they proposed the inclusion of the smallest particle size diameter, giving rise to the Modified Andreasen Model, also known as Alfred Model, Equation 2-5.

$$
C P F T=\frac{d^{q}-D_{s}^{q}}{D_{L}^{q}-D_{s}^{q}} * 100
$$

where $\mathrm{d}$ is the particle diameter evaluated, $\mathrm{D}_{\mathrm{S}}$ and $\mathrm{D}_{\mathrm{L}}$ are the smallest and largest particle diameter of the PSD, respectively.

Furthermore, Funk and Dinger (1994) found that a distribution factor of $\mathrm{q}=0.37$ provides the highest packing density; hence, requiring small water amounts which affect the system flowability. An increase in the volume of fines provides enhancements in flow behaviour, thus lower q values are required (Yousuf, Sanchez, and Shammeh 2019). Kumar and Santhanam (2003) suggest q-factor lower than 0.23 for high flowable concretes (i.e. selfconsolidated concretes), whereas q-factor between 0.25 and 0.30 for conventional applications (i.e. vibrated concrete). Moreover, q-factor above 0.32 is recommended for roller compacted concretes (dry-mixes) (Mangulkar and Jamkar 2013; Yousuf, Sanchez, and Shammeh 2019). 
A drawback in the equations describing the continuous packing models is the inability to calculate the packing density of the system. Nevertheless, Funk and Dinger (1994) modified the Westman and Hugill algorithm initially proposed for discrete distributions (Westman and Hugill 1930) and were able to calculate porosity and $\Phi_{\mathrm{p}}$ in continuous distributions, described as follows:

First, the packing factor (i.e. packing density $\Phi_{\mathrm{p}}$ of the unimodal distribution) described as per Equation 2-6 should be calculated for each particle size present in the PSD.

$$
P_{f}=1-\left(\frac{1}{\operatorname{CSR}}\right)^{0.37}
$$

Equation 2-6

where CSR is the class size ratio between two adjacent sizes (i.e. larger size over small size).

Then, the apparent volume for each single particle size can define as per Equation 2-7.

$$
V_{a}=1 / P_{f}
$$

Equation 2-7

where $V_{a}$ is the apparent volume of the arrangement of particles for each particle size (i.e. bulk volume)

Then, apparent volumes can be computed for all the possible sizes available in the PSD from largest to smallest, Equation 2-8.

$$
\begin{aligned}
& V_{a 1}=a_{1} x_{1} \\
& V_{a 2}=x_{1}+a_{2} x_{2} \\
& V_{a 3}=x_{1}+x_{2}+a_{3} x_{3} \\
& \cdots \\
& V_{a n}=\sum_{i=1}^{n-1} x_{i}+a_{n} x_{n}
\end{aligned}
$$

Equation 2-8 
where $\mathrm{a}_{\mathrm{i}}$ is the apparent volume of the $\mathrm{i}^{\text {th }}$ size particle in a mono-dispersion, $\mathrm{x}_{\mathrm{i}}$ is the mass fraction of the $\mathrm{i}^{\text {th }}$ size particle and $\mathrm{V}_{\text {an }}$ is the apparent volume calculated with reference to the $\mathrm{i}^{\text {th }}$ sized particle.

Finally, the largest calculated apparent volume (i.e. maximum $\mathrm{V}_{\mathrm{a}}$ ), which represents the worst packing, should be selected to account for the predicted apparent volume, packing factor, and porosity of the entire particle distribution. Therefore, the expected porosity can be calculated using Equation 2-9.

$$
\operatorname{Porosity}(\%)=\left(1-\frac{1}{V_{a(\max )}}\right) * 40 \%
$$

The equation above includes a correction factor of $40 \%$, based on the assumption that narrow distributions (i.e. mono dispersions) will pack about to about $40 \%$ porosity (i.e. random packing). The later allows the calculation of porosities in systems with a wide PSD as well as narrow PSD.

The packing density of the continuous distribution will be defined as per Equation 2-10

$$
\phi_{p}=1-\text { porosity }
$$

Figure 2-5 presents the calculated porosity of distributions designed using the Alfred Model at different distribution factors. Increasing the assortment of particles (i.e. $\mathrm{D}_{\mathrm{s}} / \mathrm{D}_{\mathrm{L}}$ ) provide a significant reduction in porosity. Besides, the use of a distribution factor slightly lower than 0.37 (i.e. 0.21 to 0.37 ), represents minimal effects on the packing. 


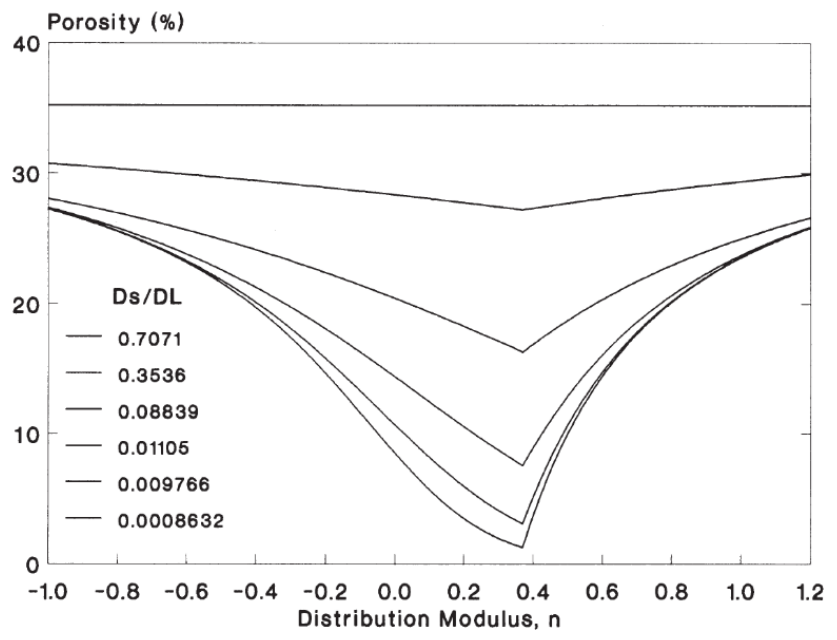

Figure 2-5: Porosity of continuous distributions at different distribution factors (Funk and Dinger 1994)

Although PPMs have been effectively used to manufacture highly packed systems with suitable hardened properties, these models currently present some drawbacks. First, PPMs assume that all particles in the system are spherical, which is not the case in real granular systems. Second, PPMs only account for the dry skeleton of cementitious mixtures; hence, the action of water, PC hydration, particle forces/interactions, and other particle features such as shape, texture, etc., are disregarded. Finally, the use of PPM simply yields the best proportioning (i.e. lowest dry porosity) of a series of granular sized systems as per the type of targeted concrete (i.e. self-levelling, vibrated, etc.) without providing further information on the fresh state performance (i.e. yield stress and viscosity) of the material for a wide range of torque regimes. For those reasons, supplementary tools such as Mobility Parameters (Section 2.3) may be coupled with PPMs to better describe the fresh state behaviour of cementitious mixtures. Such tools should consider the fluid medium, the influence of the particles features along with their fresh state interaction. 


\subsection{Mobility parameters}

Concrete in the fresh state can be considered as a multiphase material. Firstly, the combination of water and fine particles (i.e. PC and LF) form the cement paste. In this phase the minimum water volume is required to enable the flow of the paste. This amount is also responsible for separating adjacent fine particles and then allowing mobility of the system, assuming negligible agglomeration (Funk and Dinger 1994). The latter distance is called interparticle separation distance - IPS.

Secondly, cement paste plus coarse and fine aggregate form concrete. Similarly, a minimum volume of paste is necessary to enable the flow of the concrete mixture. This in turn, creates separation among adjacent aggregates which is defined as the maximum paste thickness - MPT (de Oliveira et al. 2000; Varhen et al. 2016; de Grazia, Sanchez, and Pileggi 2018).

The latter concepts are known as "mobility parameters" and they have shown promising results in the prediction of fresh state properties of highly packed cementitious materials (de Oliveira et al. 2000; de Grazia, Sanchez, and Pileggi 2018).

\subsubsection{Interparticle Separation Distance (IPS) \& Maximum Paste Thickness (MPT)}

The IPS concept was proposed by Funk and Dinger (1994) to predict the viscosity of slurries for castable ceramics (i.e. cement paste applications). It is defined as the average distance between two adjacent fine particles (i.e. smaller than $100 \mu \mathrm{m}$ ) in well-dispersed suspensions and can be computed using Equation 2-11. The IPS is illustrated in Figure 2-6 starting from the dry powder, to the addition of water which fills pores, creating a layer that separates all the particles. 


$$
I P S=\frac{2}{V S A} *\left(\frac{1}{V_{S}}-\frac{1}{1-P_{o f}}\right)
$$

where IPS is the interparticle separation distance in $\mu \mathrm{m}, \mathrm{VSA}$ is the volume surface area in $\mathrm{m}^{3} / \mathrm{cm}^{2}, V_{S}$ is the volume solid proportion and $\mathrm{P}_{\text {of }}$ is the pore fraction of the dry system.

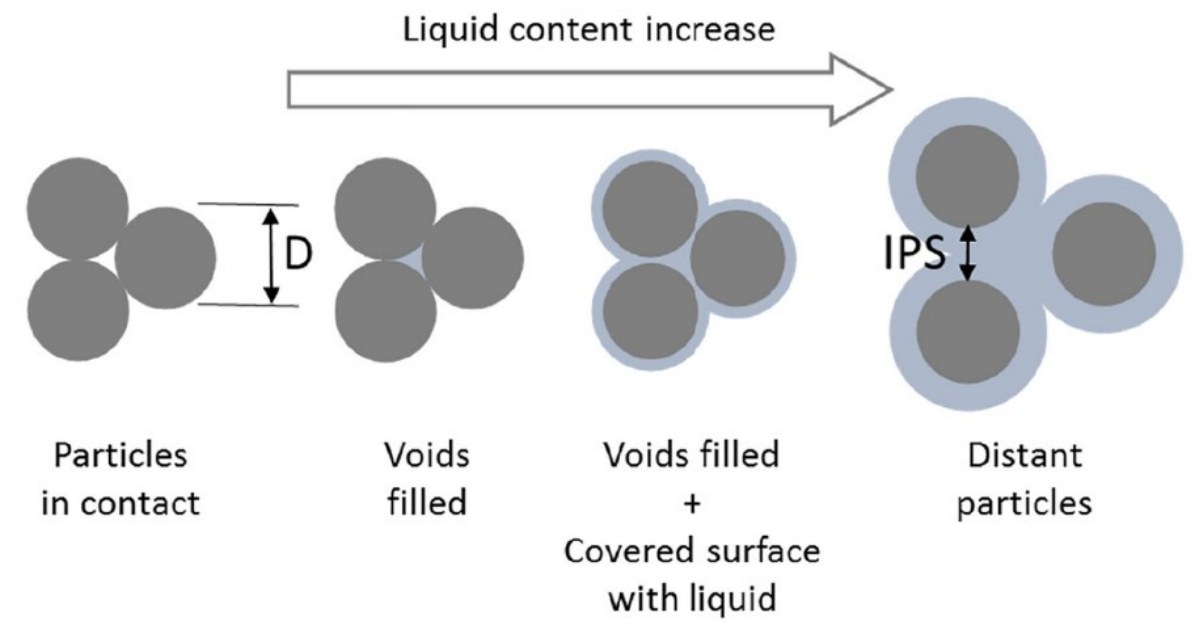

Figure 2-6: Increase of the IPS with water increment (John et al. 2018a)

The IPS equation considers packing and surface effects. The pore fraction parameter accounts for the system PSD and packing condition. Whereas, the VSA (Equation 2-12) accounts for the fineness of the powder and the morphology of particles.

$$
V S A=S S A * \rho
$$

Equation 2-12

where SSA is the specific surface area of the particles $\left(\mathrm{m}^{2} / \mathrm{g}\right)$ and $\rho$ is the density of the particles in $\left(\mathrm{g} / \mathrm{cm}^{3}\right)$.

The increase in the IPS represents a thicker layer of water surrounding the fine particles, which in turn reduces particle collision while improving system mobility and flow (Funk and Dinger 1994; Oliveira et al. 2000; F.S. Ortega et al. 2002).

Applying the same concept for particles larger than $100 \mu \mathrm{m}$, (i.e. coarse fraction), the fluid that surrounds coarse and fine aggregates will be the cement paste. The average distance between two adjacent coarse particles filled with cement paste is denominated Maximum 
Paste Thickness (MPT - Figure 2-7) (de Oliveira et al. 2000; Varhen et al. 2016; de Grazia et al. 2020). MPT can be calculated using Equation 2-13.

$$
M P T=\frac{2}{V S A_{C}} *\left(\frac{1}{V_{S(C)}}-\frac{1}{1-P_{o f(C)}}\right)
$$

where MPT is given in $\mu \mathrm{m}, \mathrm{VSA}_{\mathrm{C}}$ is the volume surface area for coarse particles in $\mathrm{m}^{3} / \mathrm{cm}^{2}$, $\mathrm{V}_{\mathrm{S}(\mathrm{C})}$ is the coarse volume solid proportion and $\mathrm{P}_{\text {of }}$ is the dry porosity calculated for the coarse fraction only.

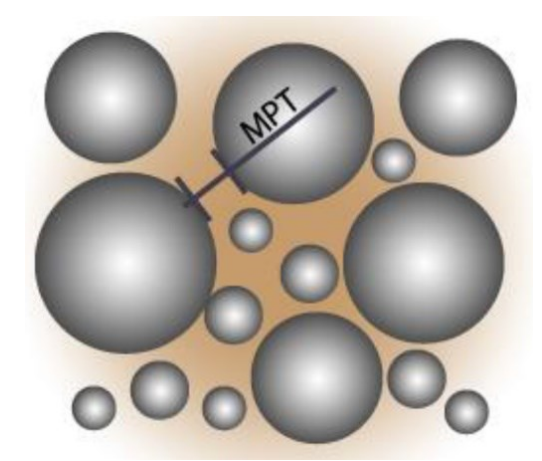

Figure 2-7: Maximum paste thickness between coarser particles. (de Grazia et al. 2020)

Recent studies suggest that the increase in IPS and MPT values might reduce the mixing energy of paste and concrete mixtures, thus improvement flow properties (Varhen et al. 2016; de Grazia et al. 2020). Although, other studies suggest that despite the correlation between mobility parameters and flow of cementitious mixtures, the IPS and MPT overlook other physical aspects related to energy dissipation during collisions such as the interaction between particles of different sizes or properties of the fluid medium (Damineli et al. 2016; John et al. 2018a). In this context it is anticipated that the sole use of IPS or MPT might be incomplete or insufficient. Moreover, there is a lack of quantitative studies linking mobility parameters and fresh state behaviour. 


\subsubsection{Water Film Thickness (WFT) \& Paste Film Thickness (PFT)}

More recently, Wong and Kwan (2008c) introduced the concept of the Water Film Thickness (WFT), while Kwan and Li (2012) developed the Paste Film Thickness (PFT). Both concepts resemble IPS and MPT, respectively, however, the rational approach is different. WFT and PFT are based on the measurement of an experimental wet packing density (Wong and Kwan 2008a; Kwan and Wong 2008b) where the minimum requirement to fill the interparticle porosity of the paste powder is determined. Any additional water is considered as "excess water" that coats the particles according to the solid surface area, forming a layer that allows flow. PFT is the extension of the concept to mortars and concrete, where the excess of cement paste coats the coarser aggregates allowing flow. WFT and PFT have been applied with success in cement pastes, mortar, and concrete mixtures (Kwan and Wong 2008a; Li and Kwan 2011, 2013).

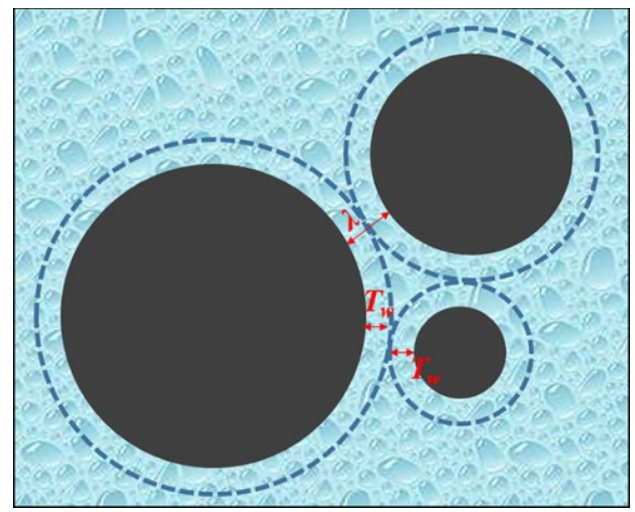

Figure 2-8: Water film thickness surrounding different particles sizes (Guo et al. 2017)

On the other hand, IPS and MPT consider the distance between the surfaces of particles, while WFT and PFT consider the thickness of the layer of fluid covering individual particles, illustrated by $\mathrm{T}_{\mathrm{w}}$ in Figure 2-8. Furthermore, and most importantly, IPS and MPT are purely theoretical parameters, based on particle characteristics and mix-design 
characteristics of the material, reducing the need for extensive trial and error processes, as might be the case of WFT and PFT.

\subsection{Fillers in cementitious materials}

Another alternative to reduce $\mathrm{PC}$ in cementitious materials is the substitution of the $\mathrm{PC}$ by alternative mineral additions that might present binding properties such as SCM or weakly reactive that only help in the optimization of PC such as LF. Traditional SCM like fly ash (FA), silica fume (SF), or granulated blast furnace slag (GBFS) possess pozzolanic properties. They react with the products of $\mathrm{PC}$ hydration (i.e. portlandite $\left.-\mathrm{Ca}(\mathrm{OH})_{2}\right)$ to form a cementitious gel (i.e. C-S-H), yet, they do not without the presence of PC paste as an activator (Lothenbach, Scrivener, and Hooton 2011b; M. C. G. Juenger and R. Siddique 2015). Numerous studies show that SCMs enhance concrete microstructure, leading to lower porosities, higher compressive strength, and improvement in durability related aspects (Thomas 2013; Rafat Siddique 2011; Mehta 2008). However, as previously discussed, potential sources of these materials are being used by the cement and concrete industry and its production rates (i.e. approx. 730 million tons per year) are not enough to correspond to the PC demand. Conversely, mineral fillers present large availability around the globe (i.e. $>6000$ million tons per year) at relatively low cost (Scrivener, John, and Gartner 2018; Wang, Shi, Farzadnia, Shi, and Jia 2018; John et al. 2018a), much higher than the yearly PC global production of about 4500 Million tons (Scrivener, John, and Gartner 2018).

Mineral fillers can be defined as inert or low reactivity fine particulate material, resulting from the grinding process of different types of rocks such as limestone, sandstone, dolomite, granite, and others (Scrivener, John, and Gartner 2018; John et al. 2018a). 
Limestone fillers (LF) are particularly popular due to their excellent performance and often close availability to existing cement plants since it is a by-product of the limestone aggregate plants. Besides, current standards on cement and concrete production allow certain limits of filler additions which usually specifies a chemical composition with high amounts of calcium carbonates (i.e. limestones) $>75 \%$ of $\mathrm{CaCO}_{3}$ (Hawkins, Tennis, and Detwiler 2005; Hooton, Nokken, and Thomas 2007; John et al. 2018a).

Table 2-1: Properties of the different types of mineral fillers

\begin{tabular}{ccccl}
\hline $\begin{array}{c}\text { Type } \\
\text { filler }\end{array}$ & Main oxides & Shape & $\begin{array}{c}\text { Density } \\
\left(\mathbf{g r} / \mathbf{c m}^{3}\right)\end{array}$ & \multicolumn{1}{c}{ Observation } \\
\hline Limestone & $>53 \% \mathrm{CaO}$ & Rounded & $\sim 2.70-2.76$ & $\begin{array}{l}\text { Excellent performance. } \\
\text { Low reactivity }\end{array}$ \\
\hline Granite & $>50 \mathrm{SiO}_{2}$ & Angular & $\sim 2.66$ & Difficulties in the fresh state \\
& $\sim 14 \% \mathrm{Al}_{2} \mathrm{O}_{3}$ & & & Lower performance than LF. \\
Dolomite & $\sim 30 \% \mathrm{CaO}$ & Rounded & $\sim 2.82-2.90$ & Possible dedolomitization \\
\hline & $\sim 20 \% \mathrm{MgO}$ & & & $\begin{array}{l}\text { Difficulties in the fresh state. } \\
\text { Health risk due to crystalline } \\
\text { Quartz }\end{array}$ \\
& $\sim 98 \% \mathrm{SiO}_{2}$ & Angular & $\sim 2.65$ & silica dust (particles $<150 \mu \mathrm{m})$ \\
\hline
\end{tabular}

Data from: (Di Salvo Barsi et al. 2020; Nguyen et al. 2018; Matos et al. 2020; L. G. Li et al. 2019; John et al. 2018a; Scrivener, John, and Gartner 2018).

Although the vast majority of research on the use of mineral fillers in cementitious materials focus on LFs, recent studies have been developed over the last years to evaluate the impact of distinct types of fillers on the performance of cement-based mixtures. It has been found, for instance, that granite or quartz fillers may worsen the fresh state behaviour of paste and mortar mixtures due to their angular shape (Matos et al. 2020; L. G. Li et al. 2019). Furthermore, dolomite fillers might present dedolomitization (i.e. decomposition of dolomite into calcite and magnesium ions), which is an expansive process that may harm 
the hardened state performance of cementitious mixtures; yet no evidence of this effect has been reported so far (Scrivener, John, and Gartner 2018; Damineli et al. 2016; John et al. 2018a). Table 2-1 displays a summary of some properties of distinct type of fillers reported in the literature.

\subsubsection{Overview: grindability, reactivity, dilution}

Limestone is a softer material than PC, enabling the production of fillers with a wide particle size distribution, including particles finer than cement. Mixtures made of PC and LF with a clever selection of the LF particle sizes may result advantageous due to improvements in the mixture packing density (Hooton, Nokken, and Thomas 2007; Hawkins, Tennis, and Detwiler 2005). Moreover, LF particles with similar or larger sizes than PC can partially substitute the cement grains to optimize the PC content in the system (John et al. 2018a).

Although LFs were initially believed to be inert particles, recent studies have shown reactivity between the alumina phases of $\mathrm{PC}$ (i.e. $\mathrm{C}_{3} \mathrm{~A}, \mathrm{C}_{4} \mathrm{AF}$ ) and calcium carbonate from LF, resulting in the formation of carbo-aluminates (Wang, Shi, Farzadnia, Shi, and Jia 2018; Hawkins, Tennis, and Detwiler 2005). Besides, some researchers suggest that $\mathrm{CaCO}_{3}$ can be incorporated into the C-S-H (i.e. calcium silica hydrates) formed by $\mathrm{C}_{3} \mathrm{~S}$ (Tricalcium-silicates) (Tikkanen, Cwirzen, and Penttala 2014; Hooton, Nokken, and Thomas 2007), changing its morphology into shorter and thicker fibers of C-S-H (Wang, Shi, Farzadnia, Shi, and Jia 2018; Ramachandran and Zhang 1986). The reactivity of LF depends on its fineness and the availability of alumina phases in the cement paste, thus higher concentrations of alumina or very fine LF particles enlarge the chemical effects of LF. Considering that the percentage of alumina in the PC is relatively low (i.e. $<8 \%$ ), the 
chemical effects of LF are deem to be minor (Oey et al. 2013; Wang, Shi, Farzadnia, Shi, and Jia 2018). In fact, substitution levels up to 5\% of LF might chemically react with PC, above this amount most of the limestone acts as an inert filler (Matschei, Lothenbach, and Glasser 2007; Tikkanen, Cwirzen, and Penttala 2014).

Since LFs are almost inert, their inclusion in the cementitious system as direct substitutes of PC reduces the concentration of reactive particles (e.g. PC or SCMs) and the hydration products alike. This increases the free water that reacts with PC in a phenomenon known as the dilution effect (Wang, Shi, Farzadnia, Shi, Jia, et al. 2018; John et al. 2018a), which affects the material properties like reduction in compressive strength and higher porosities. Dilution can be partially compensated by increasing the fineness of reactive particles or lowering the water content in the mixture (John et al. 2018a).

\subsubsection{Limestone filler in the fresh state}

The influence of LF in fresh state behaviour of cementitious materials is not totally established. Some scholars claim improvements in flowability (M. Nehdi, S. Mindess, and P.C. Aitcin 1998; Derabla and Benmalek 2014; Sua-iam and Makul 2013; Binhowimal, Hanzic, and Ho 2017), while others suggest that the use of LFs results in a lower slump, higher yield stress, and plastic viscosity (Ferraris, Obla, and Hill 2001; Ma et al. 2013; Bonavetti et al. 2003). A variety of factors play a role in the flow response, for instance morphology of the LF, particle size, impurities such as clay and $\mathrm{MgO}$, electrostatic interactions, etc. (Wang, Shi, Farzadnia, Shi, and Jia 2018). However, two main theories have succeeded in explaining the flow responses on cement mixtures with LF, as shown in Figure 2-9. First, the water layer theory that correlates the flowability of a mixture with the specific surface area (SSA) of the solid particles in the mix. Similarly, to the IPS concept, 
a thicker layer of water coating the solid particles provide enhancements of flow. Conversely, higher SSA causes thinner coating layers, increasing water demand for similar flow results (Hunger and Brouwers 2009; Guo et al. 2017; Ghasemi 2019). On the other hand, the packing theory considers that higher packing densities reduce the void volume that ultimately will be filled with water, resulting in lower water demand (Kronlöf 1997; Aiqin, Chengzhi, and Ningsheng 1999; Wong and Kwan 2008b). However, maximum packing density does not necessarily mean a workable mix (Kwan and Mora 2001). Further studies have shown that these two opposite theories are complementary; hence, a balance should exist between surface and packing effects to achieve adequate fresh state behaviour (Kwan and Wong 2008a; Kwan and Chen 2012).

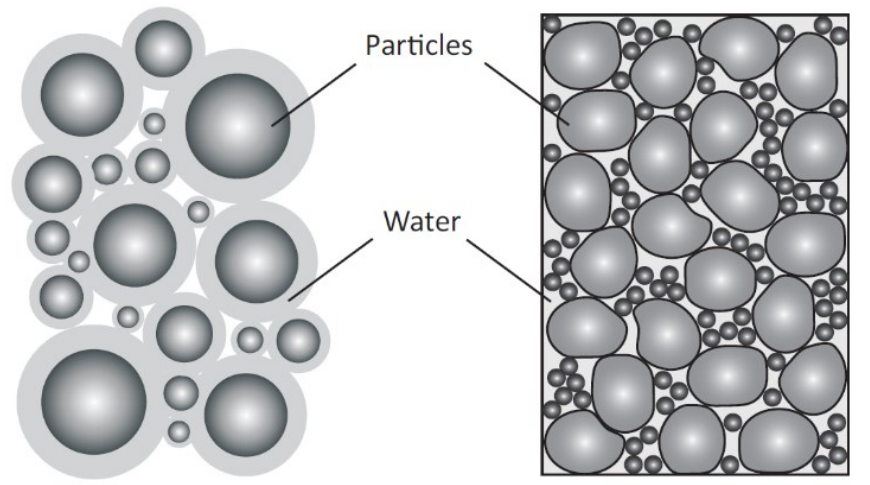

Figure 2-9: Water layer theory showing the layers of water coating the particles (left side) and packing theory with the water filling the voids between particles (right side).

\subsubsection{Limestone filler in hydration and setting time}

Despite the inert character of LF, they provide physical effects that influence the hydration process of cement (Vogt 2010). Early phases of cement hydration depend upon the number of nucleation and precipitation sites of hydrated products. The inclusion of fine LFs provide large SSA that act as nucleation sites, increasing hydration rates. As a consequence, fine fillers are surrounded by hydration products and become part of the cement paste (Vogt 2010; Tikkanen, Cwirzen, and Penttala 2014; Oey et al. 2013). 
The main factors that affect nucleation are particle sizes of the LF, the number of particles, and its morphology. Very fine particles (i.e. $<5 \mu \mathrm{m}$ ) develop faster and higher hydration heat peaks (i.e. filler effect for high SSA), nevertheless, beyond 15\% of direct replacement, the reduction of reactive materials diminish the heat release, due to dilution (Wang, Shi, Farzadnia, Shi, Jia, et al. 2018). Conversely, LF larger than $20 \mu \mathrm{m}$ only displays dilution effects, because the heat of hydration is lowered regardless of the LF dosage (Wang, Shi, Farzadnia, Shi, Jia, et al. 2018; Pailyn Thongsanitgarn et al. 2014).

The availability of more nucleation sites and faster hydration rates shortens the induction period, thereby accelerating setting time (P. Thongsanitgarn et al. 2011; Wang, Shi, Farzadnia, Shi, and Jia 2018; Villagran-Zaccardi, Falcone, and Benito. 2015). This acceleration is intensified by finer LF particles, due to higher SSA (Oey et al. 2013). Studies suggest that direct replacement of PC by moderate to high dosages of LF $(>15 \%)$, does not shorten setting time, as the dilution effects become predominant (M. Heikal, H. El-Didamony, and M.S. Morsy 2000). When LFs are proportioned to replace or increase the volume of the cement paste (i.e. equal w/c than pure PC mixes) setting occurs faster regardless the size of the LF (Tikkanen, Cwirzen, and Penttala 2014; Oey et al. 2013; Wang, Shi, Farzadnia, Shi, and Jia 2018).

\subsubsection{Limestone filler in strength and packing}

Inclusion of LFs in cementitious materials can be performed in two different ways: a) direct replacement of PC (i.e. substitution of PC with LF) and b) addition of fine particles to replace or increase the volume of paste (i.e. cement paste substitution). By extension, the influence of LF in compressive strength will be different according to the selected approach. 
Using LF as a direct replacement of PC causes dilution of the reactive particles, thus, lowering the hydration products. This results in a weaker and more porous matrix with lower compressive strength when the amount of water is kept constant. Studies performed with direct substitution showed that $f^{\prime} c$ decreases with increasing amounts of LF since it does not form C-S-H and the $\mathrm{w} / \mathrm{c}$ of the mixture is increased (P. Thongsanitgarn et al. 2011; Ramezanianpour et al. 2009). However, it is important to highlight that replacement dosages below $10 \%$ of LF have little to negligible effects on $f^{\prime} c$. It occurs that very fine particles of LF enhance the packing condition of the system compensating to some extent the dilution effects caused by small replacement amounts. Similarly, Portland cements with higher fineness can compensate dilution, as finer PC particles are more reactive, it enables the use of LF up to $15 \%$, as direct replacement, without significant loss in hardened properties (Guemmadi et al. 2008; Tsivilis et al. 1999). Beyond those values, dilution effects are dominant and $f^{\prime} c$ will decrease.

Conversely, the inclusion of LF to replace or increase the cement paste represents a constant w/c ratio compared to the pure PC mixture, thus LF leads to higher packing densities and higher compressive strengths (Li and Kwan 2015). Studies showed improvements in $f^{\prime} c$ values at high limestone dosages (i.e. $>50 \%$ ) as long as the $\mathrm{w} / \mathrm{c}$ ratio is reduced to compensate dilution effects (John et al. 2018a; Palm et al. 2016), nevertheless flow properties might be compromised.

\subsubsection{Existing standards limiting filler content.}

As described previously the use of LFs can improve compressive strength when dilution effects are considered. Thus, it is viable to use large amounts of LF to reduce the carbon footprint of cementitious materials. However, current standards only provide guidelines to 
use LF on a direct replacement basis, restraining LF to low dosages (i.e. $<15 \%)($ John et al. 2018b). Table 2-2 presents the accepted ranges of LF replacement according to different standards worldwide.

Table 2-2: Percentage of limestone fillers (wt.\%) allowed by current cement standard worldwide (John et al. 2018a)

\begin{tabular}{|c|c|c|c|c|c|c|c|c|c|c|}
\hline Region & $\overline{\text { EUR }}$ & S. AFR & ARG & AUS & N.Z. & USA & CAN & CHN & BRA & IND \\
\hline $\begin{array}{l}\text { Max. filler } \\
\% \text { accepted }\end{array}$ & 35 & 35 & 25 & 20 & 20 & 15 & 15 & 15 & 10 & 5 \\
\hline $\begin{array}{l}\text { Standard } \\
\text { version }\end{array}$ & 1992 & 2020 & 2015 & 2010 & 2009 & 2012 & 2008 & 2007 & 1990 & 2003 \\
\hline
\end{tabular}

\subsection{Gap in the state of the art.}

Using particle packing models in combination with high amounts of limestone fillers can be used to reduce cement content in cementitious materials. However, there is a lack of effective strategies to predict the fresh and hardened properties of highly packed mixtures with a high content of LF. The use of mobility parameters to forecast fresh behaviour seems promising, and further work should be directed on developing IPS and MPT concepts due to their practical approach and theoretical character that could reduce trial and error efforts. Therefore, the present research focusses on enhancing the understanding of the IPS parameter, aiming to better understand the IPS values in order to accurately predict the flow behaviour of highly packed cement paste mixes with high LF content. To deep understand the parameters that affect IPS and the complex character of concrete mixtures, MPT is out of the scope of the present work and must be further investigated into mortars and concrete mixtures in the future.

Regarding hardened state properties, there is still a debate about the degree of enhancement provided by high dosages of LF on mechanical properties. Moreover, previous studies suggest that the sole use of $\mathrm{w} / \mathrm{c}$ ratio is insufficient to explain the hardened state behaviour 
of densely packed systems with LF inclusion (de Grazia et al. 2019, 2020). For this reason, this research also aims to develop models to better predict the compressive strength of these mixtures.

Finally, this research intends to build up the knowledge and confidence in the use of large dosages of LF to reduce PC promoting the production of a greener cement-based material. 


\subsection{References}

Aiqin, Wang, Zhang Chengzhi, and Zhang Ningsheng. 1999. "The Theoretic Analysis of the Influence of the Particle Size Distribution of Cement System on the Property of Cement" 29: 1721-26.

Andreasen, A. H. M., and J. Andreasen. 1930. "Ueber Die Beziehung Zwischen Kornabstufung Und Zwischenraum in Produkten Aus Losen Körnern (Mit Einigen Experimenten)." Colloid and Polimer Science 50 (3): 217-28.

Binhowimal, S. A.M., L. Hanzic, and J. C.M. Ho. 2017. "Filler to Improve Concurrent Flowability and Segregation Performance of Concrete." Australian Journal of Structural Engineering. https://doi.org/10.1080/13287982.2017.1333184.

Bonavetti, V., H Donza, G. Menéndez, O. Cabrera, and E. F. Irassar. 2003. "Limestone Filler Cement in Low w/c Concrete: A Rational Use of Energy." Cement and Concrete Research 33 (6): 865-71. https://doi.org/10.1016/S0008-8846(02)01087-6.

Damineli, Bruno L., Vanderley M. John, Björn Lagerblad, and Rafael G. Pileggi. 2016. "Viscosity Prediction of Cement-Filler Suspensions Using Interference Model: A Route for Binder Efficiency Enhancement." Cement and Concrete Research 84: 819. https://doi.org/10.1016/j.cemconres.2016.02.012.

Derabla, Riad, and Mohamed Larbi Benmalek. 2014. "Characterization of Heat-Treated Self-Compacting Concrete Containing Mineral Admixtures at Early Age and in the Long Term." Construction and Building Materials 66: 787-94. https://doi.org/10.1016/j.conbuildmat.2014.06.029.

Dewar, J.D. 1999. Computer Modelling of Concrete Mixtures. London, UK: E \& FN Spoon - Taylor \& Francis Group.

Dinger, Dennis R., and James E. Funk. 1997. "Particle-Packing Phenomena and Their Application in Materials Processing." MRS Bulletin 22 (12): 19-23. https://doi.org/10.1557/S0883769400034692.

F.S. Ortega, R.G. Pileggi, A.R. Studart, and V.C. Pandofelli. 2002. "IPS A Viscosity Predictive Parameter." American Ceramic Society Bulletin 81 (1): 44-52.

Fennis, S.A.A.M. 2011. "Design of Ecological Concrete by Particle Packing Optimization.” Delft University of Technology.

Fennis, S.A.A.M., and Joost C. Walraven. 2012. "Using Particle Packing Technology for Sustainable Concrete Mixture Design.” Heron 57 (2): 73-101.

Ferraris, Chiara F, Karthik H Obla, and Russell Hill. 2001. "The Influence of Mineral Admixtures on the Rheology of Cement Paste and Concrete" 31: 245-55.

Fuller, William B, and S.E. Thompson. 1907. "The Laws of Proportioning Concrete." American Society of Civil Engineers 33: 223-98.

Funk, James E., and Dennis R. Dinger. 1994. Predictive Process Control of Crowded Particulate Suspensions. https://doi.org/10.1007/978-1-4615-3118-0.

Furnas, C.C. 1929. "Flow of Gases through Beds of Broken Solids." Bureau of Mines Bulletin 307. Washington: Goverment printing office. https://doi.org/10.1016/s00160032(30)91076-9.

_. 1931. "Grading Aggregates I — Mathematical Relations for Beds of Broken Solids of Maximum Density." U.S. Bureau of Mines 23 (9): 1052-58. https://doi.org/10.1021/ie50261a017.

Ghasemi, Y. 2019. "Effect of Water Film Thickness on the Flow in Conventional Mortars 
and Concrete." Materials and Structures 52 (3): 1-15.

https://doi.org/10.1617/s11527-019-1362-9.

Grazia, M.T. de. 2018. "Contribution to the Understanding of Fresh and Hardened State

Properties of Low Cement Concrete." Ottawa University.

Grazia, M.T. de, L.F.M. Sanchez, R.C.O. Romano, and R.G. Pileggi. 2019.

"Investigation of the Use of Continuous Particle Packing Models (PPMs) on the Fresh and Hardened Properties of Low-Cement Concrete (LCC) Systems."

Construction and Building Materials 195: 524-36. https://doi.org/10.1016/j.conbuildmat.2018.11.051.

_. 2020. "Evaluation of the Fresh and Hardened State Properties of Low Cement Content Systems." Magazine of Concrete Research 72 (5): 232-45.

Grazia, M.T. de, Leandro F. M. Sanchez, and Rafael G. Pileggi. 2018. "Evaluation of the Fresh and Hardened State Properties of Low Cement Content Systems." Magazine of Concrete Research 72 (5): 232-45.

Guemmadi, Z'hor, Musa Resheidat, Hacéne Houari, and Belkacem Toumi. 2008. "Optimal Criteria of Algerian Blended Cement Using Limestone Fines." Journal of Civil Engineering and Management 14 (4): 269-75. https://doi.org/10.3846/13923730.2008.14.26.

Guo, Yiqun, Tongsheng Zhang, Jiangxiong Wei, Qijun Yu, and Shixi Ouyang. 2017. "Evaluating the Distance between Particles in Fresh Cement Paste Based on the Yield Stress and Particle Size." Construction and Building Materials 142: 109-16. https://doi.org/10.1016/j.conbuildmat.2017.03.055.

Hawkins, P, P D Tennis, and R J Detwiler. 2005. The Use of Limestone in Portland Cement : A State-of-the-Art Review. Stokie, Illinois, US: Portland Cement Association.

Hooton, R. D., M Nokken, and M D A Thomas. 2007. "Portland Limestone Cement: State of the Art Report and Gap Analysis For CSA A 3000." Toronto.

Hunger, M., and H J H Brouwers. 2009. "Flow Analysis of Water-Powder Mixtures: Application to Specific Surface Area and Shape Factor." Cement and Concrete Composites 31 (1): 39-59. https://doi.org/10.1016/j.cemconcomp.2008.09.010.

John, Vanderley M., Bruno L. Damineli, Marco Quattrone, and Rafael G. Pileggi. 2018a. "Fillers in Cementitious Materials - Experience, Recent Advances and Future Potential." Cement and Concrete Research 114 (September 2017): 65-78. https://doi.org/10.1016/j.cemconres.2017.09.013.

John, Vanderley M., Bruno L. Damineli, Marco Quattrone, and Rafael G Pileggi. 2018b. "Cement and Concrete Research Fillers in Cementitious Materials - Experience, Recent Advances and Future Potential." Cement and Concrete Research 114 (September 2017): 65-78. https://doi.org/10.1016/j.cemconres.2017.09.013.

Kronlöf, Anna. 1997. "Filler Effect of Inert Mineral Powder in Concrete." Espoo: VTT Technical Research Centre of Findland.

Kumar, Senthil V., and Manu Santhanam. 2003. "Particle Packing Theories and Their Application in Concrete Mixture Proportioning: A Review." Indian Concrete Journal 77 (9): 1324-31.

Kwan, Albert K.H., and Jia Jian Chen. 2012. "Roles of Packing Density and Water Film Thickness in Rheology and Strength of Cement Paste." Journal of Advance Concrete Technology 10: 332-44. https://doi.org/10.3151/jact.10.332. 
Kwan, Albert K.H., and Leo G. Li. 2012. "Combined Effects of Water Film Thickness and Paste Film Thickness on Rheology of Mortar." Materials and

Structures/Materiaux et Constructions 45 (9): 1359-74. https://doi.org/10.1617/s11527-012-9837-y.

Kwan, Albert K.H., and C.F. Mora. 2001. "Effects of Various Shape Parameters on Packing of Aggregate Particles." Magazine of Concrete Research 53 (2): 91-100.

Kwan, Albert K.H., and H.H.C. Wong. 2008a. "Effects of Packing Density, Excess Water and Solid Surface Area on Flowability of Cement Paste." Advances in Cement Research 20 (1): 1-11. https://doi.org/10.1680/adcr.2008.20.1.1.

—. 2008b. "Packing Density of Cementitious Materials : Part 2 _ Packing and Flow of OPC + PFA + CSF." Materials and Structures 41: 773-84. https://doi.org/10.1617/s11527-007-9281-6.

Larrard, F. de. 1989. "Ultrafine Particles for the Making of Very High Strength Concretes." Cement and Concrete Research 19: 161-72.

- 1999. Concrete Mixture Proportioning: A Scientific Approach. E \& FN Spo. London.

Larrard, F. de, and T. Sedran. 1994. "Optimization of Ultra-High-Performance Concrete by the Use of a Packing Model." Cement and Concrete Research 24 (6): 997-1009. https://doi.org/10.1016/0008-8846(94)90022-1.

Larrard, F. de, and Thierry Sedran. 2002. "Mixture-Proportioning of High-Performance Concrete." Cement and Concrete Research 32 (11): 1699-1704. https://doi.org/10.1016/S0008-8846(02)00861-X.

Li, L. G., Y. M. Wang, Y. P. Tan, and A. K.H. Kwan. 2019. "Filler Technology of Adding Granite Dust to Reduce Cement Content and Increase Strength of Mortar." Powder Technology 342: 388-96. https://doi.org/10.1016/j.powtec.2018.09.084.

Li, Leo G., and Albert K.H. Kwan. 2011. "Mortar Design Based on Water Film Thickness." Construction and Building Materials 25 (5): 2381-90. https://doi.org/10.1016/j.conbuildmat.2010.11.038.

—. 2013. "Concrete Mix Design Based on Water Film Thickness and Paste Film Thickness." Cement and Concrete Composites 39: 33-42. https://doi.org/10.1016/j.cemconcomp.2013.03.021.

- 2015. "Adding Limestone Fines as Cementitious Paste Replacement to Improve Tensile Strength, Stiffness and Durability of Concrete." Cement and Concrete Composites 60: 17-24. https://doi.org/10.1016/j.cemconcomp.2015.02.006.

Lothenbach, Barbara, Karen Scrivener, and R. D. Hooton. 2011. "Supplementary Cementitious Materials." Cement and Concrete Research 41 (12): 1244-56. https://doi.org/10.1016/j.cemconres.2010.12.001.

M. C. G. Juenger, and R. Siddique. 2015. "Recent Advances in Understanding the Role of Supplementary Cementitious Materials in Concrete." Cement and Concrete Research 78: 71-80. https://doi.org/10.1016/j.cemconres.2015.03.018.

M. Heikal, H. El-Didamony, and M.S. Morsy. 2000. "Limestone-Filled Pozzolanic Cement." Cement and Concrete Research 30: 1827-34.

M. Nehdi, S. Mindess, and P.C. Aitcin. 1998. "Rheology of High-Performance Concrete: Effect of Ultrafine Particles." Cement and Concrete Research 28 (5): 687-97.

Ma, Kunlin, Guangcheng Long, Youjun Xie, and Rong Zhu. 2013. "Rheological Properties of Compound Pastes with Cement-Fly Ash-Limestone Powder." Kuei 
Suan Jen Hsueh Pao/Journal of the Chinese Ceramic Society 41 (5): 582-87. https://doi.org/10.7521/j.issn.0454-5648.2013.05.02.

Malvern-Instruments. 2016. "Optimizing Powder Packing Behavior by Controlling Particle Size and Shape." 2016. www.malvern.com.

Mangulkar, Mn, and Ss Jamkar. 2013. "Review of Particle Packing Theories Used For Concrete Mix Proportioning." International Journal Of Scientific \& Engineering Research 4 (5): 143-48.

Matos, Paulo Ricardo De, Rafael Dors Sakata, Philippe Jean, Paul Gleize, and Jorge De. 2020. "Eco-Friendly Ultra-High Performance Cement Pastes Produced with Quarry Wastes as Alternative Fillers." Journal of Cleaner Production.

Matschei, T., B. Lothenbach, and F. P. Glasser. 2007. "The Role of Calcium Carbonate in Cement Hydration." Cement and Concrete Research 37 (4): 551-58. https://doi.org/10.1016/j.cemconres.2006.10.013.

Mehdipour, Iman, and Kamal H. Khayat. 2018. "Understanding the Role of Particle Packing Characteristics in Rheo-Physical Properties of Cementitious Suspensions: A Literature Review." Construction and Building Materials. https://doi.org/10.1016/j.conbuildmat.2017.11.147.

Mehta, Kumar P. 2008. "High-Performance, High-Volume Fly Ash Concrete for Sustainable Development." International Workshop on Sustainable Development and Concrete Technology 31 (4): 3-14.

Moini, Mohamadreza, Ismael Flores-Vivian, Adil Amirjanov, and Konstantin Sobolev. 2015. "The Optimization of Aggregate Blends for Sustainable Low Cement Concrete." Construction and Building Materials 93: 627-34. https://doi.org/10.1016/j.conbuildmat.2015.06.019.

Nguyen, Hoang Anh, Ta Peng Chang, Jeng Ywan Shih, and Herry Suryadi Djayaprabha. 2018. "Enhancement of Low-Cement Self-Compacting Concrete with Dolomite Powder." Construction and Building Materials 161: 539-46. https://doi.org/10.1016/j.conbuildmat.2017.11.148.

Oey, Tandré, Aditya Kumar, Jeffrey W. Bullard, Narayanan Neithalath, and Gaurav Sant. 2013. "The Filler Effect: The Influence of Filler Content and Surface Area on Cementitious Reaction Rates.” Journal of the American Ceramic Society 96 (6): 1978-90. https://doi.org/10.1111/jace.12264.

Oliveira, I. R., A. R. Studart, R. G. Pileggi, and V. C. Pandolfelli. 2000. Dispersão e Empacotamento de Partículas. Fazendo Arte Editorial.

Oliveira, I.R. de, A.R. Studart, R.G. Pileggi, and V.C. Pandolfelli. 2000. Dispersão e Empacotamento de Partículas: Princípios e Aplicações Em Processamento Cerâmico. Sao Paulo: Fazendo Arte.

Palm, Sebastian, Tilo Proske, Moien Rezvani, Stefan Hainer, Christoph Müller, and Carl Alexander Graubner. 2016. "Cements with a High Limestone Content - Mechanical Properties , Durability and Ecological Characteristics of the Concrete." Construction and Building Materials 119: 308-18.

Rafat Siddique, Mohammad Iqbal Khan. 2011. Supplementary Cementinf Materials. Springer.

Ramachandran, V. S., and Chun Mei Zhang. 1986. "Dependence of Fineness of Calcium Carbonate on the Hydration Behaviour of Tricalcium Silicate." Durability of Building Materials 4 (1): 45-66. 
Ramezanianpour, Ali A., E. Ghiasvand, I. Nickseresht, M. Mahdikhani, and F. Moodi. 2009. "Influence of Various Amounts of Limestone Powder on Performance of Portland Limestone Cement Concretes." Cement and Concrete Composites 31 (10): 715-20. https://doi.org/10.1016/j.cemconcomp.2009.08.003.

Salvo Barsi, Antonela Di, Guillermina Marchetti, Mónica A. Trezza, and Edgardo F. Irassar. 2020. "Carbonate Rocks as Fillers in Blended Cements: Physical and Mechanical Properties." Construction and Building Materials 248. https://doi.org/10.1016/j.conbuildmat.2020.118697.

Scrivener, Karen L, Vanderley M. John, and Ellis Gartner. 2018. "Eco-Efficient Cements : Potential Economically Viable Solutions for a Low-CO 2 Cement-Based Materials Industry." Cement and Concrete Research 114 (February): 2-26. https://doi.org/10.1016/j.cemconres.2018.03.015.

Shafiei, M., A. Ghasemian, M. Eslami, F. Nojoomi, and H. Rajabi-Vardanjani. 2019. "Risk Factors and Control Strategies for Silicotuberculosis as an Occupational Disease." New Microbes and New Infections 27: 75-77. https://doi.org/10.1016/j.nmni.2018.11.002.

Shenoy, A.V. 1999. "Steady Shear Viscous Properties." In Rheology of Filled Polymer Systems, 243-311. Springer, Dordrecht.

Stovall, T., F. de Larrard, and M. Buil. 1986. "Linear Packing Density Model of Grain Mixtures.” Powder Technology 48: 1-12. https://doi.org/10.1016/00325910(86)80058-4.

Sua-iam, Gritsada, and Natt Makul. 2013. "Use of Limestone Powder during Incorporation of $\mathrm{Pb}$-Containing Cathode Ray Tube Waste in Self-Compacting Concrete." Journal of Environmental Management 128: 931-40. https://doi.org/10.1016/j.jenvman.2013.06.031.

Thomas, Michael. 2013. Supplementary Cementing Materials in Concrete. Supplementary Cementing Materials in Concrete. CRC Press - Taylor \& Francis group. https://doi.org/10.1201/b14493.

Thongsanitgarn, P., W. Wongkeo, S. Sinthupinyo, and A. Chaipanich. 2011. "Effect of Limestone Powders on Compressive Strength and Setting Time of PortlandLimestone Cement Pastes." In TIChE International Conference 2011. Songkhla, Thailand. https://doi.org/10.4028/www.scientific.net/AMR.343-344.322.

Thongsanitgarn, Pailyn, Watcharapong Wongkeo, Arnon Chaipanich, and Chi Sun Poon. 2014. "Heat of Hydration of Portland High-Calcium Fly Ash Cement Incorporating Limestone Powder: Effect of Limestone Particle Size." Construction and Building Materials 66: 410-17. https://doi.org/10.1016/j.conbuildmat.2014.05.060.

Tikkanen, Johanna, Andrzej Cwirzen, and Vesa Penttala. 2014. "Effects of Mineral Powders on Hydration Process and Hydration Products in Normal Strength Concrete." Construction and Building Materials 72: 7-14. https://doi.org/10.1016/j.conbuildmat.2014.08.066.

Tsivilis, S., E. Chaniotakis, E. Badogiannis, G. Pahoulas, and A. Ilias. 1999. "A Study on the Parameters Affecting the Properties of Portland Limestone Cements." Cement and Concrete Composites 21 (2): 107-16. https://doi.org/10.1016/S09589465(98)00031-6.

Varhen, Christian, Isabela Dilonardo, Roberto Cesar, De Oliveira Romano, Rafael Giuliano, Antonio Domingues, and De Figueiredo. 2016. "Effect of the Substitution 
of Cement by Limestone Filler on the Rheological Behaviour and Shrinkage of Microconcretes" 125: 375-86.

Villagran-Zaccardi, Y. A., D.D. Falcone, and D.E. Benito. 2015. "Influence of Limestone Powder in the Setting and Hydration of Cement Paste in the Fresh State." In XIII Conference on Durability of Building Materials and Components, edited by Marco Quattrone, 359-66.

Vogt, Carsten. 2010. "Influence of Ultrafine Particles on Concrete Properties and Application to Concrete Mix Design." School of Architecture and the Built Environment Division of Concrete Structures.

Wang, Dehui, Caijun Shi, Nima Farzadnia, Zhenguo Shi, and Huangfei Jia. 2018. “A Review on Effects of Limestone Powder on the Properties of Concrete." Construction and Building Materials 192: 153-66. https://doi.org/10.1016/j.conbuildmat.2018.10.119.

Wang, Dehui, Caijun Shi, Nima Farzadnia, Zhenguo Shi, Huangfei Jia, and Zhihua Ou. 2018. "A Review on Use of Limestone Powder in Cement-Based Materials: Mechanism, Hydration and Microstructures." Construction and Building Materials 181: 659-72. https://doi.org/10.1016/j.conbuildmat.2018.06.075.

Westman, A. E R, and H. R. Hugill. 1930. "The Packing of Particles." Journal of the American Ceramic Society 13 (10): 767-79. https://doi.org/10.1111/j.11512916.1930.tb16222.x.

Wong, H.H.C., and Albert K.H. Kwan. 2008a. "Packing Density of Cementitious Materials : Part 1 - Measurement Using a Wet Packing Method." Materials and Structures 41: 689-701. https://doi.org/10.1617/s11527-007-9274-5.

Wong, H H C, and Albert K.H. Kwan. 2008b. "Packing Density of Cementitious Materials : Measurement and Modelling," no. 3: 165-75. https://doi.org/10.1680/macr.2007.00004.

- 2008c. "Rheology of Cemen Paste: Role of Excess Water to Solid Surface Area Ratio." Journal of Materials in Civil Engineering 20 (2): 189-97. https://doi.org/10.1061/(ASCE)0899-1561(2008)20.

Yousuf, S., L.F.M. Sanchez, and S.A. Shammeh. 2019. "The Use of Particle Packing Models (PPMs) to Design Structural Low Cement Concrete as an Alternative for Construction Industry." Journal of Building Engineering 25 (October 2018): 100815. https://doi.org/10.1016/j.jobe.2019.100815. 


\title{
Chapter 3: Assessment of Properties of Low Cement Content Paste Using Interparticle Separation as an Insight on Fresh State
}

\author{
Gonzalo Lozano Rengifo $^{1 *}$, Leandro Francisco Moretti Sanchez ${ }^{2}$, Edward G. Sherwood ${ }^{1}$ \\ ${ }^{1}$ Department of Civil Engineering, Carleton University, Ottawa, Canada \\ ${ }^{2}$ Department of Civil Engineering, Ottawa University, Ottawa, Canada
}

\subsection{Abstract}

Reducing Portland Cement (PC) has been a major concern of the concrete industry and research community over the last 2-3 decades. As much as $8 \%$ of the global $\mathrm{CO}_{2}$ emissions stem from clinker production. Hence, a wide number of research projects have focused on reducing $\mathrm{PC}$ in cementitious materials using numerous strategies such as the use of supplementary cementing materials (SMC's), limestone fillers (LF) and/or advanced mixproportioning techniques. Yet, the impact of these procedures on the overall behaviour of materials with low PC content, especially in the fresh state and long-term durability, is still not fully understood. This work aims to understand the influence of the distance between the fine particles, the so-called Inter-Particle Separation (IPS), on the fresh state behaviour of cement-based pastes designed through the use of Particle Packing Models and incorporating LF. Evaluations on the fresh (i.e. rheological behaviour and setting time) and hardened states (compressive strength) were conducted in all mixtures. Results show that IPS directly correlates with the viscosity of cement-based pastes for all shear rates appraised. Moreover, the use of LF increases the hydration rate of PC pastes. Finally, it is clear that the water-to-cement ratio keeps being the main factor controlling the compressive strength of cement pastes with reduced PC content and high levels of LF replacement. 
Keywords: Inter-Particle Separation (IPS), limestone fillers, (LF) Particle Packing Models (PPM), setting time, rheology, viscosity.

\subsection{Introduction}

Multiple strategies to reduce PC consumption in the concrete industry have been conducted over the last 2-3 decades. PC is well known for being the most extensive constituent of concrete, contributing as much as $8 \%$ of the total $\mathrm{CO}_{2}$ emissions worldwide (Mehta 2002; Bonavetti et al. 2003; Andrew 2018). Therefore, it is not surprising that the main focus to achieve greener materials in past research was to partially replace Portland Cement (PC) in concrete by other products such as supplementary cementitious materials (SCM's) (Mehta 2008; Mehta and Monteiro 2006; Mindess, Young, and Darwin 2003) and/or mineral fillers (John et al. 2018a; El-Hawary and Nouh 2018). Despite the efficiency of traditional SCM's (e.g. fly ash, blast furnace slag, silica fume, etc.), even at high levels of replacement, their future availability is known to be compromised. The concrete industry already spends the total production of SCM's, giving no space for future consumption growth. Moreover, the environmental constraints to cease the production of electric power by burning coal and the efforts to lower down $\mathrm{CO}_{2}$ in steel production might question the future sources of fly ash and slag (Snellings 2016; Lothenbach, Scrivener, and Hooton 2011a; Haegermann 2002). Conversely, limestone fillers (LF) come from a grinding process of limestone rocks that can be performed near to aggregate quarries or cement plants, having thus an enormous potential of availability. A number of studies describe the effect of LF on cement pastes (Oey et al. 2013; Tikkanen, Cwirzen, and Penttala 2014; Svermova, Sonebi, and Bartos 2003; Bonavetti et al. 2003). Essentially the inclusion of fillers increases the rate of hydration by increasing nucleation sites for CSH growth 
(Gutteridge and Dalziel 1990; Ingram and Daugherty 1991) and also provide a physical improvement by filling intergranular voids between cement particles, causing a better packing in the granular skeleton (Bentur 1991; Opoczky 1992; LIU and YAN 2010). Yet, previous studies have reported a reduction in workability of PC pastes incorporating LF; the latter is accepted to take place due to the increase in the surface area by the addition of fine powders. This is particularly true for LF fillers with particle size distribution (PSD) lower than PC (Ferraris, Obla, and Hill 2001). Conversely, Bentz et al. (2017) found an enhancement in rheological properties, yield stress, and viscosity, when a $40 \%$ vol./vol. of limestone powder was used as a PC replacement. Moreover, reduction in water demand and bleeding for inter-ground limestone cement types were reported by Hawkins, Tennis, and Detwiler (2005), linking the results to a broader PSD and dilution effect. John et al. (2018a) explain dilution as an increase in the distance between PC grains caused by the accommodation of LF particles at a constant water-to-solids ratio. Uncontrolled dilution can harm the hardened properties of $\mathrm{PC}$ paste, creating a more porous system. This problem might be compensated by increasing the fineness of PC grains or by reducing the $\mathrm{w} / \mathrm{c}$ (John et al. 2018a; Hawkins, Tennis, and Detwiler 2005; Bonavetti et al. 2003), which helps to keep a high gel-space ratio (Bonavetti et al. 2003).

The rheological behaviour of PC pastes incorporating LF seems to be more complex and yet not thoroughly studied nor understood. Several factors as packing density, solid volume concentration, surface area, and particle size distribution, among others, can contribute to the fresh state responses of cement-based mixtures (Mehdipour and Khayat 2018). The Inter-Particle Separation concept (IPS)- developed initially by Funk and Dinger (1994) for fine particles $(<100 \mu \mathrm{m})$ considers the aforementioned intrinsic parameters of the 
cementitious suspensions, attempting to predict the rheological performance of castable ceramics. Oliveira et al. (de Oliveira et al. 2000) presented viscosity results on monodispersed systems versus IPS values evidencing a reduction in the relative viscosity with the IPS increase. Further studies on paste and concrete mixtures (M.T. de Grazia 2018; Damineli et al. 2016; John et al. 2018a) showed enhancement in rheological properties when IPS is controlled and optimized; however the results showed a poor correlation, yet a scattered downward trend of Viscosity vs IPS has been developed.

\subsection{Literature background}

\subsubsection{Particle Packing Models (PPM's)}

Particle Packing aims to optimize the aggregate's skeleton of granular systems (e.g. paste or concrete mixtures) by selecting an appropriate PSD where intergranular voids left by large particles are filled with small particles and so on (Fennis and Walraven 2012b). Studies of PPMs fall into two categories, discrete models with a fundamental work developed by Furnas (1931), and continuous models initially developed by Fuller and Thompson (1907). The first approach -Discrete- considers systems of two or more narrowly defined size classes of particles; each class is packed to its maximum density, where the coarser particles pack first, forming a fixed skeleton while the smaller particles fill the cavities left by the larger particles (Mangulkar and Jamkar 2013; Dinger and Funk 1997; Kumar and Santhanam 2003). Recent developments in discrete models consider particle interactions as loosening and wall effects (Mehdipour and Khayat 2018). Moreover, discrete models, for instance, Linear Packing Density Model (LPDM) and Compressible Packing Model, (CPM) developed by De Larrard et al. (1986-1999), work with geometrical interaction in multicomponent systems and includes compaction energy 
of material placing (Stovall, Larrard, and Buil 1986; Larrard 1999). On the other hand, continuous models consider that all possible sizes are present in the particle distribution, which is more commonly found in nature (Vogt 2010; Dinger and Funk 1997). In other words, no gaps are present among the PSD, approaching adjacent size classes ratio of $1: 1$ (M.T. de Grazia et al. 2019; Mangulkar and Jamkar 2013; Dinger and Funk 1997; Kumar and Santhanam 2003). Likewise, a similarity condition must be fulfilled, meaning that a change in scale (i.e. granulation image) should not affect the packing density. In other words, an image of a group of small particles should represent the same packing density as an image of a group of large particles (Fennis and Walraven 2012b; M.T. de Grazia et al. 2019).

Continuous particle packing models have evolved since Fuller in 1907, who set a continuous ideal grading curve described by Equation 3-1, where CPFT is the cumulative percentage finer than $\mathrm{d}, \mathrm{q}$ is the factor of optimal grading that ranges between 0.45 to 0.50 , $\mathrm{d}$ represents the particle diameter under evaluation and $\mathrm{D}$ the maximum particle size (Fuller and Thompson 1907). In the early 1930s Andreasen performed an important experimental campaign, concluding that the densely packed continuous distributions might be achieved using Equation 3-1 with a q factor ranging from 0.33 to 0.50 (Andreasen and J. Andreasen. 1930).

$$
\operatorname{CPFT}(\%)=\left(\frac{d}{D}\right)^{q} * 100
$$

Later in 1980, Funk and Dinger after computer simulations of particles packing in 2D and 3D, added the concept of smallest particle size to Andreasen's equation, resulting in the Modified Andreasen's Model also called Alfred's model Equation 3-2; where CPFT is the cumulative percentage finer than $\mathrm{D}$, being $\mathrm{D}$ the particle diameter under evaluation, $\mathrm{D}_{\mathrm{s}}$ and 
$\mathrm{D}_{\mathrm{L}}$ the smallest and largest particle diameter, respectively and $q$ the distribution factor (Funk and Dinger 1994). These authors found out that the minimum dry porosity of a given system or in other words, its "maximum packing" (calculated through Westman and Hugill algorithm (Westman and Hugill 1930)), is reached when $\mathrm{q}=037$; however, distribution factors ranging from 0.2 to 0.4 were still found to provide granular systems with densely packed mixes. Beyond this proposed range, it has been found that the overall porosity increases drastically (de Oliveira et al. 2000). Kumar and Santhanam (2003) showed that low q values (e.g. $\leq 0.22$ ) are suitable for flowable mixes such as self-consolidating mixes, while q factors close to 0.37 might be adopted for dry mixes, such as roller compacted concrete.

$$
\operatorname{CPFT}(\%)=\frac{D^{q}-D_{S}^{q}}{D_{L}^{q}-D_{S}^{q}}
$$

The optimization of granular systems through PPMs may bring numerous advantages; i.e. higher packing densities, reduced porosity, therefore less volume of lubricant (e.g. water or paste) is required to fill empty pores (Kwan and Mora 2001; Mehdipour and Khayat 2018). The addition of fine particles such as SCM's or LF might result in an even greater reduction of water requirements (Kronlöf 1997; Larrard 1999), enabling the use of lower w/c, that in turn, improves mechanical performance along with bleeding reduction and provide higher dimensional stability (Wong and Kwan 2008b). Moreover, cementitious materials designed through PPMs may display enhanced mechanical properties and durability related parameters (Yousuf, Sanchez, and Shammeh 2019).

\subsubsection{Inter-Particle Separation Distance (IPS)}

Despite the advantages of PPMs, highly packed systems with a reduced amount of binder and water may present some challenges in the fresh state (Yousuf, Sanchez, and Shammeh 
2019); therefore, there is a need to predict and control the fresh state properties of these highly packed systems. Viscosity prediction of suspensions has been predicted by models such as Krieger-Dougherty or Quemada (Dörr, Sadiki, and Mehdizadeh 2013), however, they rely on the critical solid content of the suspension and parameters that should be adjusted experimentally for different material combinations. Alternative models based on the fundamental properties of particles and the fluid of the mixture, with analytical character rather than experimental, may be more suitable to predict the fresh state behaviour of cement-based materials. In this regard, Funk and Dinger developed the concept of IPS for castable ceramics, which is defined as the average distance between particles finer than $100 \mu \mathrm{m}$, normally filled by water (Funk and Dinger 1994; de Oliveira et al. 2000; Damineli et al. 2016; de Grazia 2018). The IPS accounts for the porosity of the granular system in percent $\left(\mathrm{P}_{\mathrm{of}}\right)$, the volume fraction of solids in the system $\left(\mathrm{V}_{\mathrm{S}}\right)$, and the volumetric surface area of the particles VSA in $\mathrm{m}^{2} / \mathrm{cm}^{3}$. The resulting value of IPS is given in $\mu \mathrm{m}$ (Equation 3-3)

$$
I P S=\frac{2}{V S A} *\left(\frac{1}{V_{S}}-\frac{1}{1-P_{o f}}\right)
$$

Larger IPS represents more space among particles filled with fluid, which reduces particle interactions and friction, providing lower viscosities(F.S. Ortega et al. 2002; de Oliveira et al. 2000).

Other models have been proposed to calculate IPS for ceramic and/or other materials; Hao and Riman (2006) proposed a new IPS equation upon the idea of a virtual cell that surrounds every single particle. Shivashankar et al. (2013) worked on an interparticle distance based on the principle of mass conservation and binder volume fraction, however, their work relied on empirical calculations for the maximum solid content. Yet, none of 
these models has been considered a more suitable approach to calculate IPS than Funk and Dinger's, for its purely analytical approach.

\subsection{Scope of the work}

With all the aforementioned, there is a need to understand, predict, and control the fresh state behaviour of highly packed systems with a reduced amount of binder (i.e. PC). This work aims to appraise the influence of the IPS as a mean to understand the rheological and setting time behaviours of PC pastes incorporating a wide range of limestone-based fillers replacements. A viscometer and Vicat needle were used in this regard, respectively. Compressive strength of all PC pastes was also conducted and the law governing the mechanical properties development of PC systems with distinct LF replacements is then discussed.

\subsection{Materials and methods}

\subsubsection{Materials}

A Type GU (General Use) cement conforming CSA A3000-18 and two limestone fillers from a local producer were used in this research. The first filler is designated as HP-PT (i.e. replacement filler) and it is characterized by a similar PSD to the PC while the second filler, named F-PT (i.e. performance filler), presents smaller PSD than PC. Table 3-1 summarizes the chemical composition of all fine materials used in this research (i.e. PC, replacement, and performance fillers).

The PSDs of all raw materials were measured using a laser diffraction technique, which calculates the particle size by measuring the angle of light scattered by the particles as they pass through a laser beam. The obtained discrete and cumulative distributions are presented in Figure 3-1a and b, respectively. The density and specific surface area of the materials, 
presented in Table 3-1, were measured using the helium pycnometer and a multi-point Brunauer-Emmett-Teller (BET) method, respectively.

Table 3-1: Characterization of raw materials

\begin{tabular}{|c|c|c|c|}
\hline Component & PC & Replacement filler & Performance Filler \\
\hline $\mathrm{SiO}_{2}$ & 19.53 & - & - \\
\hline $\mathrm{Al}_{2} \mathrm{O}_{3}$ & 4.92 & - & - \\
\hline $\mathrm{Fe}_{2} \mathrm{O}_{3}$ & 3.21 & - & - \\
\hline $\mathrm{CaO}$ & 61.91 & - & - \\
\hline $\mathrm{SO}_{3}$ & 3.86 & - & - \\
\hline MgO & 2.66 & - & - \\
\hline LOI & 2.24 & - & - \\
\hline Total alkalis & 0.64 & - & - \\
\hline$C_{3} \mathrm{~S}$ & 55.00 & - & - \\
\hline $\mathrm{C}_{2} \mathrm{~S}$ & 14.50 & - & - \\
\hline$C_{3} A$ & 7.60 & - & - \\
\hline$C_{4} A F$ & 9.80 & - & - \\
\hline $\mathrm{CaCO}_{3}$ & - & 95.00 & 96.00 \\
\hline $\mathrm{MgCO}_{3} \mathrm{~S}$ & - & 2.00 & 2.00 \\
\hline Blaine $\left(\boldsymbol{m}^{2} / \boldsymbol{k g}\right)$ & 381.46 & 475.00 & $1,125.00$ \\
\hline BET surface area $\left(\boldsymbol{m}^{2} / \boldsymbol{g}\right)$ & 1.00 & 1.80 & 3.70 \\
\hline Density $\left(\boldsymbol{k g} / \boldsymbol{m}^{\mathbf{3}}\right)$ & 3.03 & 2.66 & 2.60 \\
\hline$V S A^{a}\left(m^{2} / \mathrm{cm}^{3}\right)$ & 3.03 & 4.79 & 9.62 \\
\hline
\end{tabular}

${ }^{a}$ VSA $=$ BET Surface Area * Density

Note: the chemical composition of all materials was provided by their respective suppliers.

a)

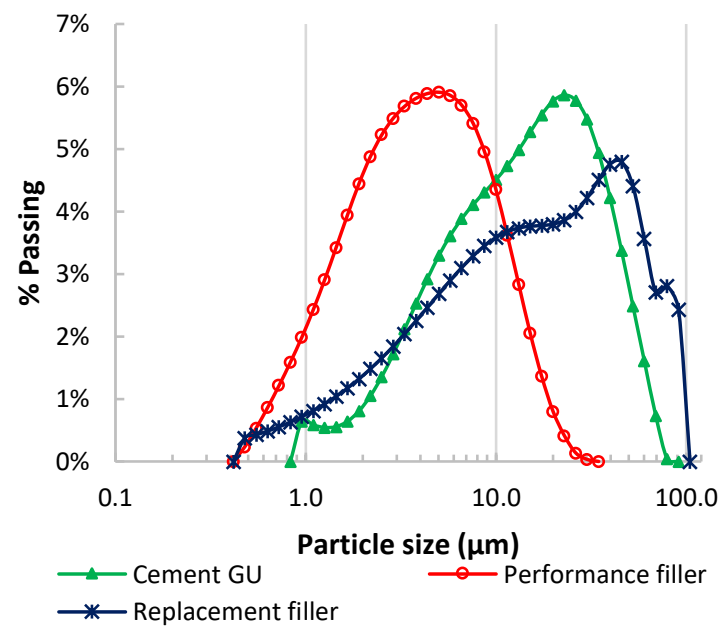

b)

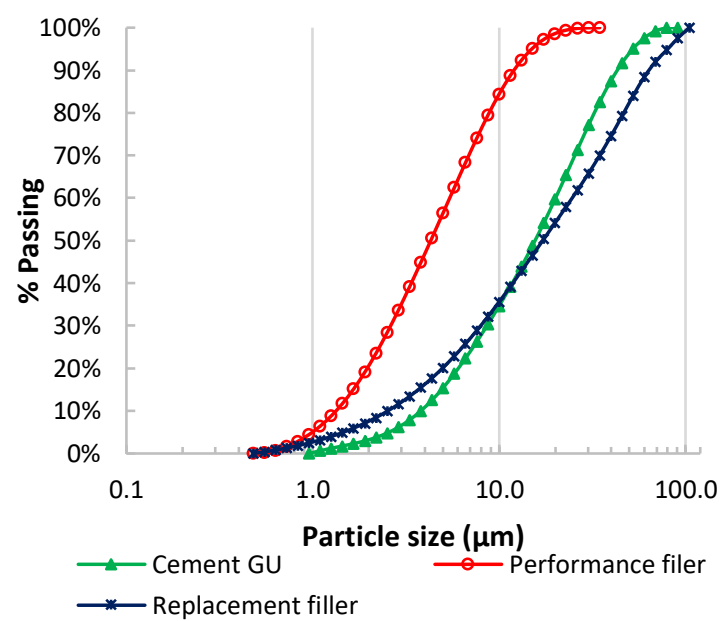

Figure 3-1: Particle size distribution of raw materials a) discrete percentage b) Cumulative percentage 


\subsubsection{Mix-design and mixing procedure}

Twenty-one PC pastes (powders + water), simulating companion concrete mixtures, were mix-proportioned through the use of continuous PPM - Alfred Model (Funk and Dinger 1994; Mangulkar and Jamkar 2013), with distribution factors of 0.21 and 0.37 . The target PC contents of the companion concrete mixes were 100,150 , and $250 \mathrm{~kg} / \mathrm{m}^{3}$. Three different water-to-fines (w/f) ratios (i.e. 0.32, 0.40, and 0.50) were selected so that distinct mechanical performance might be obtained by the mixes. It is worth noting that fines (or powders) in this work are defined as the combination of $\mathrm{PC}+$ fillers.

The target PC contents of the distinct cement pastes were always supplied to the mixes. Yet, if according to the PPM and distribution factors used, a higher amount of powder was still necessary, the remaining volume was completed by replacement and or performance fillers. Using the least square method to fit the PPM curves, the percentage of performance fillers to be added was obtained as being $21 \%$ and $10 \%$ of the total powder mass (i.e. $\mathrm{PC}+\mathrm{LFs}$ ) for $\mathrm{q}=0.21$ and $\mathrm{q}=0.37$, respectively. The percentage of replacement fillers varied according to the distribution factors and fixed PC contents of the mixes. Table 3-2 summarizes all mix-designs, including the IPS calculation and PC percentage replacement. Pure PC mixtures are denoted as PC followed by the w/f (e.g. PC-0.32), while paste mixtures with LF inclusion are denoted by the distribution factor q, the PC content, and the w/f (e.g. 0.37-250-0.32).

Considering that the "shear history" is a very relevant factor that may influence on the rheological behaviour of the PC mixes (Raucci et al. 2018; Tan, Bernal, and Provis 2017), the same mixing procedure has been adopted for all pastes fabricated in this research as per ASTM C305 (ASTM International 2014) and presented hereafter: 
- Portland cement and limestone fillers (if any) were manually mixed dry and shook over 30 seconds in closed containers.

- All the water + admixtures (if any) were poured into the mixing bowl.

- Powders were added in a period of 30 seconds.

- The mixer was started at low speed $(95 \mathrm{rpm})$ for 60 seconds.

- Then, the mixer was stopped for 30 seconds, while the material has been homogenized with a scoop and detached from the mixing bowl

- The mixer was started again at medium speed (180 rpm) and mixed for over 90 seconds.

Table 3-2: Mix-design and IPS values

\begin{tabular}{|c|c|c|c|c|c|c|c|}
\hline Mix name & $\begin{array}{c}\mathrm{PC} \\
\left(\boldsymbol{k g} / \mathrm{m}^{3}\right)\end{array}$ & $\begin{array}{c}\text { Replacement } \\
\text { Filler }\left(k g / m^{3}\right)\end{array}$ & $\begin{array}{c}\text { Performance } \\
\text { Filler }\left(\mathrm{kg} / \mathrm{m}^{3}\right)\end{array}$ & $\begin{array}{c}\text { w/f } \\
\% \text { mass }\end{array}$ & $\begin{array}{c}\text { w/c } \\
\% \text { mass }\end{array}$ & $\begin{array}{c}\text { Total \% } \\
\text { fillers }\end{array}$ & IPS \\
\hline PC-0.32 & 1,538 & - & - & 0.32 & 0.32 & - & 0.54 \\
\hline PC- 0.40 & 1,370 & - & - & 0.40 & 0.40 & - & 0.70 \\
\hline PC-0.5 & 1,205 & - & - & 0.50 & 0.50 & - & 0.90 \\
\hline $0.37-250-0.32$ & 1,198 & 172 & 144 & 0.32 & 0.40 & $21 \%$ & 0.40 \\
\hline $0.37-150-0.32$ & 729 & 607 & 147 & 0.32 & 0.65 & $51 \%$ & 0.34 \\
\hline $0.37-100-0.32$ & 490 & 829 & 149 & 0.32 & 0.96 & $67 \%$ & 0.32 \\
\hline $0.37-250-0.40$ & 1,094 & 129 & 129 & 0.40 & 0.49 & $19 \%$ & 0.52 \\
\hline $0.37-150-0.40$ & 668 & 528 & 131 & 0.40 & 0.79 & $50 \%$ & 0.44 \\
\hline $0.37-100-0.40$ & 449 & 732 & 133 & 0.40 & 1.17 & $66 \%$ & 0.41 \\
\hline $0.37-250-0.50$ & 992 & 87 & 113 & 0.50 & 0.60 & $17 \%$ & 0.68 \\
\hline $0.37-150-0.50$ & 606 & 450 & 116 & 0.50 & 0.97 & $48 \%$ & 0.57 \\
\hline $0.37-100-0.50$ & 408 & 636 & 117 & 0.50 & 1.42 & $65 \%$ & 0.53 \\
\hline $0.21-250-0.32$ & 682 & 492 & 304 & 0.32 & 0.69 & $54 \%$ & 0.30 \\
\hline $0.21-150-0.32$ & 412 & 741 & 307 & 0.32 & 1.13 & $72 \%$ & 0.28 \\
\hline $0.21-100-0.32$ & 276 & 867 & 309 & 0.32 & 1.68 & $81 \%$ & 0.27 \\
\hline $0.21-250-0.40$ & 636 & 416 & 271 & 0.40 & 0.83 & $52 \%$ & 0.39 \\
\hline $0.21-150-0.40$ & 385 & 649 & 275 & 0.40 & 1.36 & $71 \%$ & 0.36 \\
\hline $0.21-100-0.40$ & 257 & 767 & 276 & 0.40 & 2.02 & $80 \%$ & 0.35 \\
\hline $0.21-250-0.50$ & 590 & 341 & 239 & 0.50 & 0.99 & $50 \%$ & 0.50 \\
\hline $0.21-150-0.50$ & 357 & 558 & 243 & 0.50 & 1.62 & $69 \%$ & 0.46 \\
\hline $0.21-100-0.50$ & 239 & 668 & 244 & 0.50 & 2.41 & $79 \%$ & 0.44 \\
\hline
\end{tabular}




\subsubsection{Testing details}

\section{$\underline{\text { Viscometer test }}$}

Viscosity readings started at 5 minutes after the water addition. A Brookfield DV-E viscometer was used to measure paste viscosity at different velocities, 5, 6, 10, 12, 20, 30, 50,60 , and $100 \mathrm{rpm}$. The viscosimeter was equipped with a set of disc spindles, from RV No. 2 to No. 6 which allowed the viscosity appraisal for a wide range of viscosities as presented in Table 3-3. The spindles from No. 3 to 5 were used in this work

Table 3-3: Maximum value of viscosity reading for each spindle at different torque.

\begin{tabular}{cccccccccc}
\hline $\begin{array}{c}\text { Spindle } \\
\text { No }\end{array}$ & $\begin{array}{c}\mathbf{5} \\
\mathbf{r p m}\end{array}$ & $\mathbf{6}$ & $\mathbf{1 0}$ & $\mathbf{1 2}$ & $\mathbf{2 0}$ & $\mathbf{3 0}$ & $\mathbf{5 0}$ & $\mathbf{6 0}$ & $\mathbf{1 0 0}$ \\
\hline 1 & 2.00 & 1.67 & 1.00 & 0.83 & 0.50 & 0.33 & 0.20 & 0.17 & 0.10 \\
2 & 8.00 & 6.67 & 4.00 & 3.33 & 2.00 & 1.33 & 0.80 & 0.67 & 0.40 \\
3 & 20.00 & 16.67 & 10.00 & 8.33 & 5.00 & 3.33 & 2.00 & 1.67 & 1.00 \\
4 & 40.00 & 33.33 & 20.00 & 16.67 & 10.00 & 6.67 & 4.00 & 3.33 & 2.00 \\
5 & 80.00 & 66.67 & 40.00 & 33.33 & 20.00 & 13.33 & 8.00 & 6.67 & 4.00 \\
6 & 200.00 & 166.67 & 100.00 & 83.33 & 50.00 & 33.33 & 20.00 & 16.67 & 10.00 \\
7 & 800.00 & 666.67 & 400.00 & 333.33 & 200.00 & 133.33 & 80.00 & 67.67 & 40.00 \\
\hline
\end{tabular}

Note: Viscosity values are given in Pa.s

As suggested by the user manual of the equipment (Brookfield Ametek 2017), paste mixtures were placed in a container of $600 \mathrm{ml}$ or larger with an inner diameter of $83 \mathrm{~mm}$. In all cases, the container was filled up with the same paste volume of $600 \mathrm{ml}$. An UpDown ramp method was used, starting the readings at $5 \mathrm{rpm}$, mounting every 10 seconds to the following speed, reaching $100 \mathrm{rpm}$ as its peak value. A down ramp followed by another Up and Down cycle was then performed. Figure 3-2 presents the shear history experienced by all pastes during the viscometer test. 


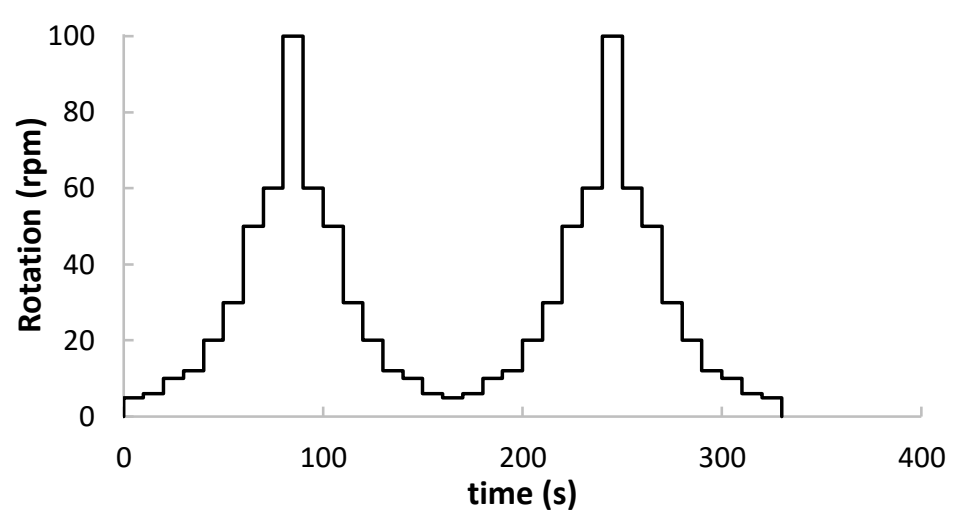

Figure 3-2 Shear history experienced by pastes during viscometer test

\section{$\underline{\text { Setting time }}$}

A metallic conical frustum mold of $40 \pm 1 \mathrm{~mm}$ height, $60 \pm 1 \mathrm{~mm}$ top diameter and $70 \pm 1$ $\mathrm{mm}$ bottom diameter was filled for the measurement of initial and final setting time. A manual Vicat instrument was used to monitor setting, following the ASTM C191 (ASTM International 2018a). The first reading was taken after 30 minutes after mixing and checked continuously every 15 minutes. In every reading the needle was placed in a different location of the sample, providing at least $5 \mathrm{~mm}$ distance from previous penetrations.

\section{Compressive strength}

Cylindrical cement paste specimens with a diameter of $50.6 \pm 0.2 \mathrm{~mm}$ and $99.5 \pm 0.5 \mathrm{~mm}$ height were produced for compressive strength evaluation at 7, 14, and 28 days. All the sample containers were provided with a top cover to avoid water evaporation during the first $24 \mathrm{~h}$ after molding. Once the cylinders were taken out of their molds, they were stored in a climate chamber at $95 \%$ relative humidity and $25^{\circ} \mathrm{C}$. Prior to the compressive strength test, both circular end faces of the samples were carefully ground in circular grinder were samples are vertically supported by a thick metal block with a cylindrical opening of the same diameter of the samples. This way, plane-parallel loading surfaces, perpendicular to the sample axis could be ensured. Finally, immediately before testing, samples were 
slightly dried out with a towel to remove any excess of superficial water, then their diameter and height were measured, followed by placing them in the test machine. The operational features of the test such as loading rate, etc., were selected as per ASTM C-39 (ASTM International 2018b).

\subsection{Results}

\subsubsection{Rheology}

Four viscosity curves, from two consecutive cycles (i.e. two ascending and 2 descending curves), were generated for each paste mixture. The descending curve of the first cycle was selected as the most representative of the rheological behaviour of all mixes. Figure 3-3 illustrates the viscosity measurements captured over the two cycles for an arbitrary mix.

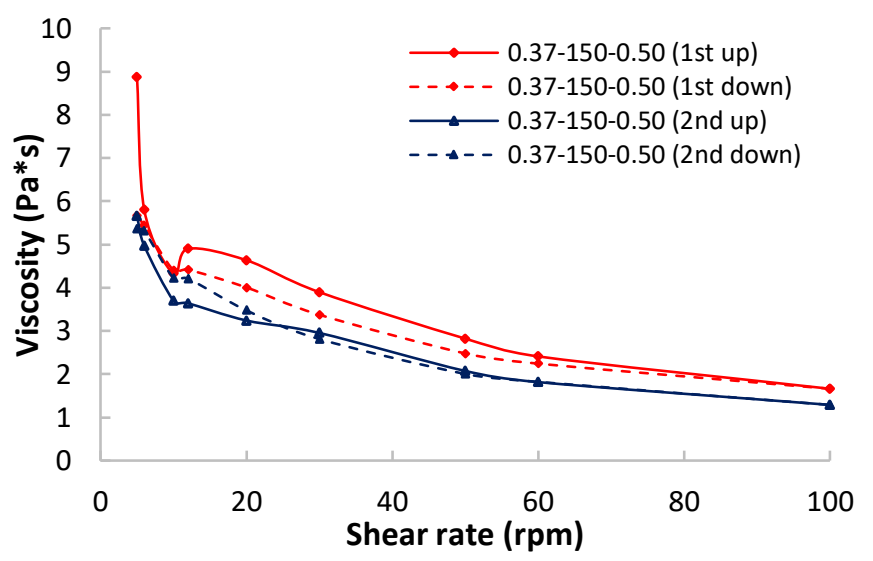

Figure 3-3 Viscometer results sample 0.37-150-0.5.

Note: Red color: first cycle ramp, blue lines: second cycle. Solid and dotted lines show the upward and downward ramps respectively.

The rheological behaviour results of the 21 pastes evaluated in this work are presented in Figure 3-4. They are divided into three main families according to the water-to-fines ratio. A general downward trend can be noticed for all pastes; at low shear rates (5 rpm) the viscosity values displayed are the maximum ones, lessening as a function of the shear rate, and stabilizing at faster rates (60 to $100 \mathrm{rpm}$ ); the latter describes a shear-thinning behaviour of all mixes. Pastes with $\mathrm{w} / \mathrm{f}=0.32$ presented minimum viscosities of $4.8 \mathrm{~Pa} . \mathrm{s}$ at 
$60 \mathrm{rpm}$. For those paste mixtures, the higher the PC content (and thus the low the replacement level by LF), the higher their average viscosity over the whole shear spectrum. Conversely, PC pastes designed with w/f of 0.4 and 0.5 showed a distinct behaviour; i.e. pastes with higher replacement levels presented a higher average viscosity. The latter was even more visual for $\mathrm{w} / \mathrm{f}$ of 0.50 . Minimum viscosity values at $60 \mathrm{rpm}$ were $2.23 \mathrm{~Pa} . \mathrm{s}$ and 1.52 for pure $\mathrm{PC}$ at $\mathrm{w} / \mathrm{f}=0.40$ and $\mathrm{w} / \mathrm{f}=0.50$ respectively. The maximum viscosities reached at $60 \mathrm{rpm}$ were 4.57 Pa.s for the mixture 0.21-100-0.40 and 2.91 Pa.s for 0.21-100-0.50. The last two mixes embodied the lowest PC content studied in each family.

a)

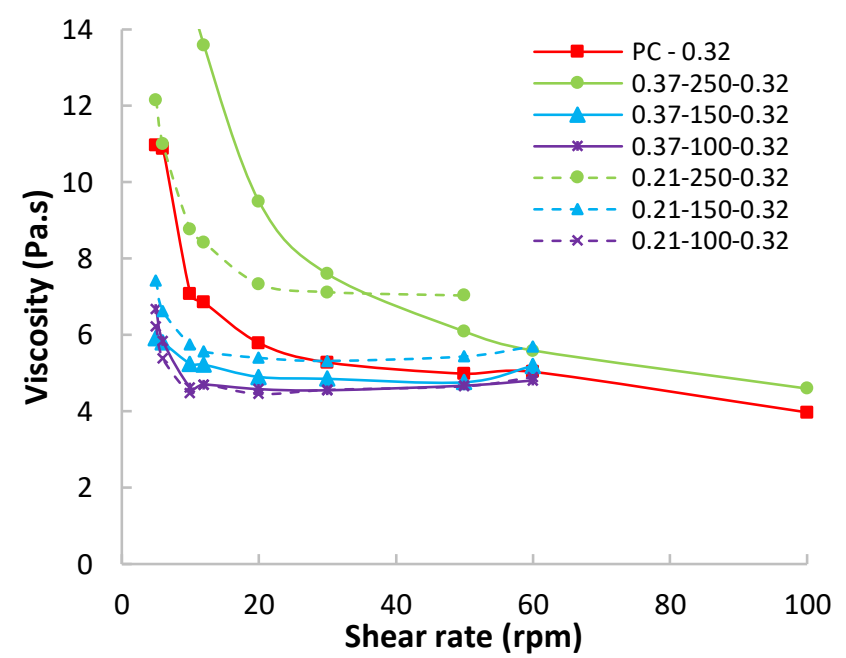

b)

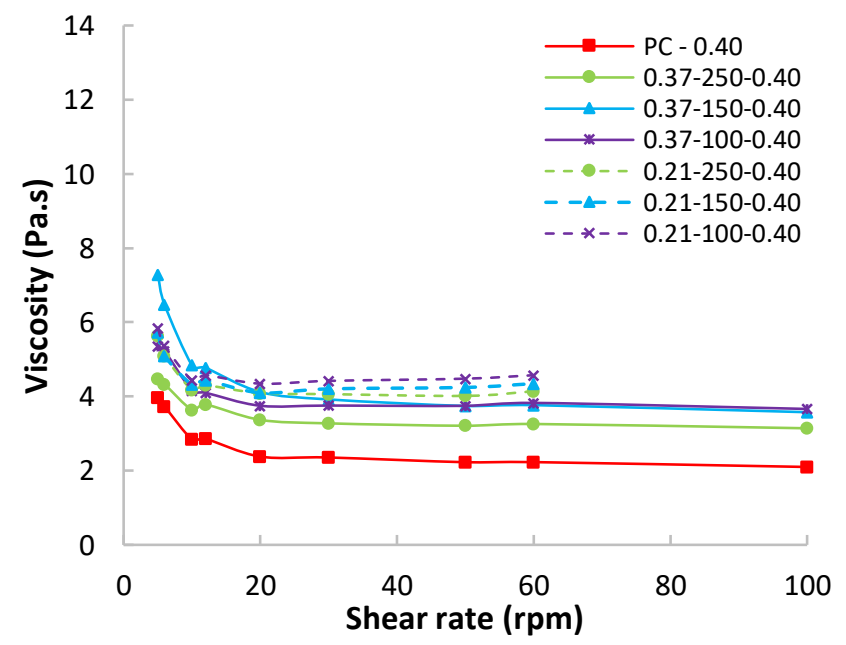


c)

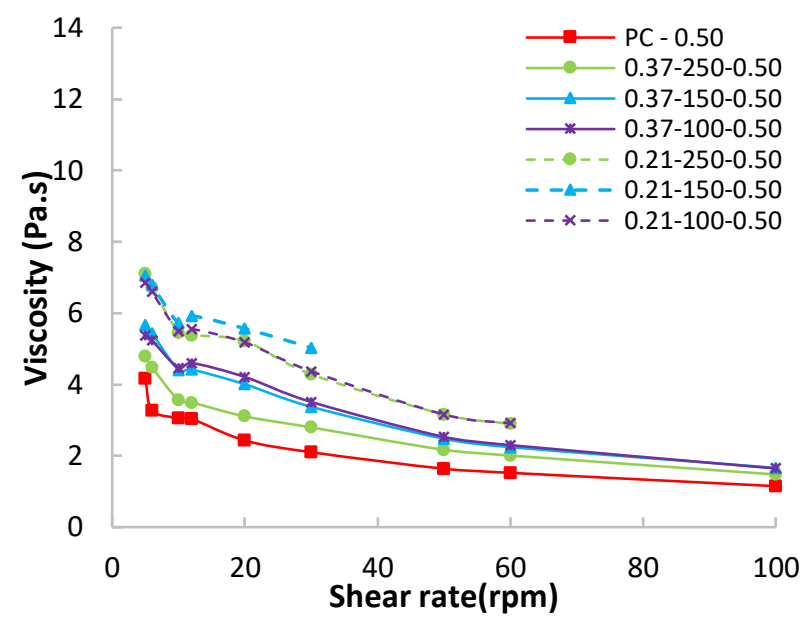

Figure 3-4 Rheological behaviour for all paste families. a) $\mathrm{w} / \mathrm{f}=0.32$, b) $\mathrm{w} / \mathrm{f}=0.40$, c) $\mathrm{w} / \mathrm{f}=0.50$.

Note: The pure mixtures are presented in red, whereas the mixtures with 250,150 , and $100 \mathrm{~kg} / \mathrm{m}^{3}$ are presented in green and circle marker, blue triangle marker, and purple and X-marker, respectively.

Moreover, within the green, blue, and purple mixtures, the ones developed with $\mathrm{q}=0.37$ are presented with solid lines, whereas the ones manufactured with $\mathrm{q}=0.21$ are shown with dashed lines.

It should be noted that some of the viscosity values were not captured by the viscosimeter, because those values were outside of the reading range of the spindle selected to appraise the viscosity profile of the mixtures. Moreover, as suggested by the user manual, changing spindles for the same mixture was not recommended, in order to avoid dispersion in the results.

\subsubsection{Setting time}

Table 3-4 presents the measured setting time for the 21 paste mixtures studied. As a general trend, it is evident that the initial setting is lower when $\mathrm{w} / \mathrm{f}$ lessens. The initial setting time of the control mixes, pure cement (i.e. no limestone filler addition), ranged from 156 to 229 minutes for mixtures with $\mathrm{w} / \mathrm{f}=0.32$ and $\mathrm{w} / \mathrm{f}=0.50$, respectively. Studying the results by groups of w/f (i.e. last number of the mixture designation) it is possible to see a clear acceleration in hydration rate, for most of the mixes, when limestone fillers are used to replace PC. The minimum initial setting measured was 102 minutes for a mixture with low replacement level and low w/f (i.e. 0.37-250-0.32), while mixture at high levels of 
replacement and w/f (i.e. 0.21-100-0.50) had an initial setting of 282 minutes, almost one hour delayed compared to its control pure cement $\mathrm{w} / \mathrm{f}=0.50$.

Table 3-4: Initial and final setting of studied mixes

\begin{tabular}{lll}
\hline Mix name & Initial setting (min) & \multicolumn{1}{c}{ Final setting (min) } \\
\hline PC-0.32 & 156 & 240 \\
$0.37-250-0.32$ & 102 & 165 \\
$0.37-150-0.32$ & 102 & 195 \\
$0.37-100-0.32$ & 107 & 250 \\
PC-0.40 & 185 & 290 \\
$0.37-250-0.40$ & 163 & 320 \\
$0.37-150-0.40$ & 162 & 335 \\
$0.37-100-0.40$ & 180 & 425 \\
$0.21-250-0.40$ & 132 & 330 \\
$0.21-150-0.40$ & 157 & 480 \\
$0.21-100-0.40$ & 189 & 530 \\
PC-0.50 & 229 & 335 \\
$0.37-250-0.50$ & 216 & 425 \\
$0.37-150-0.50$ & 229 & 455 \\
$0.37-100-0.50$ & 266 & 600 \\
$0.21-250-0.50$ & 193 & 470 \\
$0.21-150-0.50$ & 217 & 600 \\
$0.21-100-0.50$ & 282 & 630 \\
\hline
\end{tabular}

Final setting time for pure $\mathrm{PC}$ pastes ranged from 240 minutes to 335 minutes for $\mathrm{w} / \mathrm{f}=0.32$ and $\mathrm{w} / \mathrm{f}=0.50$, respectively. Conversely to initial setting, replacing $\mathrm{PC}$ by limestone fillers slow down the final set of pastes. Yet, mixes with $\mathrm{w} / \mathrm{f}=0.32$ presented a final setting slower or comparable to its control pure PC. Pastes with $\mathrm{w} / \mathrm{f}=0.40$ and 0.50 can almost double the final setting time of the controls, reaching 530 minutes and 630 minutes, for the pastes with the lowest amount of Portland cement at their corresponding water content family.

\subsubsection{Compressive strength}

The evolution of compressive strength at 7, 14, and 28 days for all mixtures studied in this research is shown in Figure 3-5. Each value in the graphs represents the average obtained on three specimens. The vertical bars represent the standard deviation obtained in each of 
the gathered compressive values. In general, the use of limestone fillers as PC replacement reduces the compressive strength in comparison with pure PC pastes. However, for the mixes $\mathrm{q}=0.37$ and $\mathrm{PC}$ content of $250 \mathrm{~kg} / \mathrm{m}^{3}$, at the different water to fines ratios, the compressive strength data obtained was similar to or even higher than pure cement pastes. Additionally, considering $f^{\prime} c>32 \mathrm{MPa}$ as a suitable value to use in structural applications, pastes using a water-to-fines ratio between 0.32 to 0.40 and $\mathrm{PC}$ replacement up to $54 \%$ can be acceptable, entailing and important reduction in Portland cement's use.

a)

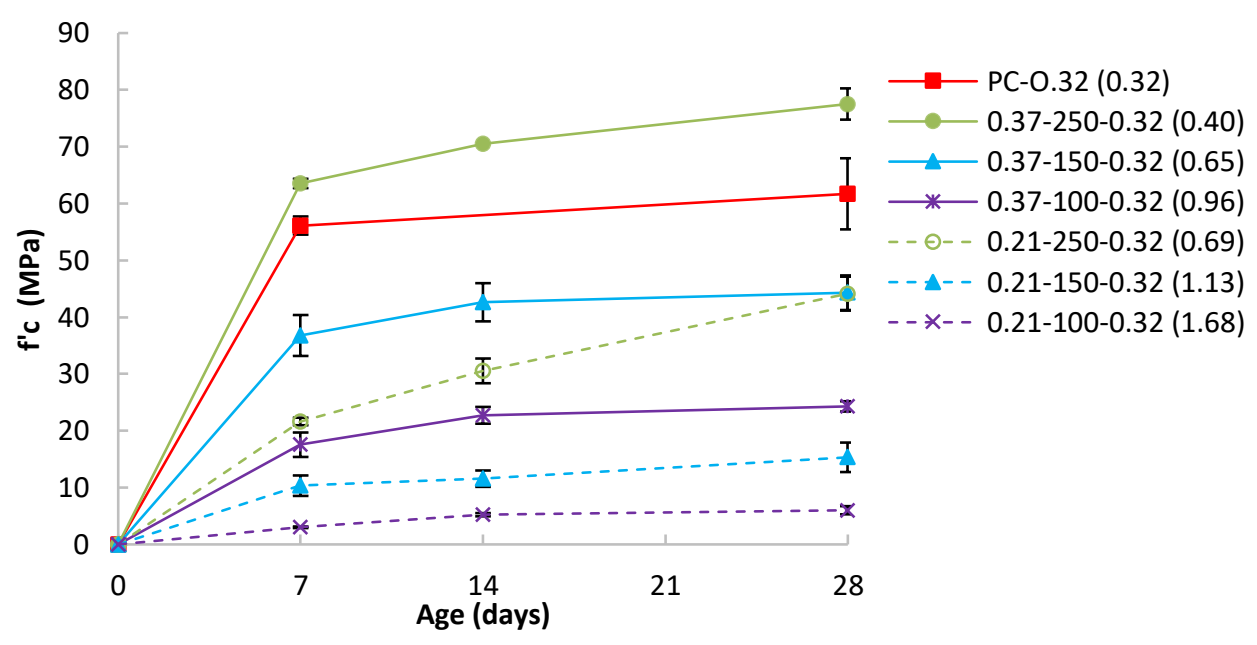

b)

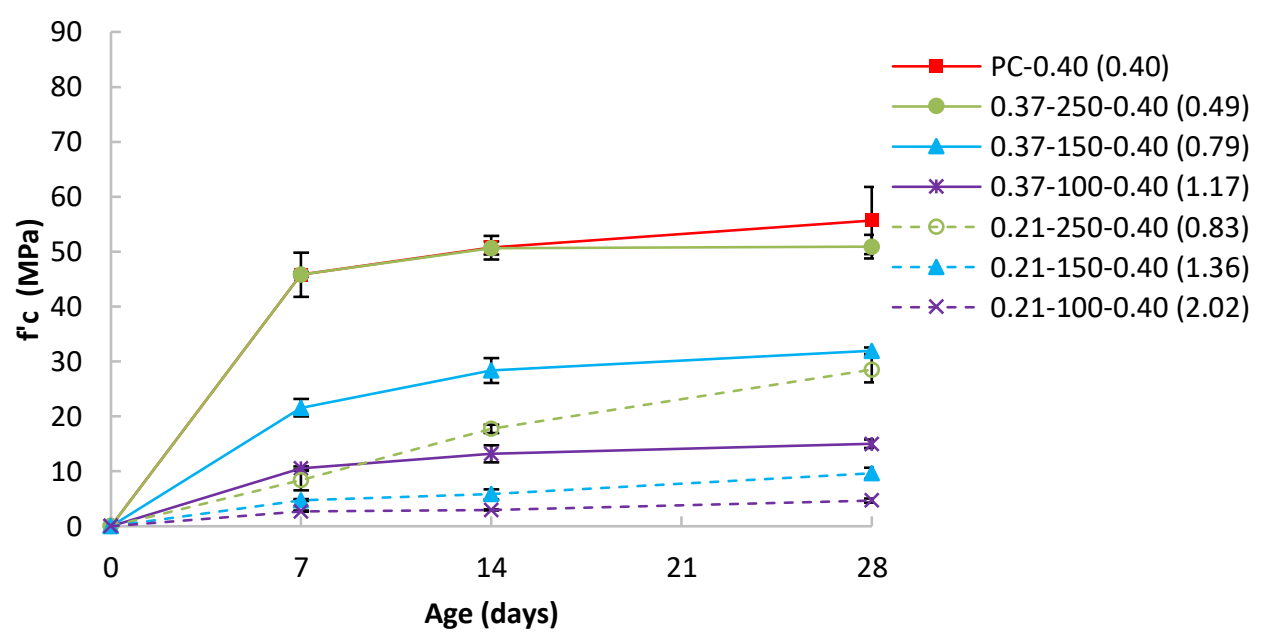


c)

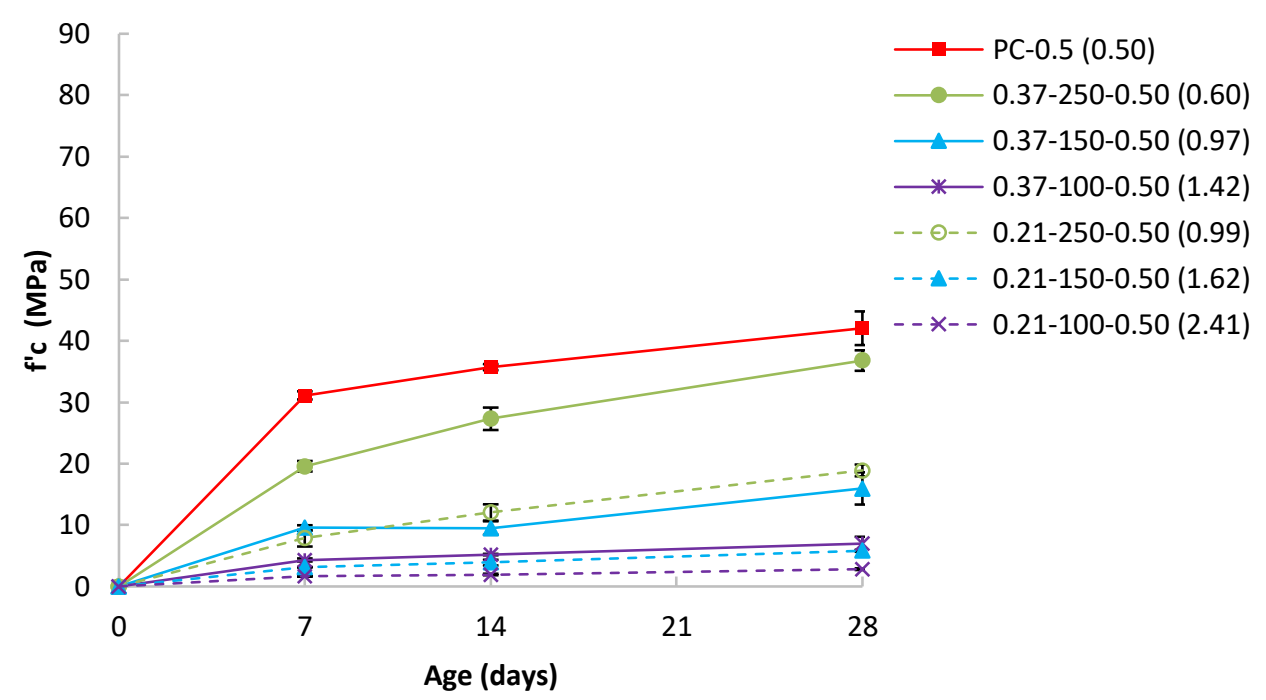

Figure 3-5: Evolution of compressive strength for all paste families. a) $w / f=0.32, b) w / f=0.40$, c) $w / f=0.50$. Note: The first number of the mixture notation stands for the $\mathrm{q}$ factor, the second is the PC content in $\mathrm{kg} / \mathrm{m}^{3}$ and the third one corresponds to the w/f. The number in brackets stands for the w/c.

The $f^{\prime} c$ at 28 days for pastes with a w/f=0.32 (Figure 3-5a) varied from 6.0 MPa to 77.5 $\mathrm{MPa}$ for PC replacements of $81 \%$ and $21 \%$ respectively. It should be noted that the mixture $0.37-250-0.32$ reached higher $f^{\prime} c$ than the control of pure cement by $25 \%$, which can be associated with a better packing condition, microstructure enhancement, and an adequate level of dilution.

Regarding the pastes with $\mathrm{w} / \mathrm{f}=0.40$ (Figure $3-5 \mathrm{~b}$ ), the $f^{\prime} \mathrm{c}$ at 28 days ranged from $4.7 \mathrm{MPa}$ for $80 \%$ of $\mathrm{PC}$ replacement up to $55.7 \mathrm{MPa}$ for pure Portland cement. At w/f=0.50 (Figure 3-5c), the values varied from $2.8 \mathrm{MPa}$ for $79 \%$ replacement to $42.1 \mathrm{MPa}$ for pure cement. Comparing the plots $\mathrm{a}, \mathrm{b}$ and $\mathrm{c}$, a trend can be identified: the higher the water content the higher the f'c reduction when compared to its control/pure PC, at similar levels of replacement, suggesting a double dilution effect produced by the replacement of PC and the increase of water, which also can be understood as larger distances between cement particles. 


\subsection{Discussion.}

\subsubsection{Rheology behaviour as a function of IPS}

A comparison between the calculated IPS and the viscosity for two different speeds (50 and $60 \mathrm{rpm}$ ) is illustrated in Figure 3-6a and b, respectively. A downward trend is clearly observed in both plots; however, some mixes containing a low amount of water (i.e. $\mathrm{w} / \mathrm{f}=0.32$ ) presented important scattering from the trend line, which might be attributed to laboratory measurement errors. Yet, it is evident that the paste viscosity is strongly dependent on the IPS and the parameters that comprise this index (Equation 3-3). The higher the IPS, the lower is the frictional effects amongst the particles, and thus the higher is the flow. According to the PSD of the materials, the inclusion of limestone fillers, regardless of the type (i.e. performance or replacement) provides the system with particles smaller than PC, increasing their volume surface area. Hence, IPS decreases, and viscosity rises in all shear rates studied. The rheological behaviour of pure PC pastes showed lower viscosities than the companions containing LF. It might have occurred due to particularly two effects: lower VSA than pastes with fillers and a possible lubricant effect of PC (M.T. de Grazia et al. 2019). Therefore, finer grinding of PC particles in combination with limestone LF with similar PSD or slightly larger than PC might improve rheological behavior (Scrivener, John, and Gartner 2018; John et al. 2018a). 
a)

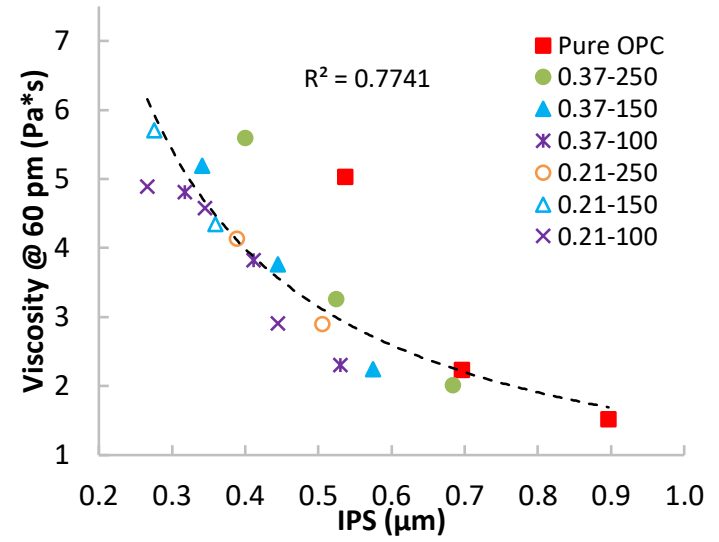

b)

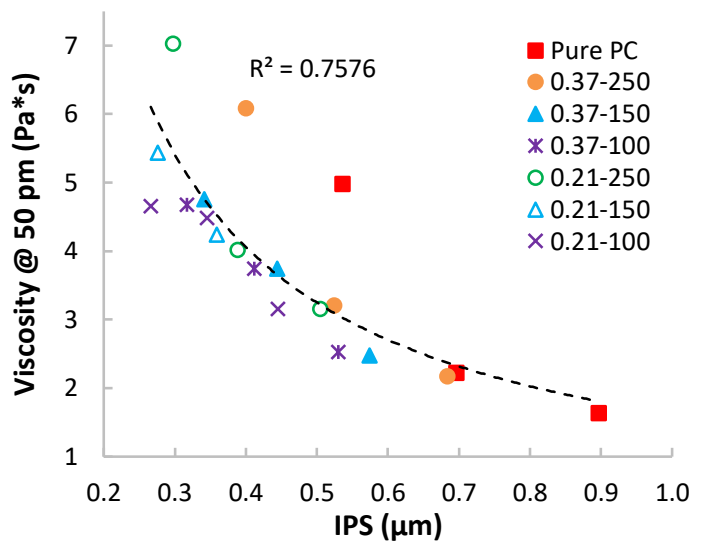

Figure 3-6 Viscosity of cement pastes at two different shear rates vs. Inter-Particle separation. Note: The first number of the mixture notation stands for the q factor and the second one is the PC content in $\mathrm{kg} / \mathrm{m}^{3}$

\subsubsection{Setting time and filler content}

Looking at the initial setting time, it is possible to identify an accelerated hydration process for systems containing LF, especially evident for pastes with $\mathrm{w} / \mathrm{f}=0.32$. This is likely due to the availability of more nucleation sites promoted by the higher surface area of LF (Tikkanen, Cwirzen, and Penttala 2014; Bonavetti et al. 2003). Moreover, a larger number of nucleation sites for C-S-H grow might reduce the spacing between clusters of C-S-H in development, that in turn promotes a faster bonding between those clusters, which is in agreement with the percolation theory and the reduction of the percolation threshold (Scherer et al. 2012). However, the latter effects are diminished or completely surpassed by important dilution effects on mixes with moderate to high water content (e.g. w/f=0.40 and 0.50) and high PC replacement levels (i.e. $100 \mathrm{~kg} / \mathrm{m} 3$ ), reaching similar setting times as the control mixes (pure cement) or even delaying setting when dilution overcomes the improvements on hydration (John et al. 2018a; Scrivener, John, and Gartner 2018). This is the case for mixes $0.21-100-0.40,0.37-100-0.50$ and $0.21-100-0.50$ with $80 \%, 65 \%$ and $79 \%$ of PC replacement. 
Conversely, the time for reaching the final set of most of the paste mixes studied is higher than the pure PC control mixes. Only mixes $0.37-250-0.32$ and $0.37-150-032$ with the lowest water content at $21 \%$ and $51 \%$ of replacement present an accelerated final setting.

\subsubsection{Compressive Strength}

It is well established that compressive strength of cementitious systems such as cement paste, mortar, and or concrete mixtures made of PC changes as a function of the w/c ratio according to Abrams' Law (Abrams 1924; Mehta and Monteiro 2006). Yet, when limestone fillers become part of the system as a direct replacement of PC, numerous authors (Wang, Shi, Farzadnia, Shi, and Jia 2018; P. Thongsanitgarn et al. 2011; J. Zhang and Li 2012; John et al. 2018a) reported reductions of compressive strength, especially for replacement ratios of $20 \%$ or higher. Moreover, some authors claimed that for systems presenting an important amount of fillers, new relationships should be developed to describe mechanical properties such as compressive strength. Thus, the water-to-fines ratio was verified as a potential parameter governing the development of mechanical properties of those mixes as per (John et al. 2018a)

Figure 3-7a presents the relationship $f^{\prime} c$ versus the w/f ratio of the distinct pastes. Although downward trends are verified in this plot, they vary as a function of ingredients (i.e. PC,

LF and water contents) present in the system and thus, distinct constitutional laws should be implemented for different families: Equation 3-4 for pure OPC-red and family 0.37250, Equation 3-5 for families 0.37-150 and 0.21-250, and Equation 3-6 for families 0.37$100,0.21-150$ and $0.21-100$. Hence, these results seem to indicate that the $w / f$ is not the leading but rather a secondary parameter that might be used to forecast the mechanical performance of systems with high LF and reduced PC contents. Conversely, Figure 3-7b 
presents the results of $f^{\prime} c$ versus the actual $\mathrm{w} / \mathrm{c}$ ratio used in all pastes fabricated in this research. Looking at the plot, one verifies that this relationship describes a single downward trend that can better describe compressive strength base on the single parameter of w/c as presented by the modified Abrams' Law show in Equation 3-7.

a)

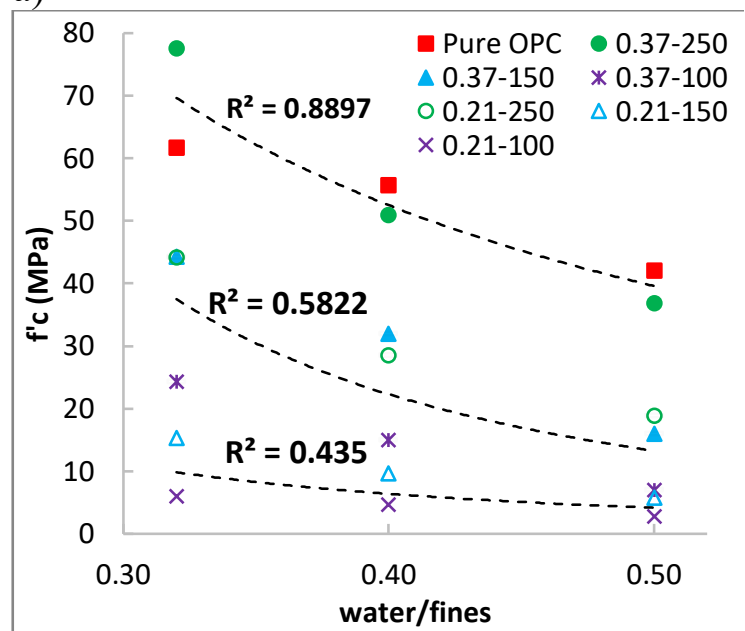

b)

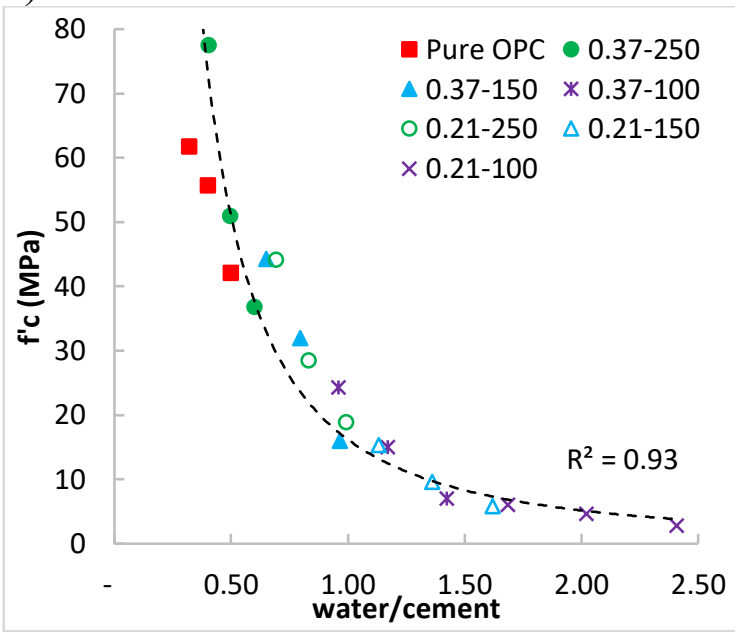

Figure 3-7 Compressive strength based on: a) water to cement ratio, b) water to fines ratio Note: The first number of the mixture notation stands for the q factor and the second one is the PC content in $\mathrm{kg} / \mathrm{m}^{3}$

$$
\begin{aligned}
f^{\prime} c & =\frac{192.3}{24.2^{\left(\frac{w}{f}\right)}} \\
f^{\prime} c & =\frac{224.5}{157.8^{\left(\frac{w}{f}\right)}} \\
f^{\prime} c & =\frac{98.6}{339.3^{\left(\frac{w}{f}\right)}} \\
f^{\prime} c & =\frac{122.6}{5.9^{\left(\frac{w}{c}\right)}}
\end{aligned}
$$

Equation 3-7

where $\mathrm{f}^{\prime} \mathrm{c}$ is compressive strength in $\mathrm{MPa}, \mathrm{w} / \mathrm{c}$ is the mass proportion between water and $\mathrm{PC}$, while $\mathrm{w} / \mathrm{f}$ is the mass proportion of water and total powder (i.e. $\mathrm{LF}+\mathrm{PC}$ ).

Based on the previous description, one may notice that the sole use of $w / f$ (as proposed by John et al. 2018) is an incomplete alternative to forecast the mechanical performance (i.e. 
compressive strength) of mixtures with high LF and reduced PC content, since other parameters such as w/c seem to play a major role on the f'c results. Further studies must be performed to better evaluate the relationship between $\mathrm{w} / \mathrm{c}$ and $\mathrm{w} / \mathrm{f}$.

It is worth mentioning that other mechanical properties such as modulus of elasticity, flexural or tensile strength and durability related aspects should be studied to fully understand the hardened state performance of highly packed cementitious pastes with low PC content and high LF dosages, however, the assessment of those properties were out of the scope of this paper.

\subsection{Conclusions}

This project aimed to understand the influence of the IPS on the rheological behaviour, setting time and compressive strength of cement pastes designed through the use of continuous PPMs with low PC content and high amounts of LF. The main findings obtained in this research are presented hereafter:

- Inter-Particle Separation distance (IPS) is an effective tool able to predict the rheological behavior of cement pastes containing limestone fillers.

- The use of limestone fillers increases paste viscosity in a direct proportion to the percentage replacement used. Smaller particles than PC with larger surface area are the main reason for this phenomenon.

- Mixes containing limestone fillers at replacement levels lower than 50\% showed faster setting times due to accelerated rates of hydration and a possible reduction in the percolation threshold. However, beyond 50\% replacement, setting time was found to slow down, even taking longer times than control mixes due to excessive cement dilution. 
- Differently from previous literature data, the compressive strength of low cement content pastes followed the conventional Abrams Law and thus the water-tocement ratio was the leading parameter setting this property. Further studies are still needed in this area to prove this finding, besides verifying the possibility of incorporating secondary parameters such as $w / f$ to enhance the mechanical properties prediction of systems with reduced PC and high amounts of LF.

\subsection{Recommendations for future research}

This research has investigated the viscosity, setting time and compressive strength of low PC content highly packed systems with high dosages of LFs. However, to better understand the influence of IPS on the fresh state behaviour of those mixtures, it is important to explore their response while the use of chemical admixtures, specifically plasticizers. Furthermore, although it has been found that IPS might be a powerful tool to predict the fresh state properties of cementitious mixtures, there are currently no models able to describe such relationship, especially for different torque regimes. Likewise, IPS has been initially applied to evaluate the fresh state behaviour of cementitious mixtures, yet the hardened properties might also be influenced by it. Finally, it has been demonstrated that $w / c$ is the leading factor to set compressive strength of cementitious mixtures; however, the influence of LFs and w/f should be further studied to be included in the prediction models of f'c. 


\subsection{References}

Abrams, Duff. A. 1924. "Design of Concrete Mixtures.” Lewis Institute. Lewis Institute, Structutal Materials Research Laboratoty, Chicago.

http://www2.cement.org/pdf_files/ls001.pdf.

Andreasen, A. H. M., and J. Andreasen. 1930. "Ueber Die Beziehung Zwischen Kornabstufung Und Zwischenraum in Produkten Aus Losen Körnern (Mit Einigen Experimenten)." Colloid and Polimer Science 50 (3): 217-28.

Andrew, Robbie M. 2018. "Global CO2 Emissions from Cement Production, 19282017.” Earth System Science Data 10 (4): 2213-39. https://doi.org/10.5194/essd-102213-2018.

ASTM International. 2014. "ASTM C305-14 Standard Practice for Mechanical Mixing of Hydraulic Cement Pastes and Mortars of Plastic Consistency," 1-3. https://doi.org/10.1520/C0305-14.2.

- 2018a. "ASTM C191-18a, Standard Test Methods for Time of Setting of Hydraulic Cement by Vicat Needle." ASTM International, 1-8. https://doi.org/10.1520/C0191-18A.2.

_ 2018b. "ASTM C39-18: Standard Test Method for Compressive Strength of Cylindrical Concrete Specimens." ASTM International, 1-8. https://doi.org/10.1520/C0039.

Bentur, A. 1991. Microstructure, Interfacial Effects and Micromechanics of Cementitious Composites. Advances in Cementitiou Materials. Mindess, S. USA: The American Ceramic Society.

Bentz, Dale P, Chiara F Ferraris, Scott Z Jones, Didier Lootens, and Franco Zunino. 2017. "Limestone and Silica Powder Replacements for Cement : Early-Age Performance" 78: 43-56.

Bonavetti, V., H Donza, G. Menéndez, O. Cabrera, and E. F. Irassar. 2003. "Limestone Filler Cement in Low w/c Concrete: A Rational Use of Energy." Cement and Concrete Research 33 (6): 865-71. https://doi.org/10.1016/S0008-8846(02)01087-6.

Brookfield Ametek. 2017. "More Solutions to Sticky Problems."

Damineli, Bruno L., Vanderley M. John, Björn Lagerblad, and Rafael G. Pileggi. 2016. "Viscosity Prediction of Cement-Filler Suspensions Using Interference Model: A Route for Binder Efficiency Enhancement." Cement and Concrete Research 84: 819. https://doi.org/10.1016/j.cemconres.2016.02.012.

Dinger, Dennis R., and James E. Funk. 1997. "Particle-Packing Phenomena and Their Application in Materials Processing." MRS Bulletin 22 (12): 19-23. https://doi.org/10.1557/S0883769400034692.

Dörr, Aaron, Amsini Sadiki, and Amirfarhang Mehdizadeh. 2013. "A Discrete Model for the Apparent Viscosity of Polydisperse Suspensions Including Maximum Packing Fraction.” Journal of Rheology 57 (3): 743-65. https://doi.org/10.1122/1.4795746.

El-Hawary, Moetaz, and Khallad Nouh. 2018. "Properties and Sustainability of Concrete Containing Fillers*." Australian Journal of Civil Engineering 16 (2): 96-105. https://doi.org/10.1080/14488353.2018.1453968.

F.S. Ortega, R.G. Pileggi, A.R. Studart, and V.C. Pandofelli. 2002. "IPS A Viscosity Predictive Parameter." American Ceramic Society Bulletin 81 (1): 44-52.

Fennis, S.A.A.M., and Joost C. Walraven. 2012. "Using Particle Packing Technology for 
Sustainable Concrete Mixture Design.” Heron 57 (2): 73-101.

Ferraris, Chiara F, Karthik H Obla, and Russell Hill. 2001. "The Influence of Mineral Admixtures on the Rheology of Cement Paste and Concrete" 31: 245-55.

Fuller, William B, and S.E. Thompson. 1907. "The Laws of Proportioning Concrete." American Society of Civil Engineers 33: 223-98.

Funk, James E., and Dennis R. Dinger. 1994. Predictive Process Control of Crowded Particulate Suspensions. https://doi.org/10.1007/978-1-4615-3118-0.

Furnas, C.C. 1931. "Grading Aggregates I - Mathematical Relations for Beds of Broken Solids of Maximum Density." U.S. Bureau of Mines 23 (9): 1052-58. https://doi.org/10.1021/ie50261a017.

Grazia, M.T. de. 2018. "Contribution to the Understanding of Fresh and Hardened State Properties of Low Cement Concrete." Ottawa University.

Grazia, M.T. de, L.F.M. Sanchez, R.C.O. Romano, and R.G. Pileggi. 2019. "Investigation of the Use of Continuous Particle Packing Models (PPMs) on the Fresh and Hardened Properties of Low-Cement Concrete (LCC) Systems." Construction and Building Materials 195: 524-36. https://doi.org/10.1016/j.conbuildmat.2018.11.051.

Gutteridge, Walter, and John Dalziel. 1990. "Filler Cement: The Effect of the Secondary Component of the Hydration of Portland Cement. Part I. A Fine Non-Hydraulic Filler." Cement and Concrete Research 20 (c): 778-82.

Haegermann, Bernd. 2002. "The Cement Industry Sustainability Initiative Within the World Business Council for Sustainable Development." Vdz Congress, 506-13.

Hao, Tian, and Richard E Riman. 2006. "Calculation of Interparticle Spacing in Colloidal Systems” V: 374-77. https://doi.org/10.1016/j.jcis.2004.10.014.

Hawkins, P, P D Tennis, and R J Detwiler. 2005. The Use of Limestone in Portland Cement : A State-of-the-Art Review. Stokie, Illinois, US: Portland Cement Association.

Ingram, Kevin D, and Kenneth E Daugherty. 1991. "A Review of Limestone Additions to Portland Cement and Concrete" 13: 165-70.

John, Vanderley M., Bruno L. Damineli, Marco Quattrone, and Rafael G. Pileggi. 2018. "Fillers in Cementitious Materials - Experience, Recent Advances and Future Potential." Cement and Concrete Research 114 (September 2017): 65-78. https://doi.org/10.1016/j.cemconres.2017.09.013.

Kronlöf, Anna. 1997. "Filler Effect of Inert Mineral Powder in Concrete.” Espoo: VTT Technical Research Centre of Findland.

Kumar, Senthil V., and Manu Santhanam. 2003. "Particle Packing Theories and Their Application in Concrete Mixture Proportioning: A Review." Indian Concrete Journal 77 (9): 1324-31.

Kwan, Albert K.H., and C.F. Mora. 2001. "Effects of Various Shape Parameters on Packing of Aggregate Particles." Magazine of Concrete Research 53 (2): 91-100.

Larrard, F. de. 1999. Concrete Mixture Proportioning: A Scientific Approach. E \& FN Spo. London.

LIU, Shuhua, and PeiyU YAN. 2010. "Effect of Limestone Powder on Microstructure of Concrete" 25 (2): 328-31. https://doi.org/10.1007/s11595-010-2328-5.

Lothenbach, Barbara, Karen Scrivener, and R. D. Hooton. 2011. "Cement and Concrete Research Supplementary Cementitious Materials." Cement and Concrete Research 
41 (12): 1244-56. https://doi.org/10.1016/j.cemconres.2010.12.001.

Mangulkar, Mn, and Ss Jamkar. 2013. "Review of Particle Packing Theories Used For Concrete Mix Proportioning.” International Journal Of Scientific \& Engineering Research 4 (5): 143-48.

Mehdipour, Iman, and Kamal H. Khayat. 2018. "Understanding the Role of Particle Packing Characteristics in Rheo-Physical Properties of Cementitious Suspensions: A Literature Review." Construction and Building Materials. https://doi.org/10.1016/j.conbuildmat.2017.11.147.

Mehta, Kumar P. 2002. "Greening of the Concrete Industry for Sustainable Development." Concrete International 24 (7): 23-28.

- 2008. "High-Performance, High-Volume Fly Ash Concrete for Sustainable Development." International Workshop on Sustainable Development and Concrete Technology 31 (4): 3-14.

Mehta, Kumar P., and Paulo J.M. Monteiro. 2006. CONCRETE Microstructure, Properties Ans Materials. McGraw Hill. https://doi.org/10.1036/0071462899.

Mindess, Sidney, Francis J Young, and David Darwin. 2003. Concrete. 2nd Edition. Edited by Inc Pearson Educatioon. New jersey: Prentice Hall.

Oey, Tandré, Aditya Kumar, Jeffrey W. Bullard, Narayanan Neithalath, and Gaurav Sant. 2013. "The Filler Effect: The Influence of Filler Content and Surface Area on Cementitious Reaction Rates.” Journal of the American Ceramic Society 96 (6): 1978-90. https://doi.org/10.1111/jace.12264.

Oliveira, I.R. de, A.R. Studart, R.G. Pileggi, and V.C. Pandolfelli. 2000. Dispersão e Empacotamento de Partículas: Princípios e Aplicações Em Processamento Cerâmico. Sao Paulo: Fazendo Arte.

Opoczky, L. 1992. "Progress of the Particle Size Distribution during the Inter-Grinding Ofclinker - Limestone Mixture.” Zem.-Kalk - Gips 45 12: 648-51.

Raucci, J S, R T Cecel, R C O Romano, R G Pileggi, and Vanderley M. John. 2018. "Effect of Mixing Method on the Mini-Slump Spread of Portland Cement Pastes." Ibracom Structures and Materials 11 (2): 410-20.

Scherer, George W., Jie Zhang, John A. Quintanilla, and Salvatore Torquato. 2012. "Hydration and Percolation at the Setting Point." Cement and Concrete Research 42 (5): 665-72. https://doi.org/10.1016/j.cemconres.2012.02.003.

Scrivener, Karen L, Vanderley M. John, and Ellis Gartner. 2018. "Eco-Efficient Cements : Potential Economically Viable Solutions for a Low-CO 2 Cement-Based Materials Industry." Cement and Concrete Research 114 (February): 2-26. https://doi.org/10.1016/j.cemconres.2018.03.015.

Shivashankar, Tirumani S, Ravi K Enneti, Seong-jin Park, Randall M German, and Sundar V Atre. 2013. "The Effects of Material Attributes on Powder - Binder Separation Phenomena in Powder Injection Molding." Powder Technology 243: 7984. https://doi.org/10.1016/j.powtec.2013.03.037.

Snellings, Ruben. 2016. "Assessing, Understanding and Unlocking Supplementary Cementitious Materials.” RILEM Technical Letters 1: 50. https://doi.org/10.21809/rilemtechlett.2016.12.

Svermova, Lucie, Mohammed Sonebi, and Peter J M Bartos. 2003. "Influence of Mix Proportions on Rheology of Cement Grouts Containing Limestone Powder" 25: 737-49. https://doi.org/10.1016/S0958-9465(02)00115-4. 
Tan, Zhijun, Susan A Bernal, and John L Provis. 2017. "Reproducible Mini-Slump Test Procedure for Measuring the Yield Stress of Cementitious Pastes." Materials and Structures 50 (235): 1-12. https://doi.org/10.1617/s11527-017-1103-x.

Thongsanitgarn, P., W. Wongkeo, S. Sinthupinyo, and A. Chaipanich. 2011. "Effect of Limestone Powders on Compressive Strength and Setting Time of PortlandLimestone Cement Pastes." In TIChE International Conference 2011. Songkhla, Thailand. https://doi.org/10.4028/www.scientific.net/AMR.343-344.322.

Tikkanen, Johanna, Andrzej Cwirzen, and Vesa Penttala. 2014. "Effects of Mineral Powders on Hydration Process and Hydration Products in Normal Strength Concrete." Construction and Building Materials 72: 7-14. https://doi.org/10.1016/j.conbuildmat.2014.08.066.

Wang, Dehui, Caijun Shi, Nima Farzadnia, Zhenguo Shi, and Huangfei Jia. 2018. "A Review on Effects of Limestone Powder on the Properties of Concrete." Construction and Building Materials 192: 153-66. https://doi.org/10.1016/j.conbuildmat.2018.10.119.

Westman, A. E R, and H. R. Hugill. 1930. "The Packing of Particles." Journal of the American Ceramic Society 13 (10): 767-79. https://doi.org/10.1111/j.11512916.1930.tb16222.x.

Wong, H H C, and Albert K.H. Kwan. 2008. "Packing Density of Cementitious Materials : Measurement and Modelling," no. 3: 165-75. https://doi.org/10.1680/macr.2007.00004.

Yousuf, S., L.F.M. Sanchez, and S.A. Shammeh. 2019. "The Use of Particle Packing Models (PPMs) to Design Structural Low Cement Concrete as an Alternative for Construction Industry." Journal of Building Engineering 25 (October 2018): 100815. https://doi.org/10.1016/j.jobe.2019.100815.

Zhang, Jing, and Zhu Li. 2012. "Impact of the Limestone Powder on the Properties of Cement Paste and Mortar," 236-40. https://doi.org/10.4028/www.scientific.net/AMM.174-177.236. 


\title{
Chapter 4: Influence of Inter-particles Separation Distance on the Properties of Low Cement Content Paste
}

\author{
Gonzalo A. R. Lozano ${ }^{1 *}$, Mayra T. de Grazia ${ }^{2}$, Leandro F. M. Sanchez ${ }^{2}$, Edward G. \\ Sherwood ${ }^{1}$, \\ ${ }^{1}$ Departmentof Civil Engineering, Carleton University, Ottawa, Canada \\ ${ }^{2}$ Department of Civil Engineering, Ottawa University, Ottawa, Canada
}

\subsection{Abstract}

Pressure is mounting to decrease the carbon footprint of concrete construction. Amongst viable alternatives, the use of particle packing models (PPMs) and limestone fillers (LF) are deemed to be quite efficient. A number of studies have been conducted on using continuous PPMs to proportion cementitious materials incorporating LF. Yet, the outcomes obtained in the fresh and hardened states are extremely variable and remain mostly not well understood. In this work, the concept of inter-particle separation distance (IPS) is employed to describe the overall performance of cement paste mixtures incorporating high LF dosages. Forty-two paste mixes displaying three water-to-fines ratios $(0.32,0.40$ and 0.50$)$, two packing conditions $(q=0.21$ and 0.37$)$, and three targeted cement contents $(100,150$ and $250 \mathrm{~kg} / \mathrm{m} 3$ ) with and without admixtures are studied. Various fresh state properties (i.e. rheological profile, slump retention, and setting time) along with compressive strength were appraised from all mixes. Results suggest that the fresh state behaviour of highly packed systems incorporating LF can be predicted through the IPS and data available in the mix-design. Furthermore, the concept of interparticle spacing among cement particles (IPScement) is proposed in this work to better describe the initial setting and compressive strength of cementitious mixtures. 
Keywords: Limestone fillers, particle packing models, interparticle separation distance, rheology, setting time, specific surface area, mini-slump, compressive strength.

\subsection{Introduction}

Environmental constraints demand a reduction of greenhouse gases in the concrete industry, CO2 among them (Scrivener, John, and Gartner 2018; United Nations 2015). Portland cement (PC), the main concrete constituent, contributes up to $8 \%$ of the total $\mathrm{CO} 2$ released in the atmosphere annually (Andrew 2018; Gartner and Hirao 2015; Worrell et al. 2002). Thus, a wide range of research is being developed on strategies to decrease PC use in concrete (Mehta 2002; Noël, Sanchez, and Fathifazl 2016; Fennis 2011). Amongst the possible solutions, replacing PC by supplementary cementing materials (SCMs) is likely the most adopted strategy. The benefits of using traditional SCMs (e.g. fly ash, blast furnace slag or silica fume) on the fresh and hardened states of sustainable concrete have been largely studied and proved; yet recent studies show that their short and especially long-term availability will not be enough to correspond to the rise in PC demand (Lothenbach, Scrivener, and Hooton 2011b, 2011a; Snellings 2016; M. C. G. Juenger and R. Siddique 2015). However, mineral fillers (MF) might become one of the viable solutions to SCMs shortage, due to its large availability (Scrivener, John, and Gartner 2018). Almost every inorganic mineral with no deleterious reaction with PC can be classified as MF. The use of MF, derived from limestone, granite, sandstone, quartz, and dolomite materials, have already been reported. However, limestone fillers (LF) seem to be the most used filler type (John et al. 2018a; Scrivener, John, and Gartner 2018). PC replacement by LF in cementitious materials is deemed as a sustainable alternative for two main reasons. First, LF may be considered as a replacement of PC, reducing its overall content and thus 
concrete carbon footprint. Second, the use of LF may also reduce waste disposal since several types of LF are by-products of quarries that otherwise would have been disposed in landfills.

According to Scrivener, John, and Gartner (2018), replacement up to $10 \%$ of PC by LF represents negligible or low harmful effects on the hardened state properties of cementitious materials (i.e. paste, mortar, concrete). However, when conventional mixdesign methods are used, direct replacement of larger amounts of PC by LF can drastically affect the fresh and hardened properties of the material (Lagerblad and Forssberg 2004; Ling and Kwan 2016; P. Thongsanitgarn et al. 2011). (John et al. 2018a) attributed the latter to the so-called "dilution" effect, described as the reduction of PC particles due to the addition of fillers at constant water content. Adjustments in the water content (i.e. waterto-cement ratio - w/c) or the PC fineness were found to compensate these effects, at least partially (John et al. 2018a).

Further reduction in the PC content can be achieved through the use of advanced mixdesign techniques such as particle packing models (PPMs) (Fennis 2011). This procedure aims to refine the skeleton of granular systems by filling the voids among coarse particles with small particles, lessening thus the overall porosity of the system (Kumar and Santhanam 2003; Dinger and Funk 1997). The latter results in lower amounts of required fluid to enable the mixture flow in the fresh state, leading to a decrease in both water and paste demands (Yousuf, Sanchez, and Shammeh 2019; M.T. de Grazia et al. 2019).

PPMs can be used to calculate the optimized replacement percentages of LF, based on the materials properties and target performance, avoiding thus direct replacement approaches. It has been found that concrete mixtures designed through PPMs and containing high 
amounts of LF (e.g. $60 \%$ of the total fines content) may display suitable behaviour in the hardened state (M.T. de Grazia et al. 2019). Nevertheless, highly packed systems incorporating large LF replacement ratios were found to yield important challenges in their fresh state, caused primarily by the low free water content along with the presence of small particles with high specific surface area (SSA) (Ling and Kwan 2016; M.T. de Grazia et al. 2019).

In this context, mobility parameters (e.g. Interparticle Separation Distance - IPS and Maximum Paste Thickness - MPT, which represent the distance between two adjacent fine or coarse particles of granular systems, respectively) were proposed to better describe the fresh state performance of cementitious materials (Funk and Dinger 1994; F.S. Ortega et al. 2002). Reduction in viscosity and flow enhancement of cement pastes have been observed with the increase of the distance between the fine particles (i.e. IPS) (Funk and Dinger 1994; F.S. Ortega et al. 2002; Mayra T. de Grazia, Sanchez, and Pileggi 2018). Previous research has also demonstrated the potential benefits of using mobility parameters coupled with PPMs to better describe the fresh state performance of cementitious mixtures (Mayra T. de Grazia, Sanchez, and Pileggi 2018; M.T. de Grazia et al. 2019). Yet, to the best knowledge of the authors, there are very few studies establishing the direct impact of IPS on the fresh state outcomes (i.e. viscosity, setting time, etc.) of cementitious mixtures, especially in highly packed systems containing significant amounts of LF. Moreover, the range of IPS values to be used for targeting distinct fresh state behaviours as well as its influence on the hardened state properties of cementitious mixes (e.g. compressive strength) are still unknown and need further investigation. 


\subsection{Literature Review}

\subsubsection{Limestone fillers in cementitious materials}

Limestone fillers (LF) have been used regularly in the concrete and cement industry since the 1980s (Hooton, Nokken, and Thomas 2007). LFs have a great potential to partially replace PC, since they are widely available (often near to cement plants), do not need further calcination (further grinding is usually required), besides being quite compatible with PC due to their low reactivity and volume stability (Scrivener, John, and Gartner 2018; John et al. 2018a). Furthermore, it has been found that the use of LF may enhance the fresh and hardened state properties of cementitious systems (Proske et al. 2013, 2014; LIU and YAN 2010; John et al. 2018a). All these qualities are translated in a high quality low commercial price material with very low embodied energy.

The suitable grindability of limestone also enables the production of fillers with a large particle size distribution (PSD), which may be advantageous to cementitious mixtures due to improvements in the mixture packing density (Kwan and Wong 2008b; Knop and Peled 2016a, 2016b). Yet, poor results were also observed, especially when conventional mixproportioning approaches were implemented (John et al. 2018a). When properly selected and proportioned, LF might provide the cementitious system with a wider PSD, reducing the system porosity and water demand. Such lessening in water demand can be used either to enhance the mixture flow (i.e. when the water volume is kept constant) or to reduce the w/c (i.e. removal of supplementary water to keep the same flow), leading to improvements in the hardened properties (Aiqin, Chengzhi, and Ningsheng 1999). Finally, another important effect of using LF is related to its specific surface area (SSA). According to the PSD of the filler adopted (i.e. finer, similar or coarser than PC), the overall SSA of the 
system can increase or reduce. The availability of smaller particles (i.e. higher SSAs) in the system raises the number of nucleation sites and thus promotes the acceleration of hydration rates (Tikkanen, Cwirzen, and Penttala 2014; Oey et al. 2013), resulting in higher strengths at early ages. Furthermore, it has been found that high SSA particles may reduce bleeding in cementitious composites (Hawkins, Tennis, and Detwiler 2005). However, the use of fine particles (i.e. high SSAs) in the system might negatively impact on the fresh state behaviour of cementitious mixes (Wang, Shi, Farzadnia, Shi, and Jia 2018; Kwan and Chen 2012; Kwan and Wong 2008a).

\subsubsection{Particle packing Models}

PPMs are advanced mix-design techniques developed to enhance the performance of cementitious mixtures in the fresh and hardened states. The use of PPMs aims to optimize the PSD of granular systems which in turn raises their packing density while reducing porosity (Dinger and Funk 1997). PPMs are mainly divided into two categories: discrete and continuous models (Mangulkar and Jamkar 2013; Kumar and Santhanam 2003). Discrete models consider a combination of multimodal distributions containing a given number of discrete particle sizes which are rearranged to reach the system optimum packing density (Furnas 1931; Fennis 2011). The first discrete model was proposed by Furnas (Furnas 1931) accounting only for binary systems; while the most recent and common procedures are the Linear Packing Density Model (LPDM) and Compressive Packing Model (CPM) which accounts for multiple discrete sizes and were developed by De Larrard et al. (Stovall, Larrard, and Buil 1986; Larrard 1999; Larrard and Sedran 2002). Conversely, continuous models assume that all possible particle sizes are present in the distribution (i.e. no gap-graded systems) (Fuller and Thompson 1907; Andreasen and J. 
Andreasen. 1930; Dinger and Funk 1997; M.T. de Grazia et al. 2019). The first continuous PPM was presented by Fuller and Thompson (Fuller and Thompson 1907), while the modified Andreasen model (Equation 4-1), also known as Alfred model, stands-out as the latest advancement of continuous models (Mangulkar and Jamkar 2013).

$$
\operatorname{CPFT}(\%)=\frac{D^{q}-D_{S}^{q}}{D_{L}^{q}-D_{S}^{q}}
$$

Equation 4-1

where: CPFT is the cumulative (volume) percent finer than $D_{p}, D_{p}$ is the particle diameter, $\mathrm{D}_{\mathrm{L}}$ is the larger particle diameter, $\mathrm{D}_{\mathrm{s}}$ is the smaller particle diameter, and $\mathrm{q}$ is the distribution coefficient (or distribution factor).

Based on previous studies, the highest packing density and lower porosity of the Alfred model are achieved when the selection of the distribution coefficient is equal to 0.37 (Funk and Dinger 1994; Fennis and Walraven 2012a). Distribution factors above and beyond 0.37 are not commonly used since they significantly increase the system porosity; research projects have shown that the distribution factor (q factor) may vary from 0.21 to 0.37 (W. Zuo et al. 2018; Yousuf, Sanchez, and Shammeh 2019; Kumar and Santhanam 2003; M.T. de Grazia et al. 2019). High flowable mixes can be achieved with distribution factors as low as 0.21 (i.e. high amount of fines), while vibrated and or pumped concrete can be manufactured with distribution factors lying between 0.26 and 0.30 . Although quite successful in proportioning granular systems with suitable performance in the hardened state and low carbon footprint, it has been observed that the sole use of PPMs does not suffice for designing and predicting the fresh state performance of concrete mixtures, especially highly packed systems incorporating high amounts of LFs. 


\subsubsection{Inter-Particle Separation}

Funk and Dinger (1994) proposed the study of particle mobility through the concept of Interparticle Separation Distance (IPS - Equation 4-2), offering a link between the system properties (i.e. materials characteristics and PSD) and fresh state performance. IPS is considered the average thickness of a fluid layer that separates two adjacent fine particles (i.e. smaller than $100 \mu \mathrm{m}$ ) (de Oliveira et al. 2000; F.S. Ortega et al. 2002). Larger IPS values represent more space available for the particles to flow, improving the system flowability while reducing its viscosity (Pileggi et al. 2000; F.S. Ortega et al. 2002). Conversely, small IPS values increase the likelihood of particle collision, reducing the system flow properties (de Oliveira et al. 2000; Damineli et al. 2016; Pileggi et al. 2000).

$$
I P S=\frac{2}{V S A} *\left(\frac{1}{V_{S}}-\frac{1}{1-P_{o f}}\right)
$$

Equation 4-2

where: IPS is the interparticle separation distance in $\mu \mathrm{m}, \mathrm{V}_{\mathrm{s}}$ is the volume of solids per total volume, VSA is the volume surface area of the solid particles in $\mathrm{m}^{3} / \mathrm{cm}^{3}$ and $\mathrm{P}_{\text {of }}$ is the dry porosity per total volume calculated using the Westman and Hugill algorithm (Westman and Hugill 1930).

Previous works have tried to apply IPS measurements on the viscosity prediction of cementitious materials with high amounts of LF; yet, poor correlation between the factors involved was obtained, deeming IPS as a secondary parameter to describe the mixture flow (F.S. Ortega et al. 2002; Damineli et al. 2016). Recent studies showed that the increase of IPS might reduce the mixing energy required to low carbon footprint cementitious mixtures, thus enhancing flow (Varhen et al. 2016; M.T. de Grazia et al. 2019; Mayra T. de Grazia, Sanchez, and Pileggi 2018). However, there is currently a lack of research 
quantitatively linking IPS to the rheological behaviour (i.e. yield stress, plastic viscosity, etc.) of cementitious mixtures incorporating high amounts of LFs.

\subsubsection{Fresh State behaviour of cementitious materials}

The fresh state behaviour (also broadly and qualitatively defined as workability), is an important property of cementitious mixtures. It is defined as the easiness of the material to be mixed, handled, placed, and compacted as per a specific application (e.g. selfconsolidation, vibration, pumping, etc.). A wide range of test procedures such as slump, slump flow, V-funnel, etc., have been implemented in this regard; the slump test is the method conventionally selected to describe workability in the vast majority of cases (Bouvet, Ghorbel, and Bennacer 2010; Tan, Bernal, and Provis 2017; Roussel and Le Roy 2005; Roy and Roussel 2005). However, all the aforementioned procedures are the socalled "single-point" tests and thus are only able to describe the fresh behaviour of mixes under specific conditions (for instance, under self-weight conditions), which may be quite different from practical applications. The latter means that these procedures are "imprecise" or "incomplete" to describe the fresh behaviour of cementitious mixtures for a wide range of applications (Banfill 2014). Conversely, it has been found that rheology may properly quantify the performance of mixtures in the fresh state at distinct torque (or stress) regimes (Shaughnessy and Clark 1988; Ferraris 1999; Brookfield Ametek 2017).

Through rheological test procedures (normally performed with the use of rheometers and or viscometers), rheological parameters such as yield stress (i.e. minimum shear stress required to initiate flow), and viscosity (i.e. resistance to flow) may be gathered at distinct torque scenarios (Ferraris et al. 2001; Nehdi and Rahman 2004). Furthermore, the rheological profile (i.e. variation of viscosity as a function of torque applied) may be 
completely obtained, which helps the design and understanding of the fresh state performance of cementitious mixtures under specific conditions of application.

Rheology concepts have been widely implemented in science and concrete technology (Yanrong et al., n.d.; Mehdipour and Khayat 2018; Kwan and Li 2012; Mayra T. de Grazia, Sanchez, and Pileggi 2018). Yet, there is still a lack of understanding on how to design cementitious mixtures for a given rheological behaviour, especially for mixtures presenting low binder content and incorporating significant amounts of fillers. In this context, it is anticipated that rheological parameters (i.e. yield stress and viscosity) might change as a function of IPS. The higher the IPS, the lower the likelihood of particle collisions, which may directly affect the material viscosity and flow for a given torque scenario; however, this relationship is currently not fully established.

\subsection{Scope of the work}

This work investigates the influence of IPS (i.e. distance between fine particles - smaller than $100 \mu \mathrm{m}$ ) as a predictive tool on the fresh and hardened state properties of cementitious pastes incorporating high LF dosages. The cement paste mixtures developed in this work were designed based upon "companion concrete mixtures" proportioned through the use of PPMs with low cement contents (i.e. $<250 \mathrm{~kg} / \mathrm{m}^{3}$ ). This study can be divided into two phases. First, a total of 21 cement paste mixtures were proportioned with a concrete equivalent cement content ranging from 100 to $250 \mathrm{~kg} / \mathrm{m}^{3}$. Two types of LF (i.e. replacement - similar PSD than PC, and performance - lower PSD than PC) were added to enhance the system packing density while reducing PC content. The amount of replacement LF ranged from $7.3 \%$ to $59.7 \%$ and was selected to achieve the required cement content on the equivalent concrete mix. Otherwise, the amount of performance LF 
was selected based on the optimum fitting to the system PSD as per a specific q-factor selected, resulting in $10 \%$ and $21 \%$ of the total powder mass (i.e. PC + LFs) for $q$ factors of 0.37 and 0.21 , respectively. Three water-to-fines ratios (i.e. $(\mathrm{PC}+\mathrm{LF}) / \mathrm{water}-\mathrm{w} / \mathrm{f})$ have been defined (i.e. $0.32,0.40$ and 0.50 ) to represent paste volumes conventionally implemented in PC-made concrete mixtures (Varhen et al. 2016) along with evaluating the impact of this parameter on the hardened properties of cementitious materials as previously suggested by John et al. (2018a). Finally, two q-factors (i.e. 0.21 and 0.37 ) were selected to appraise cement paste mixes with distinct flowability behaviours and porosity values.

In the second phase, 21 additional cement paste mixtures were developed with chemical admixtures(i.e. superplasticizer and mid-range to increase the flow while keeping proper cohesiveness and thus avoid segregation), so that the combined influence (i.e. chemicals + mix-proportioning) on the rheological profile of mixtures displaying the same initial consistency (i.e. mini-slump flow of $95 \mathrm{~mm}$ ) might be measured.

Assessment has been conducted in the fresh (i.e. mini slump flow, viscosity, and setting time) and hardened (compressive strength) states of all mixtures and comparisons among the distinct outcomes from the two phases are performed. Finally, new insights and equations describing the behaviours observed are proposed.

\subsection{Experimental Program}

\subsubsection{Raw materials}

A conventional Portland cement (GU type, equivalent to ASTM Type I) and two types of LF (i.e. replacement and performance) were used to manufacture distinct cement paste mixtures. The replacement filler displays a similar PSD to PC, while the performance filler presents a smaller PSD when compared to PC (Figure 4-1). The chemical composition of 
the PC-GU type used complies with CSA A3000-18 and ASTM 150 (Table 4-1); the physical properties of both PC and LFs are presented in Note: the chemical composition of all materials was provided by their respective suppliers.

The SSA of the materials was measured using a multi-point Brunauer-Emmett-Teller (BET) technique with N2. The "real" specific gravity of the materials was obtained through Helium gas pycnometer. Laser diffraction spectroscopy was employed to retrieve the PSD of each powder used.

Table 4-2.

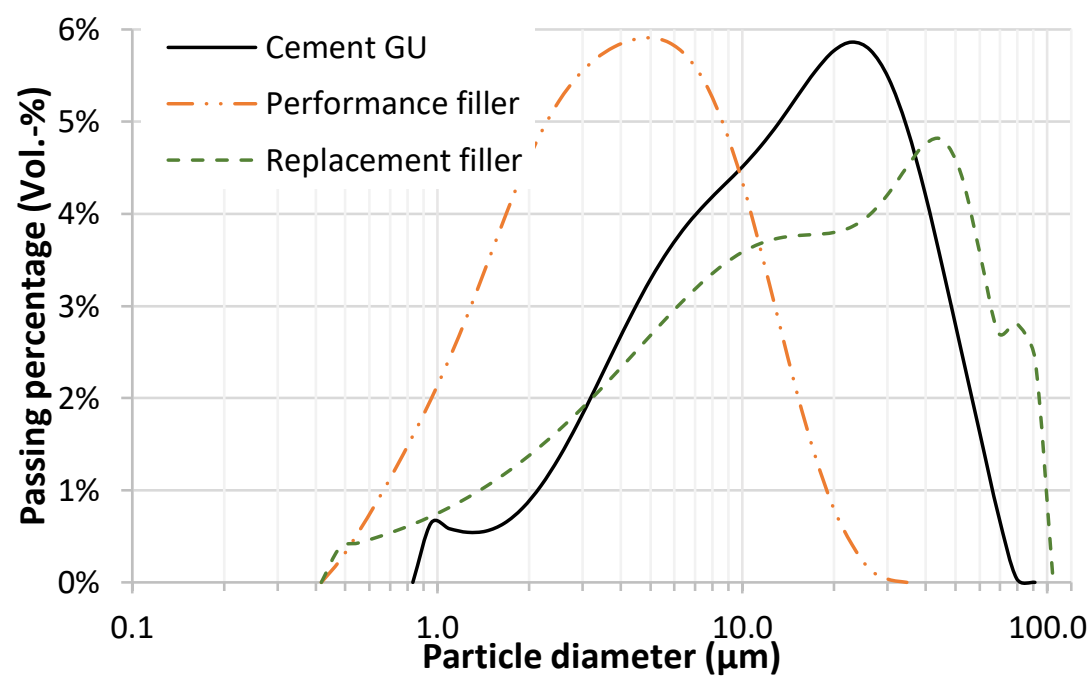

Figure 4-1: Particle size distribution of cement GU and limestone fillers

Table 4-1: Chemical composition of the Portland cement Type GU

\begin{tabular}{cccccccccccc}
\hline & $\mathrm{CaO}$ & $\mathrm{SiO}_{2}$ & $\mathbf{A l}_{\mathbf{2}} \mathrm{O}_{\mathbf{3}}$ & $\mathrm{Fe}_{\mathbf{2}} \mathrm{O}_{\mathbf{3}}$ & $\mathbf{M g O}$ & $\mathbf{S O}_{3}$ & $\mathrm{LOI}$ & $\boldsymbol{C}_{\mathbf{3}} \mathrm{S}$ & $\mathrm{C}_{\mathbf{2}} \mathrm{S}$ & $\boldsymbol{C}_{\mathbf{3}} \boldsymbol{A}$ & $\boldsymbol{C}_{4} \boldsymbol{A F}$ \\
\hline$\%$ & 61.91 & 19.53 & 4.92 & 3.21 & 2.66 & 3.86 & 2.24 & 55 & 14 & 7.6 & 9.8 \\
\hline
\end{tabular}

Note: the chemical composition of all materials was provided by their respective suppliers.

The SSA of the materials was measured using a multi-point Brunauer-Emmett-Teller (BET) technique with N2. The "real" specific gravity of the materials was obtained through 
Helium gas pycnometer. Laser diffraction spectroscopy was employed to retrieve the PSD of each powder used.

Table 4-2: Physical characterization of the powders

\begin{tabular}{lccc}
\hline \multicolumn{1}{c}{ Type } & Cement GU & Performance filler & Replacement filler \\
\hline Average size (d50), $\mu \mathrm{m}$ & 18.50 & 5.30 & 24.44 \\
Specific Surface Area, $\mathrm{m}^{2} / \mathrm{g}$ & 1.00 & 3.70 & 1.80 \\
Specific Gravity, $\mathrm{g} / \mathrm{cm}^{3}$ & 3.03 & 2.60 & 2.66 \\
$\boldsymbol{V S A}^{\boldsymbol{a}}, \mathrm{m}^{2} / \mathrm{cm}^{3}$ & 3.03 & 9.62 & 4.79 \\
\hline \multicolumn{2}{c}{${ }^{a}$ Volume Surface Area (VSA)=BET Surface Area ${ }^{*}$ Specific Gravity }
\end{tabular}

\subsubsection{Mix proportions procedure}

Evaluations were conducted on cement paste mixtures (i.e. 21 Phase I and 21 Phase II) proportioned with different $\mathrm{w} / \mathrm{c}$ and PC contents. The mixes were designed based upon "companion concrete mixtures" proportioned through the use of the modified Andreasen continuous PPM model. Distribution factors of 0.21 and 0.37 were selected as extreme values to enable a broad spectrum of results. The paste mixes were divided into three main sets characterized by $w / f$ of $0.32,0.40$ and 0.50 . As mentioned before the use of $w / f$ aims to reproduce paste volumes conventionally used in concrete mixtures and to evaluate the influence of this factor (i.e. w/f) on hardened state properties.

For each set, three PC contents (i.e. 100, 150 and $250 \mathrm{~kg} / \mathrm{m}^{3}$ ) and two distribution factors (i.e. $\mathrm{q}=0.21$ and $\mathrm{q}=0.37$ ) were selected. Moreover, a control cement paste made of pure PC was also manufactured, completing a total of seven mixes per set. The cement contents for the pure PC-made mixes were 307 to $325 \mathrm{~kg} / \mathrm{m}^{3}$ for $\mathrm{q}=0.37$ and 523 to $577 \mathrm{~kg} / \mathrm{m}^{3}$ for $\mathrm{q}=0.21$. 
First, proportions between performance and replacement LF were adopted for each mix based upon the best fitting to the distribution curves selected (i.e. Alfred Model with qfactors of 0.21 and 0.37 ). For the $0.21 \mathrm{q}$-factor, the optimum curve was achieved using $21 \%$ of performance LF, while $10 \%$ was required for the $0.37 \mathrm{q}$-factor. Furthermore, PC has been replaced with the replacement LF until the aforementioned target PC contents were reached. In order words, the amount of replacement LF was defined by the difference between the target total powder volume (particles $<100 \mu \mathrm{m}$ ) and the target PC content. In the first phase of the experimental program, all cement pastes were evaluated without chemical admixtures. Conversely in the second phase, the mixes were assessed using a combination of high range and mid-range plasticizers (Table 4-3), in order to set the same consistency (i.e. slump flow of $95 \pm 2 \mathrm{~mm}$ ) for all mixes under the mini-slump cone test. The percentages of plasticizers were measured base on the total amount of fines. Details regarding the mix-proportions of all pastes are displayed in Table 4-3. It is worth noting that the acronyms given to the distinct mixes are based on the distribution factors adopted, PC content of the concrete companion mixture, and w/f. For example, the paste designed with a distribution factor $\mathrm{q}$ of 0.37 , a target PC content of 250 and w/f equal to 0.32 is designated as $0.37-250-0.32$.

Considering the "shear history" as a very relevant factor that may impact on the rheological behaviour of PC mixes (Raucci et al. 2018; Tan, Bernal, and Provis 2017), the same mixing procedure has been adopted for all pastes fabricated in this research as per ASTM C305 (ASTM International 2014), and is presented hereafter:

- PC and LF (if any) were manually blended dry and mixed over 30 seconds in closed containers; 
- All the water + admixtures (if any) were poured into the mixing bowl;

- Powders were added to the bowl over a period of 30 seconds;

- The mixer was turned on at low speed $(95 \mathrm{rpm})$ and the pastes were mixed for 60 seconds;

- The mixer was then stopped for 30 seconds for material homogenization and detachment from the mixing bowl with a scoop;

- The mixer was started again at medium speed $(180 \mathrm{rpm})$ and the pastes were mixed for an additional 90 seconds.

Table 4-3: Mix-design of cement pastes for phase I and II

\begin{tabular}{|c|c|c|c|c|c|c|c|c|c|}
\hline $\begin{array}{l}\text { Mixtures } \\
\text { Name }\end{array}$ & $\begin{array}{c}\text { PC } \\
\text { wt. } / \%\end{array}$ & $\begin{array}{c}\text { Filler } \\
\text { R }^{*} \\
\text { wt.\% }\end{array}$ & $\begin{array}{c}\text { Filler } \\
\mathbf{P}^{* *} \\
\text { wt. } \% \\
\end{array}$ & $\begin{array}{c}\% \mathrm{PC} \\
\text { substitution }\end{array}$ & $\mathbf{w} / \mathbf{c}$ & $\begin{array}{c}\% \\
\mathbf{S P}^{\dagger}\end{array}$ & $\% \mathbf{M R}^{\ddagger}$ & $\begin{array}{c}\text { IPS } \\
(\mu \mathrm{m})\end{array}$ & $\begin{array}{c}\text { IPS/ } \\
\mathbf{d}_{\mathbf{p}}\end{array}$ \\
\hline PC-0.32 & $100.0 \%$ & $0.0 \%$ & $0.0 \%$ & - & 0.32 & 0.80 & 0.30 & 0.54 & 0.14 \\
\hline $0.37-250-0.32$ & $79.1 \%$ & $11.4 \%$ & $9.5 \%$ & $20.9 \%$ & 0.40 & 0.55 & 0.30 & 0.40 & 0.12 \\
\hline $0.37-150-0.32$ & $49.2 \%$ & $40.9 \%$ & $9.9 \%$ & $50.8 \%$ & 0.65 & 0.40 & 0.30 & 0.34 & 0.11 \\
\hline $0.37-100-0.32$ & $33.4 \%$ & $56.5 \%$ & $10.1 \%$ & $66.6 \%$ & 0.96 & 0.35 & 0.30 & 0.32 & 0.11 \\
\hline $0.21-250-0.32$ & $46.2 \%$ & $33.3 \%$ & $20.6 \%$ & $53.8 \%$ & 0.69 & 0.43 & 0.30 & 0.30 & 0.10 \\
\hline $0.21-150-0.32$ & $28.2 \%$ & $50.7 \%$ & $21.0 \%$ & $71.8 \%$ & 1.13 & 0.34 & 0.30 & 0.28 & 0.10 \\
\hline $0.21-100-0.32$ & $19.0 \%$ & $59.7 \%$ & $21.3 \%$ & $81.0 \%$ & 1.68 & 0.28 & 0.25 & 0.27 & 0.10 \\
\hline PC-0.40 & $100.0 \%$ & $0.0 \%$ & $0.0 \%$ & $0.0 \%$ & 0.40 & 0.37 & 0.15 & 0.68 & 0.18 \\
\hline $0.37-250-0.40$ & $80.9 \%$ & $9.6 \%$ & $9.5 \%$ & $19.1 \%$ & 0.49 & 0.35 & 0.15 & 0.52 & 0.15 \\
\hline $0.37-150-0.40$ & $50.3 \%$ & $39.8 \%$ & $9.9 \%$ & $49.7 \%$ & 0.79 & 0.30 & 0.15 & 0.44 & 0.15 \\
\hline $0.37-100-0.40$ & $34.2 \%$ & $55.7 \%$ & $10.1 \%$ & $65.8 \%$ & 1.17 & 0.26 & 0.15 & 0.41 & 0.14 \\
\hline $0.21-250-0.40$ & $48.1 \%$ & $31.4 \%$ & $20.5 \%$ & $51.9 \%$ & 0.83 & 0.32 & 0.15 & 0.39 & 0.13 \\
\hline $0.21-150-0.40$ & $29.4 \%$ & $49.6 \%$ & $21.0 \%$ & $70.6 \%$ & 1.36 & 0.27 & 0.15 & 0.36 & 0.13 \\
\hline $0.21-100-0.40$ & $19.8 \%$ & $59.0 \%$ & $21.3 \%$ & $80.2 \%$ & 2.02 & 0.23 & 0.15 & 0.34 & 0.13 \\
\hline PC-0.50 & $100.0 \%$ & $0.0 \%$ & $0.0 \%$ & $0.0 \%$ & 0.50 & - & - & 0.90 & 0.22 \\
\hline $0.37-250-0.50$ & $83.2 \%$ & $7.3 \%$ & $9.5 \%$ & $16.8 \%$ & 0.60 & 0.08 & 0.05 & 0.68 & 0.20 \\
\hline $0.37-150-0.50$ & $51.7 \%$ & $38.4 \%$ & $9.9 \%$ & $48.3 \%$ & 0.97 & 0.10 & 0.05 & 0.57 & 0.19 \\
\hline $0.37-100-0.50$ & $35.1 \%$ & $54.8 \%$ & $10.1 \%$ & $64.9 \%$ & 1.42 & 0.10 & 0.10 & 0.53 & 0.18 \\
\hline $0.21-250-0.50$ & $50.5 \%$ & $29.1 \%$ & $20.4 \%$ & $49.5 \%$ & 0.99 & 0.10 & 0.10 & 0.50 & 0.17 \\
\hline $0.21-150-0.50$ & $30.9 \%$ & $48.2 \%$ & $21.0 \%$ & $69.1 \%$ & 1.62 & 0.13 & 0.10 & 0.46 & 0.16 \\
\hline $0.21-100-0.50$ & $20.8 \%$ & $58.0 \%$ & $21.2 \%$ & $79.2 \%$ & 2.41 & 0.15 & 0.10 & 0.44 & 0.16 \\
\hline
\end{tabular}

* Replacement; ${ }^{* *}$ Performance; $\dagger$ Super plasticizer (high range); $\$$ Mid-range plasticizer.

Note: SP and MR were added only on phase 2

\subsubsection{Test Methods}




\section{Viscometer test}

Viscosity measurements were collected using a Brookfield DV-E viscometer as shown in

Figure 4-2a. This rotational viscometer uses disc spindles RV No. 2 to No. 6 (Figure 4-2b), but only the spindle No 5 was selected in this research to avoid discrepancy in the test outcomes due to the use of distinct geometries.

The fresh state performance of the pastes was evaluated over a period of two hours. Viscosity measurements were taken at 5, 30, 60, and 120 minutes. Individual hermetic containers were used to store the paste mixes, from the end of the mixing period to the beginning of the rheological tests. The container to store and test the pastes complied with the suggestions given by the user manual of the viscometer (Brookfield Ametek 2017), diameter larger than $83 \mathrm{~mm}$, and capacity larger than $600 \mathrm{ml}$. The total paste volume evaluated per test was $600 \mathrm{ml}$.

a)

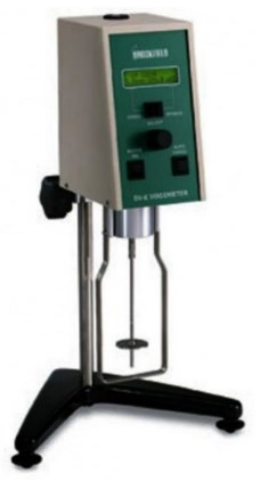

b)

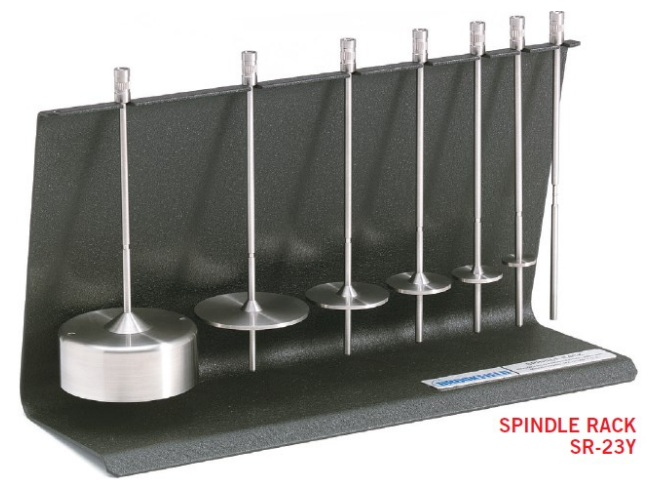

Figure 4-2: Equipment used for rheology measurements: a) Viscometer Brookfield DV-E (Ametek, n.d.), b) Spindles rack from SP1 to SP6 (Brookfield Ametek 2008)

At every evaluation period, the paste was homogenized by manual stirring, immediately before the test. Figure 4-3 describes the Up-Down ramp method used during the test. As suggested by Banfill (2014), the acceleration ramp serves to arrange the particles in the flow direction; for this reason viscosity values were not considered in the upward ramp. 
Thereafter, readings at 5, 6, 10,12, 20,30,50,60, and 100 revolutions per minute (rpm) from the deceleration curve were taken as the representative viscosities of the material.

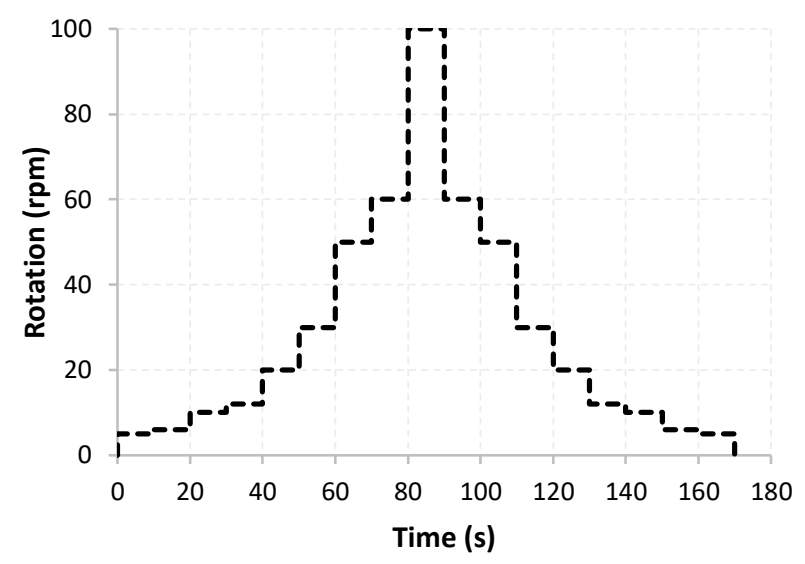

Figure 4-3: Speed ramp of the viscometer test

\section{Mini-Slump flow test}

The mini-slump cone is a simple and very common method used to measure the consistency of cement paste and grouts. In this research, a truncated cone, made of clear acrylic and opened at both ends was selected. The dimensions of the cone were $38.0 \pm 0.2$ $\mathrm{mm}$ and $19.0 \pm 0.2 \mathrm{~mm}$ for the bottom and top diameters, respectively, and $57.0 \pm 0.2 \mathrm{~mm}$ height. Moreover, an acrylic base plate with circular marks assisted the measurements of the flow spread, as illustrated in Figure 4-4.

a)

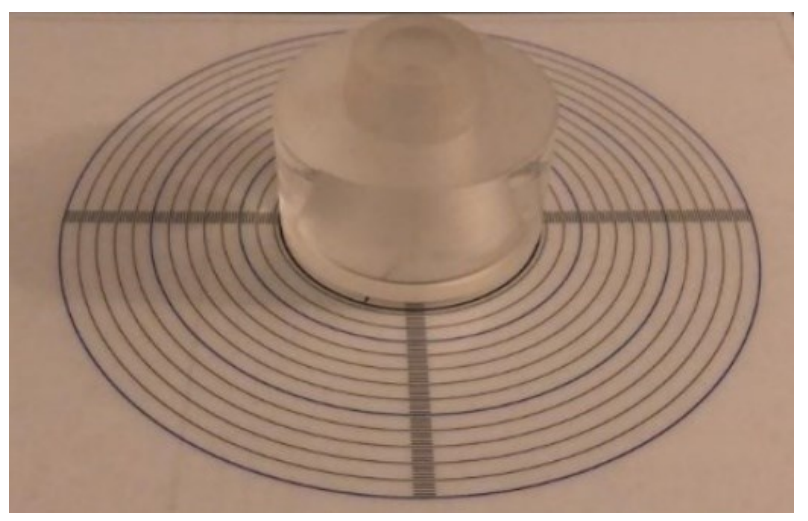

b)

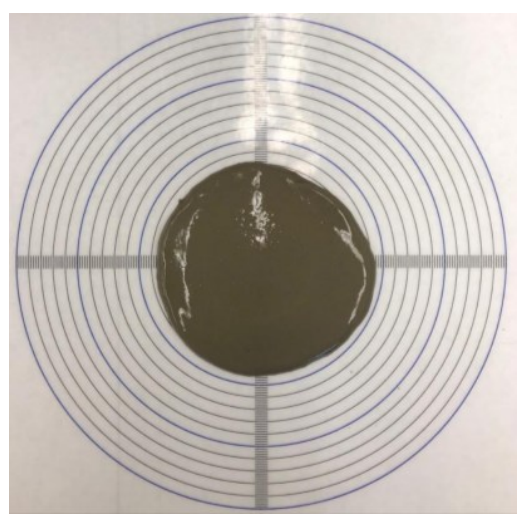

Figure 4-4: Equipment use to perform slump retention 
The test started by pouring the cement paste inside the cone and tapping the borders to remove entrapped air. Then, the top surface was flattened, and all excess of the material was removed. Afterward, the cone was smoothly lifted trying to avoid inertial effects (Tan, Bernal, and Provis 2017). Once the material reached a stable state (i.e. flow stopped), the spread diameter was calculated as the mean value of two perpendicular measurements. This experiment was only conducted in phase 2 of the experimental campaign (i.e. mixes with admixtures). It is worth noting that for every single cement paste mix, a distinct amount of plasticizer has been used, aiming for an equal consistency (or spread flow) of all mixtures immediately after batching (i.e. $95.0 \pm 2.0 \mathrm{~mm}$ ).

\section{$\underline{\text { Mini-Slum retention test }}$}

The remaining fresh paste was placed in 4 different hermetic containers, which served to repeat the test at 30,60,90, and 120 minutes after the first measurement. At every assessment, the paste mixture was homogenized by manual stirring just before the test. This test was performed only for phase two (i.e. mixes with admixtures)

\section{$\underline{\text { Setting time }}$}

The penetration depth of a $1 \mathrm{~mm}$ diameter needle was monitored over time to capture the initial and final settings of all cement paste mixtures evaluated in this research as per ASTM C191 (ASTM International 2018a). The mold of the paste samples used was a truncated cone of $60 \mathrm{~mm} \pm 1 \mathrm{~mm}$ diameter on top, $70 \mathrm{~mm} \pm 1 \mathrm{~mm}$ at the bottom, and 40 $\mathrm{mm} \pm 1 \mathrm{~mm}$ high. A manual Vicat device was employed to measure the penetration depth from 30 minutes after batching until the final set has been reached. The measurements were repeated every $15 \mathrm{~min}$ in different locations of the sample surface.

\section{Compressive strength}


Compressive strength was performed according to ASTM C-39 (ASTM International $2018 b$ ), with a $0.25 \mathrm{MPa} / \mathrm{s}$ loading rate. For every mixture, nine cylindrical specimens $(50.6 \pm 0.2 \mathrm{~mm}$ in diameter and $99.5 \pm 0.2 \mathrm{~mm}$ in length) were molded. All samples were demolded after 24 hours from mixing and stored in the moist-curing room (i.e. 95\% RH and $25^{\circ} \mathrm{C}$ ) until the compressive strength test was conducted. Prior to testing, the ends of the cylinders were ground to ensure flat surfaces. Three cylinders per mixture were tested at 7,14 , and 28 days.

\subsection{Results}

\subsubsection{Rheological behaviour}

Figure 4-5 presents the viscosity behaviour of all cement paste mixes as a function of the w/f. Pastes without admixtures are shown in Figure 4-5a, b, and c, while Figure 4-5d, e, and $\mathrm{f}$ illustrate pastes incorporating chemical admixtures as a function of their corresponding $\mathrm{w} / \mathrm{f}(0.32,0.40$ and 0.50 , respectively).

All the cement pastes (with or without admixtures) displayed a clear decrease in viscosity as a function of the rotation speed. As expected, chemical admixtures reduced the viscosity of all mixes over the entire speed rate spectrum, regardless of the w/f. Furthermore, the higher the $\mathrm{w} / \mathrm{f}$ ratio, the lower the viscosity values obtained as a function of the rotation speed.

The viscosity of the mixtures also varied as a function of the coefficient of distribution adopted (i.e. q factor) and amounts of LF used in the mix. Mixtures with larger amounts of fine particles in the system (i.e. $\mathrm{q}=0.21$ ) displayed higher viscosities when compared to mixtures with larger particles (i.e. $q=0.37$ ), expect for mixture 0.21-150-0.32 (Figure 4-5d). 
Likewise, cement paste mixtures with lower PC and high LF contents also presented higher viscosity when compared to the pure PC mixes. Exceptions are only seen for 4 mixtures of the group $w / f=0.32$ without admixtures (Figure 4-6a) and 2 mixes with admixtures (Figure 4-5d), where their viscosity profiles are found below the pure PC curve.

a)

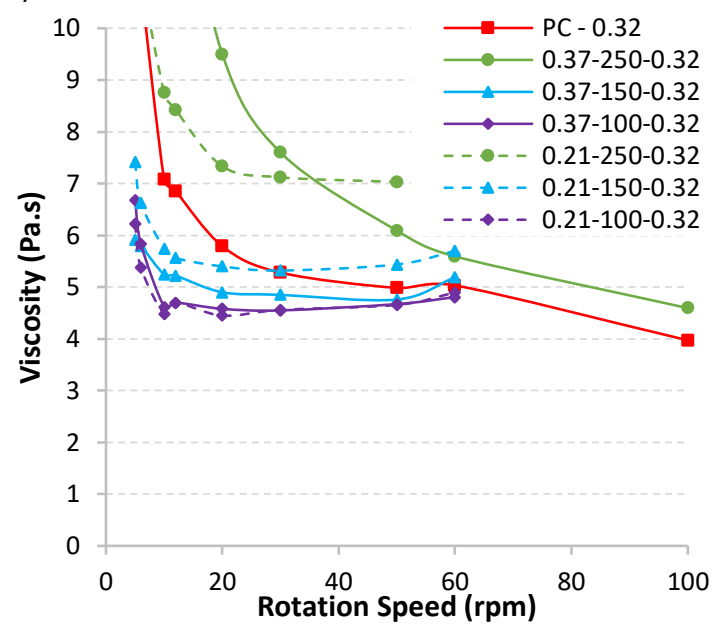

b)

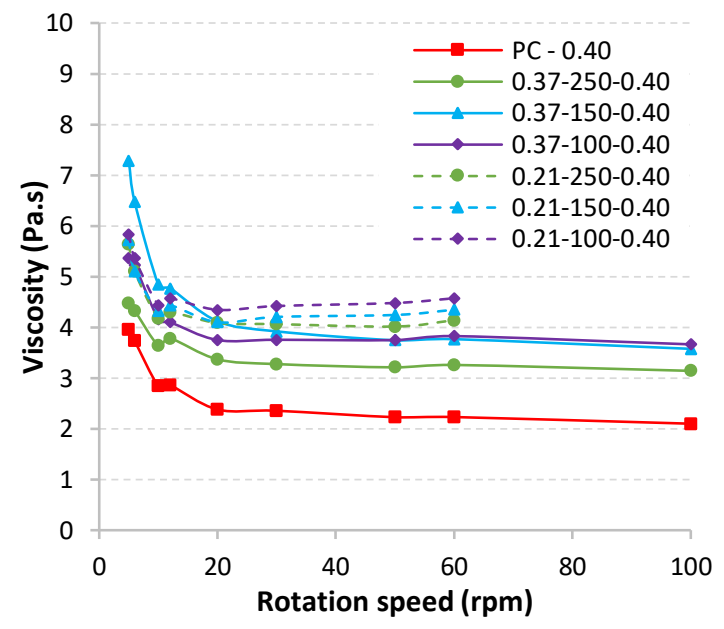

c) d)

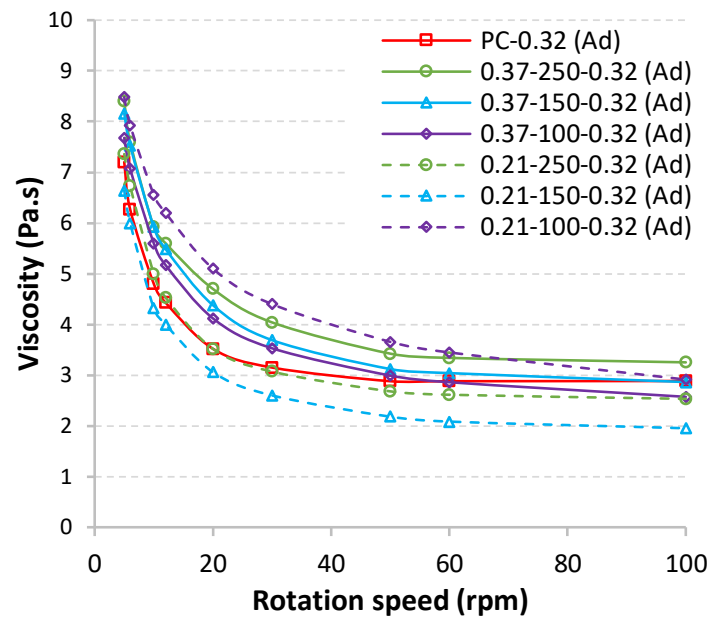

e)

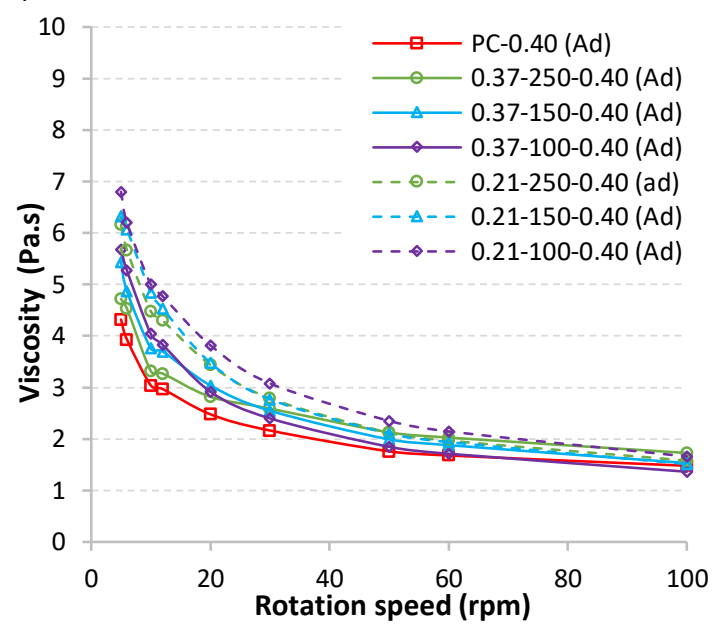

f) 

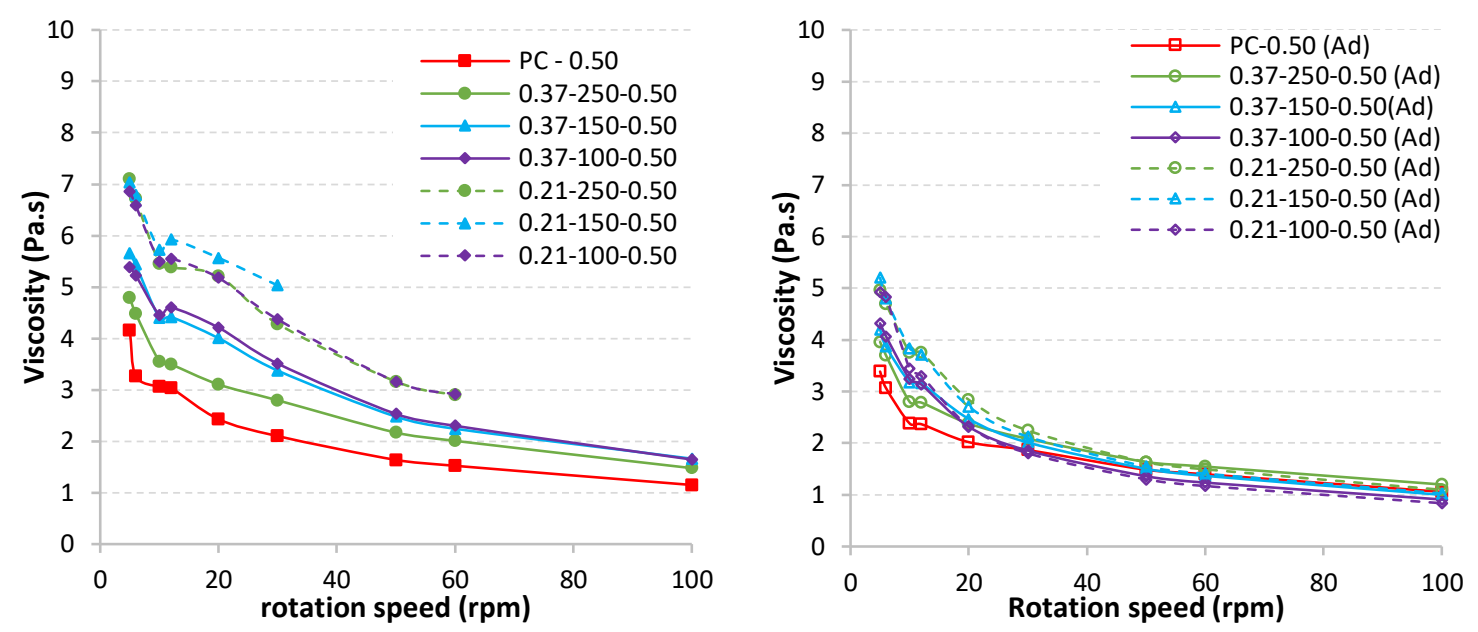

Figure 4-5: Viscosity profiles for different rotation speeds. a) to c) present phase I and d) to f) pahse II Ad. Stands for admixtures.

Note: The first number of the mixture notation stands for the q factor, the second is the PC content in $\mathrm{kg} / \mathrm{m}^{3}$ and the third one corresponds to the $\mathrm{w} / \mathrm{f}$.

The range of viscosity values gathered varied as a function of the rotation speed. At $5 \mathrm{rpm}$, $\mathrm{w} / \mathrm{f}=0.32$ mixes (without admixtures) displayed viscosity results ranging from 6.0 to 12.2 Pa.s, while for $\mathrm{w} / \mathrm{f}=0.32$ mixes (incorporating admixtures), the viscosities varied from 6.6 up to 8.5. Similarly, at the same speed, viscosities ranged from 4.0 to 7.3 Pa.s and 4.32 to 6.8 Pa.s for the group $\mathrm{w} / \mathrm{f}=0.40$ without and with admixtures, respectively. Finally, the viscosities of group $\mathrm{w} / \mathrm{f}=0.50$ at $5 \mathrm{rpm}$ ranged from 4.0 to 7.3 Pa.s without admixtures and 3.6 to 5.2 Pa.s incorporating them. It can be noticed that the viscosity values scattering is lessened for mixes incorporating chemical admixtures. At $100 \mathrm{rpm}$ the latter is even more pronounced, particularly in mixes with $\mathrm{w} / \mathrm{f}=0.40$ and 0.50 , where the viscosity difference among mixtures is only $0.36 \mathrm{~Pa}$.s for both sets of mixtures. Mixes $\mathrm{w} / \mathrm{f}=0.32$ also showed a relatively small difference of 1.3 Pa.s.

\subsubsection{Slump retention}

Results of the slump retention for mixtures incorporating chemical admixtures are presented in Figure 4-6a, b, and c, respectively for $w / f$ of $0.32,0.40$, and 0.50 . As mentioned before, all mixtures presented the same initial slump flow of $95+/-2 \mathrm{~mm}$. The 
slump flow loss as a function of time is calculated as the difference in spread between the initial value (i.e. $95 \mathrm{~mm}$ ) and the spread obtained at different time intervals (i.e. 30, 60, 90 and $120 \mathrm{~min}$ ) divided by the initial value minus the mini-slump base diameter as shown in Equation 4-3. It should be noticed that the base diameter of the mini-slump cone is $38 \mathrm{~mm}$; thus, the final spread diameters of $38 \mathrm{~mm}$ represent $100 \%$ of spread loss.

$$
\% \text { loss }=\frac{D_{I}-d_{t}}{D_{I}-b}
$$

Equation 4-3

where $D_{I}$ is the initial spread diameter, $d_{t}$ is the spread measured in the time $t$, and $b$ is the base diameter of the mini-slump cone.

a)
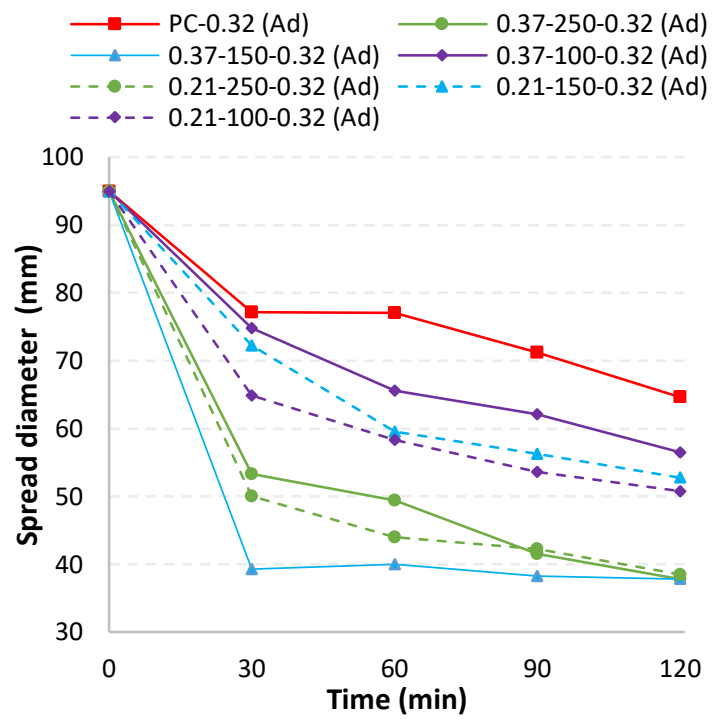

c) b)

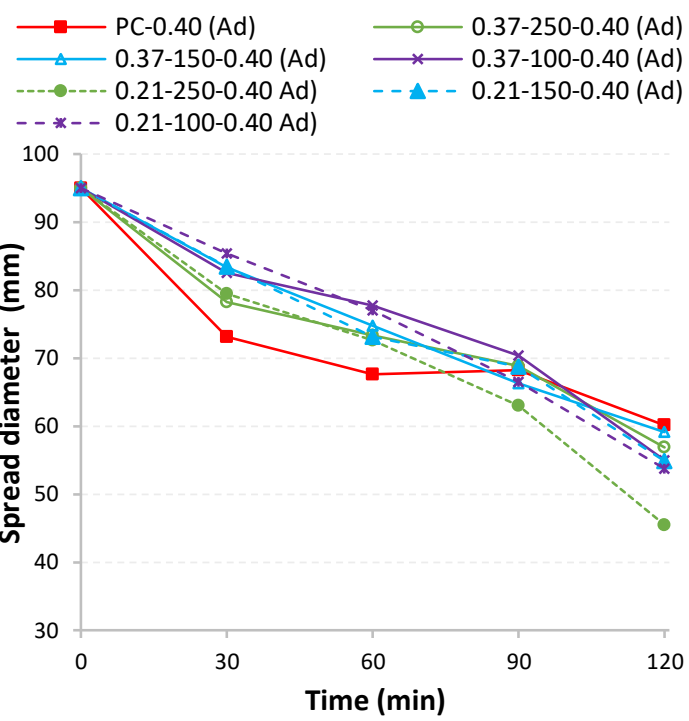




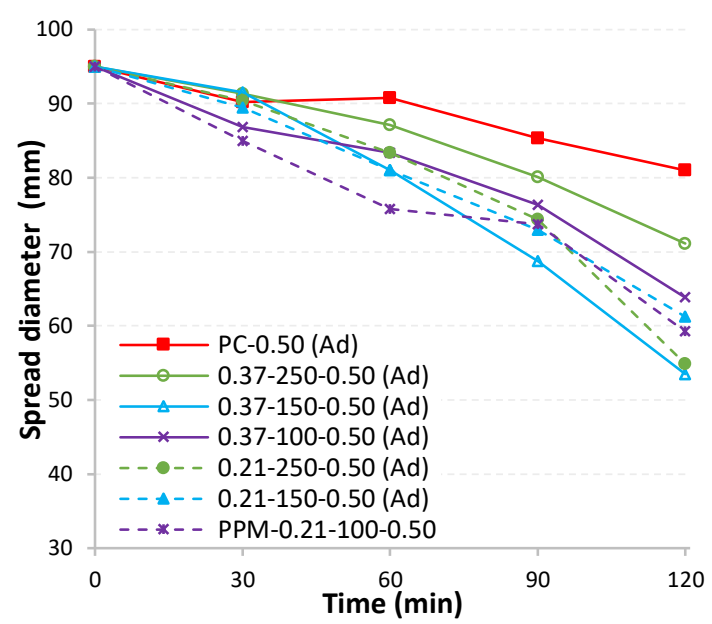

Figure 4-6: Slump retention ( $2 \mathrm{~h}$ evaluation period). a) $\mathrm{w} / \mathrm{f}=0.32, \mathrm{~b}$ ) $\mathrm{w} / \mathrm{f}=0.40$ and $\mathrm{c}$ ) $\mathrm{w} / \mathrm{f}=0.50$. All mixes evaluated contained chemical admixtures (plasticizers).

Note: The first number of the mixture notation stands for the $\mathrm{q}$ factor, the second is the PC content in $\mathrm{kg} / \mathrm{m}^{3}$ and the third one corresponds to the w/f.

From Figure 4-6 one may notice that the slump flow loss as a function of time is quite different according to each mixture evaluated. Control mixtures (i.e. pure PC) yielded the lowest slump flow reduction over time, regardless of the w/f. Paste mixtures with w/f of 0.32 displayed a significant drop in the slump flow during the first $30 \mathrm{~min}$, followed by a mild and steady decrease afterward. Otherwise, mixtures with w/f of 0.40 presented a rather constant reduction in slump flow, slightly emphasized during the last 30 min of the test (i.e. 90 to $120 \mathrm{~min}$ ). The mixtures with $\mathrm{w} / \mathrm{f}$ of 0.50 showed a quite different trend than both mixtures with w/f of 0.32 and 0.40 : a mild decrease during the first hour, followed by a sharper decrease in the second hour of the test.

Mixtures with distribution factors of 0.21 presented a faster slump flow loss when compared to 0.37 mixtures. An exemption was seen for the mixture $0.37-150-0.32$ (Ad) since it yielded the fastest slump flow loss gathered. It is also evident that the slump retention of the paste mixtures is negatively affected by LF usage with the most pronounced effects around $50 \%$ of LF replacement (i.e. mixtures with 150 and $100 \mathrm{~kg} / \mathrm{m}^{3}$ of PC). 
After 2 hours, pure PC mixes displayed the best slump retention reaching spread diameters of $65 \mathrm{~mm}$ (53\% slump flow loss) for $\mathrm{w} / \mathrm{c}=0.32,60 \mathrm{~mm}(61 \%$ loss $)$ for $\mathrm{w} / \mathrm{c}=0.40$ and 81 $\mathrm{mm}(25 \%$ loss $)$ for $\mathrm{w} / \mathrm{c}=0.50$. Paste mixtures incorporating $\mathrm{LF}$ and $\mathrm{w} / \mathrm{f}=.0 .32$ attained final slump flows from $65 \mathrm{~mm}(53 \%$ loss $-0.37-100-0.32$ (Ad)) to $38 \mathrm{~mm}(100 \%$ loss -0.37 150-0.32 (Ad). As w/f increases, the slump retention is improved, reaching slump flow diameters from $60 \mathrm{~mm}(61 \%$ loss $)$ to $45 \mathrm{~mm}(87 \%$ loss $)$ for mixes $\mathrm{w} / \mathrm{f}=0.40$ and from 81 $\mathrm{mm}(25 \%$ loss $)$ to $54 \mathrm{~mm}$ ( $73 \%$ loss $)$ for the group of $\mathrm{w} / \mathrm{f}=0.50$.

\subsubsection{Setting time}

The setting time history evaluated for the 21 paste mixtures manufactured for the two project phases (i.e. without and with chemical admixtures) through the Vicat needle is presented in Figure 4-7. As expected, the addition of chemical admixtures delayed the set initiation. The latter was more pronounced in mixtures with less water content (i.e. lower w/f), since the plasticizer dosage was higher to ensure the same initial consistency (i.e. slump flow).

For the first phase of the study, faster setting times were found in mixtures with lower w/f, whereas in the second phase, the trend was completely the opposite, i.e. longer setting times obtained for lower w/f. A different setting history was also observed for the two distribution factors studied (i.e. 0.21 and 0.37), regardless of the w/f. Mixtures with PC content of $250 \mathrm{~kg} / \mathrm{m}^{3}$ and $\mathrm{q}=0.21$ (i.e. dashed green lines) present faster setting time than $\mathrm{q}=0.37$ mixes (i.e. solid green lines). The setting time for mixtures with $150 \mathrm{~kg} / \mathrm{m}^{3}$ and $\mathrm{q}=0.21$ (i.e. dashed blue lines) are faster to or similar than those with $\mathrm{q}$ of 0.37 (solid blue lines). Conversely, mixtures with $100 \mathrm{~kg} / \mathrm{m}^{3}$ showed the opposite behaviour; i.e. longer setting times for $\mathrm{q}$ of 0.21 (i.e. dashed purple lines) when compared to $\mathrm{q}=0.37$ (solid purple 
lines). The inclusion of LF decreased setting times for most of the mixtures, especially for the group $\mathrm{w} / \mathrm{f}=0.32$ and $\mathrm{w} / \mathrm{f}=0.40$. However, some mixes of the group $\mathrm{w} / \mathrm{f}=0.50$ showed longer setting times than control mixes (i.e. red line). Moreover, mixtures with PC contents of $250 \mathrm{~kg} / \mathrm{m}^{3}$ and $150 \mathrm{~kg} / \mathrm{m}^{3}$ (i.e. green and blue color, respectively) display faster setting times than controls, yet mixtures with PC content of $100 \mathrm{~kg} / \mathrm{m}^{3}$ (i.e. dashed and solid purple lines) and $\mathrm{w} / \mathrm{f}=0.50$ showed longer setting times than controls.

The initial setting values gathered in the laboratory showed a time lag between mixes without and with admixtures of 6.5 to 8.5 hours for $w / f=0.32$ mixtures. For mixes with $\mathrm{w} / \mathrm{f}=0.40$, this difference ranged from 3.0 to 4.5 hours, while for mixtures with $\mathrm{w} / \mathrm{f}=0.50$, the time gap between them varies from 1.0 to 3.0 hours. For the first phase, the LF inclusion reduced the initial setting down to $56 \mathrm{~min}, 53 \mathrm{~min}$, and $37 \mathrm{~min}$ for w/f of $0.32,0.40$, and 0.50 , respectively. At the same time, some mixtures with $\mathrm{w} / \mathrm{f}=0.50$ displayed delayed initial setting time up to $53 \mathrm{~min}$ (i.e. $0.21-100-0.50$ ). In the second phase, shortening trends of setting time are intensified, similarly to the increasing effects observed for mixes $\mathrm{w} / \mathrm{f}=0.50$.

a)

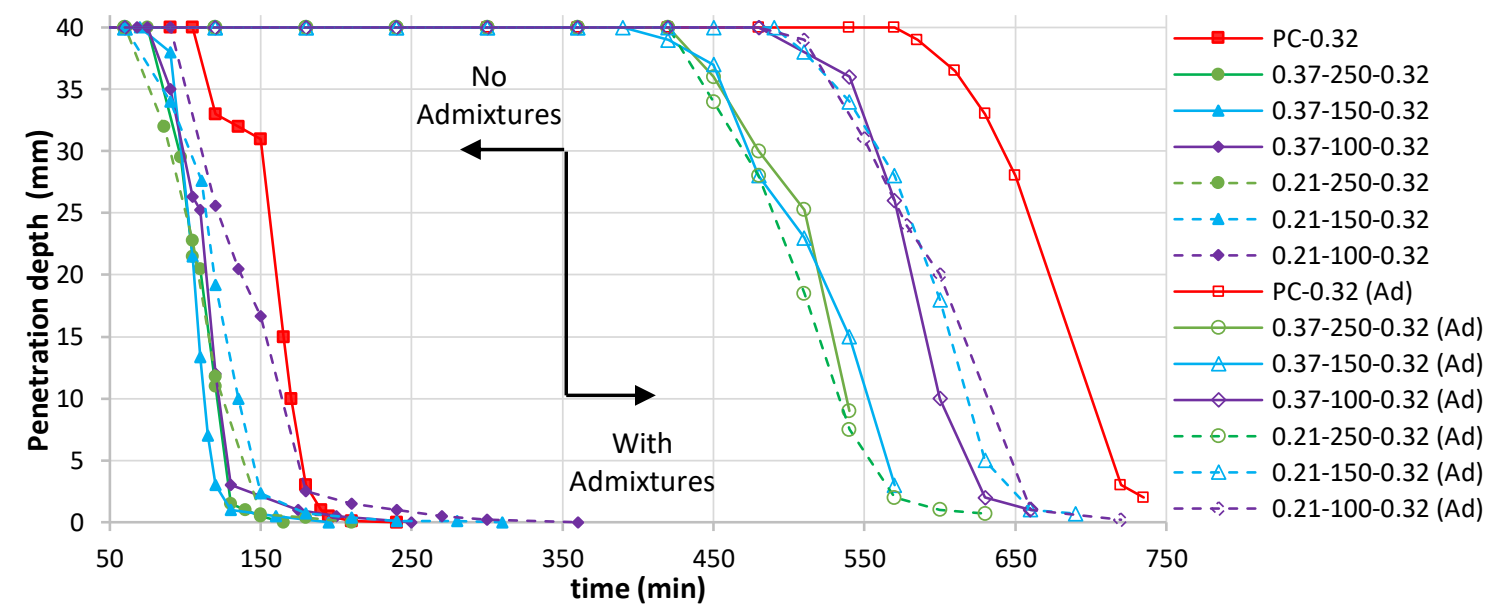

b) 


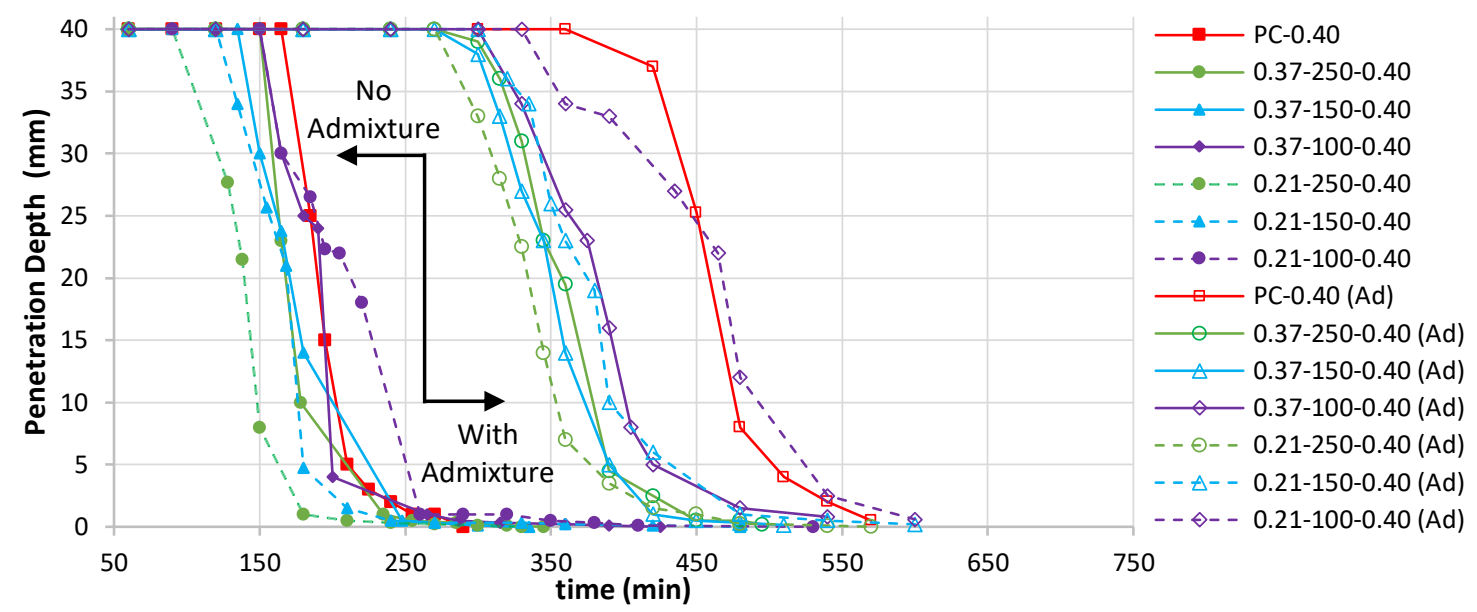

c)

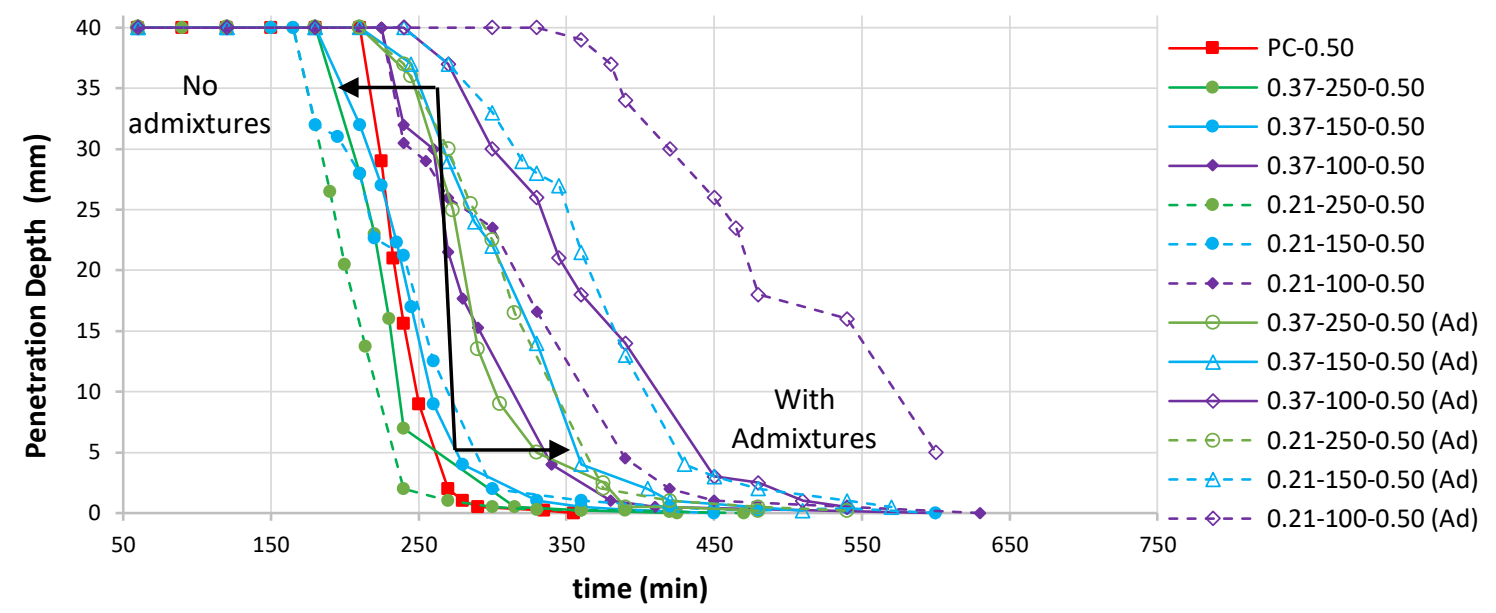

Figure 4-7: Setting history of pastes of stage 1: $0 \%$ Plasticizers and Stage 2: With Plasticizers. a) Mixes $\mathrm{w} / \mathrm{f}=0.32, \mathrm{~b}$ ) Mixes $\mathrm{w} / \mathrm{f}=0.40$ and c) mixes $w / \mathrm{f}=0.50$. Ad. Stands for admixtures

Note: The first number of the mixture notation stands for the $\mathrm{q}$ factor, the second is the PC content in $\mathrm{kg} / \mathrm{m}^{3}$ and the third one corresponds to the w/f.

\subsubsection{Compressive strength}

Figure 4-8 presents the compressive strength results of the paste mixtures (i.e. 21 Phase I and 21 Phase II) assessed at 7, 14, and 28 days, depicted in blue, orange, and green color, respectively. Shaded bars represent the f'c results of phase I ( $0 \%$ admixtures), while solid bars correspond to phase II. The w/c of all mixtures are presented in brackets along with the mixture labels. 
The compressive strength $\left(f^{\prime} c\right)$ at 7 days of pastes with chemical admixtures showed higher values than pastes without them, for most of the cases. However, 28-day f'c results are quite similar in both phases (i.e. without and with admixtures), evidencing negligible influence of plasticizers on the final compressive strength of all pastes, as expected. Exceptions were found for pastes PC-0.32 and PC 0.40 without admixtures, which could simply be an imprecise test outcome. Increasing values of $w / f$ result in lowering the compressive strengths at all ages evaluated. The use of low distribution factors (i.e. $\mathrm{q}=0.21$ ) represents larger amounts of fine particles in the system, resulting in lower $f^{\prime} c$ values compared to mixtures with $\mathrm{q}=0.37$.

It is important to highlight that the w/c seems to control the final $f^{\prime} c$ result; nonetheless, lower w/f results in higher $f^{\prime} c$ at equal w/c, as illustrated by mixtures $0.37-250-0.32$ (77.5 $\mathrm{MPa})$ and PC-0.40 (55.7 MPa) with equal $\mathrm{w} / \mathrm{c}=0.40$. Similar cases can be found in mixes $0.37-250-0.40$ versus $P C-0.50$ with $\mathrm{w} / \mathrm{c}=0.49-0.50$ and $0.37-100-0.32$ versus $0.37-150-0.50$ with a w/c=0.96-0.97. 


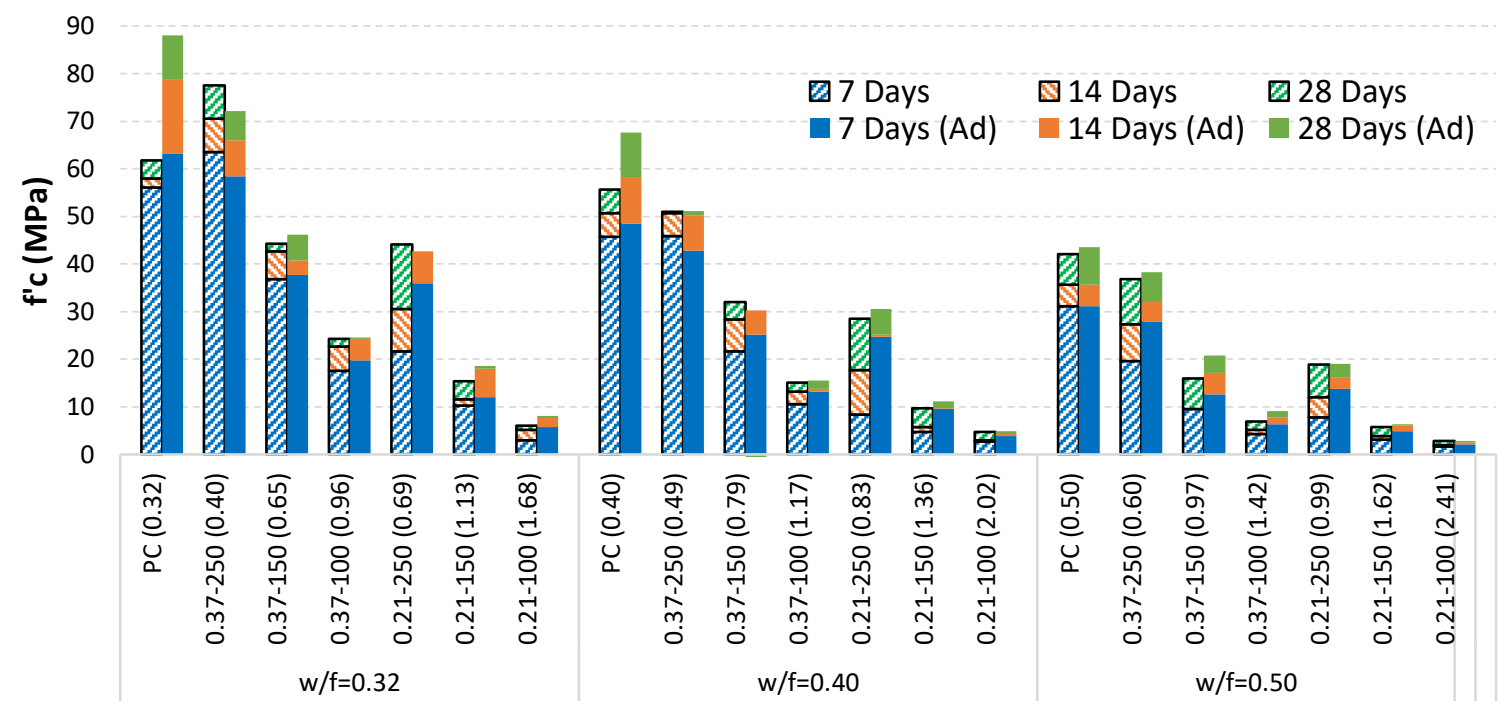

Figure 4-8: Compressive strength of pastes. Shaded bars: Mixes without admixtures. Solid bars: mixes with admixtures.

Note: The first number of the mixture notation stands for the q factor, the second is the PC content in $\mathrm{kg} / \mathrm{m}^{3}$ and the number in brackets corresponds to the w/c.

\subsection{Discussion}

\subsubsection{Influence of the IPS on the viscosity behaviour of cementitious systems}

One of the aims of this project was to understand the influence and impact of the IPS on the rheological behaviour of cement paste mixtures incorporating LF. Figure 4-9 presents measured viscosities as a function of calculated IPS values (see Table 4-3). Figure 4-9 a and $\mathrm{b}$ correspond to pastes without admixtures at 5 and $60 \mathrm{rpm}$, respectively, while Figure 4-9c and d illustrate pastes with admixtures. All the plots display a downward trend showing that the IPS indeed influences the flow behaviour of cementitious pastes, yet this relationship is more or less accurate, depending on the mixture features and the rotation speed. Therefore, one may think that other parameters might be considered to better describe the fresh state performance of those mixtures. 
a)

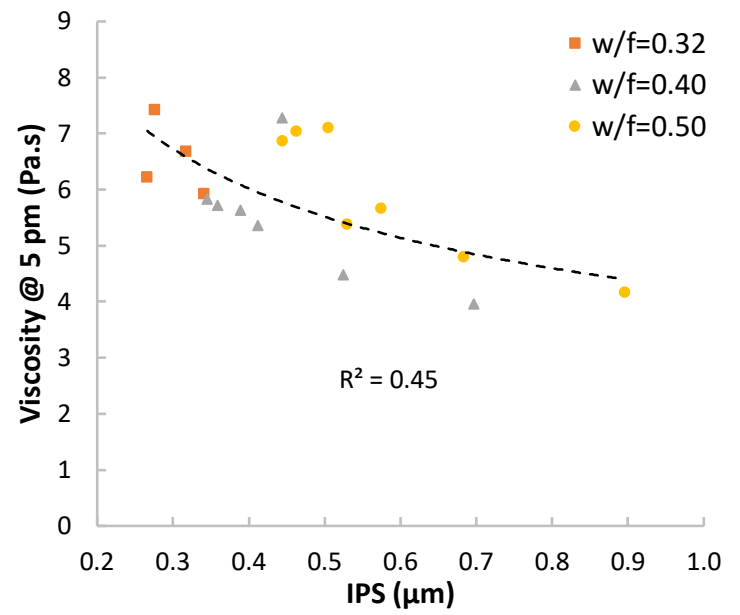

b)

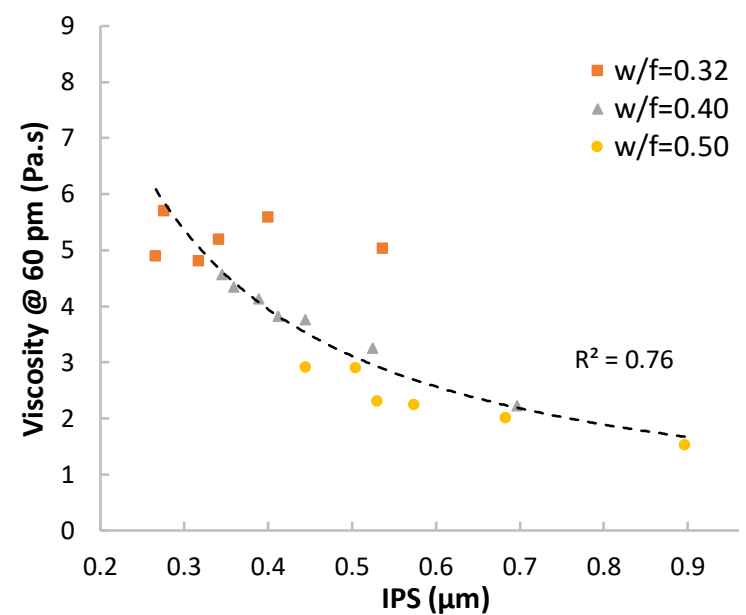

c)

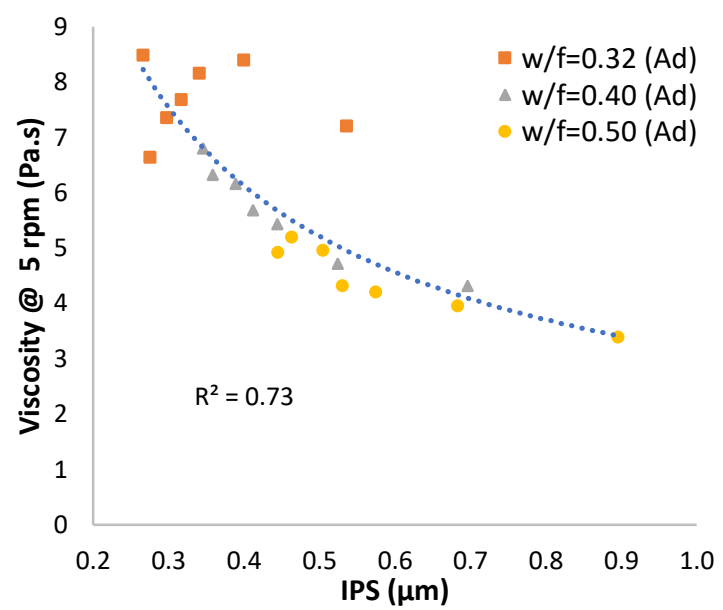

d)

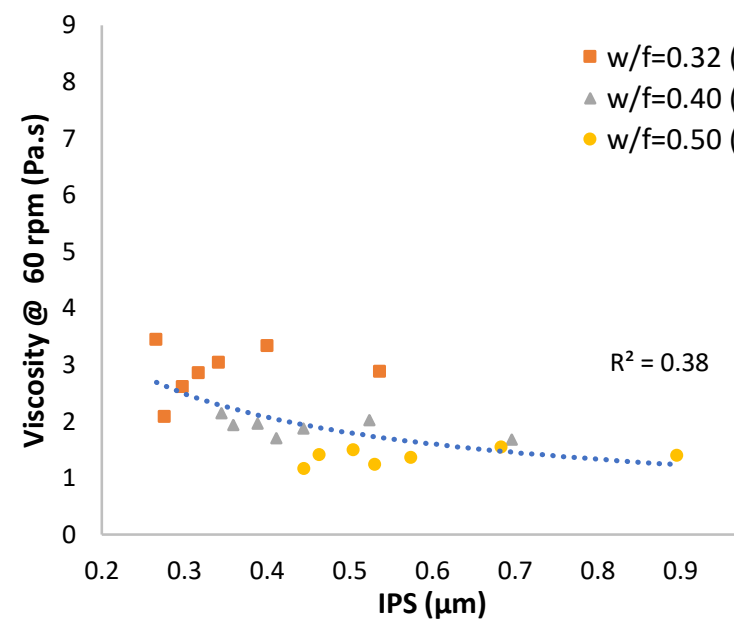

Figure 4-9: Relationship of IPS and viscosity at different shear rates a) $5 \mathrm{rpm}$, b) $60 \mathrm{rpm}$ without admixtures and c) 5rpm, d) 60 rpm with admixtures.

Some authors have studied and agreed that the sole use of IPS to predict the viscosity of cementitious materials is insufficient (Pileggi et al. 2000; F.S. Ortega et al. 2002; de Oliveira et al. 2000; Damineli et al. 2016). The IPS concept in multi-sized systems (multimodal) represents the distance between two adjacent particles enabling or preventing a third particle to move around. Thus, particles smaller than the IPS will be able to move around, whereas particles equal to or larger than the IPS will collide (Damineli et al. 2016). The latter can be described by the relationship between IPS and the diameter of a given 
particle size (dp), the so-called "IPS/dp", and might provide different insights to better predict the flow behaviour of cementitious materials through the use of IPS. Furthermore, it has been found that dp does not necessarily interact with all the particle sizes present within the PSD. According to Farris (1968), a random particle size dp only interacts with particles 10 times larger or smaller. Outside this range, there is no interaction between the particles and thus either they behave as fluid or walls, respectively. Additionally, Farris (1968) stated that multimodal systems may be studied as a combination of sub-systems. Hence, the motion ability of a given particle size to move around should be evaluated within its interaction range.

$I P S_{i}$ is defined as the interparticle spacing for the interaction range of a given particle size $d p_{i}$ and $I P S_{i} / d p_{i}$ will be the degree of freedom of the sub-system defined by the particle $d p_{i}$. Thus, the degree of freedom may be evaluated for all particle sizes present within the system. The degree of freedom of the entire system can be calculated as the weighted average of the individual IPSi / dpi values for each sub-system considered, as per Equation 4-4.

$$
\frac{I P S}{d p}=\sum_{i=1}^{n} x_{i} * \frac{I P S_{i}}{d p_{i}}
$$

where: $i$ represents the number of particle sizes present in the PSD and $x_{i}$ the volume proportion of particles of size dp $\mathrm{i}$ (i.e. discrete volume percentage of the particle size $\mathrm{dp}_{\mathrm{i}}$ ).

Figure 4-10 shows the cement paste viscosity values as a function of IPS/dp for different torque regimes. A comparison between the sole use of IPS (Figure 4-9) and the proposed ratio (Figure 4-10) evidences a significant improvement of the latter. The use of IPS/dp seems indeed to much better describe the viscosity behaviour of cementitious systems, 
emphasizing that different torque regimes (low, moderate, and high torque scenarios) will be represented by distinct trends. Hence, knowing the torque regime as per a given application (i.e. vibration, pumping, etc.), cementitious materials might be mixproportioned accounting for IPS/dp to reach targeted viscosity values.

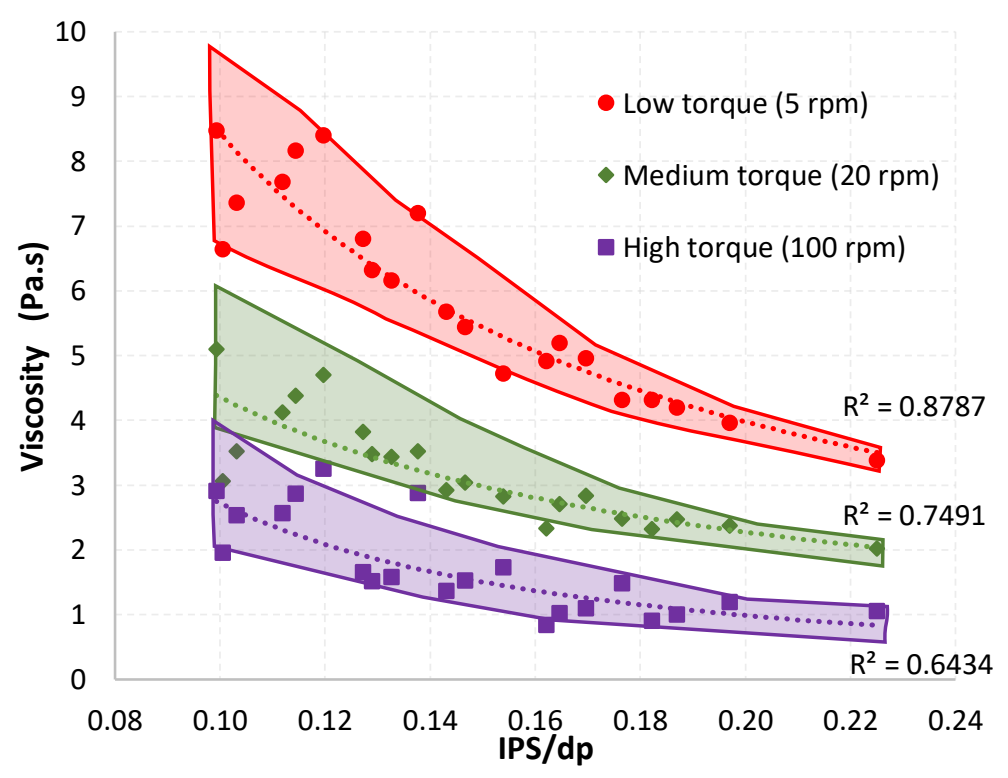

Figure 4-10: Relationship of the IPS $/ \mathrm{d}_{0}$ and viscosity at different torque regimes.

\subsubsection{Rheological behaviour}

Brookfield DV-E Viscometer provides viscosity values in Pa.s over a range of rotational speeds in rpm. These outputs require some treatment to generate the rheological profile of cementitious mixtures (i.e. shear stress versus shear rate relationship). Mitschka (1982) proposed a simple conversion from rotational speeds into shear rates. The method provides conversion curves for each disc spindle (i.e. SP1 to SP6) to be correlated linearly with the number of rpm, changing the scale of 5 to $100 \mathrm{rpm}$ into 2.05 to $41.00 \mathrm{~s}^{-1}$.

However, the shear stress calculations require further considerations. The viscosity readings can be defined as "differential" or "apparent" at a given shear rate. The first is the slope of the shear stress versus shear rate curve in a particular point, while the second is 
the inclination of a straight line connecting the origin with a given shear rate as illustrated in Figure 4-11 (Feys, Verhoeven, and Schutter 2009). For simplification purposes, the apparent viscosity (i.e. second approach) was adopted in this research. Thus, the shear stress of each viscosity reading may be calculated according to Equation 4-5

$$
\tau=\eta * \dot{\gamma}
$$

Equation 4-5

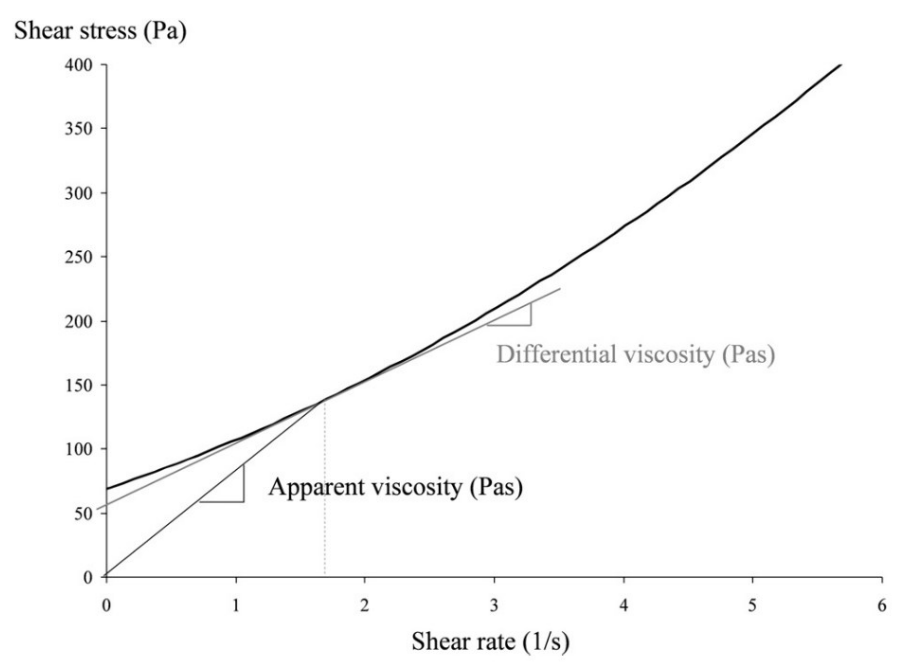

Figure 4-11: Differential viscosity and apparent viscosity determined at a given shear rate (Feys, Verhoeven, and Schutter 2009)

Figure 4-12 presents the rheological profiles of the studied mixes containing admixtures (i.e. phase 2 mixtures). An evident reduction on the apparent viscosity can be observed as w/f increases since less steep slopes are found. Furthermore, not only the slopes but also the curve shapes change as a function of $w / f$; mixes with a $w / f=0.32$ display a roughly linear trend, and thus may be classified as Bingham fluids (i.e. viscosity does not change as a function of torque). Otherwise, both mixes with $\mathrm{w} / \mathrm{f}=0.40$ and 0.50 yield a concave trend (i.e. decreasing slope as a function of the torque), being classified as shear-thinning fluids. Similar behaviour was found in mixtures without admixtures.

a)

b) 

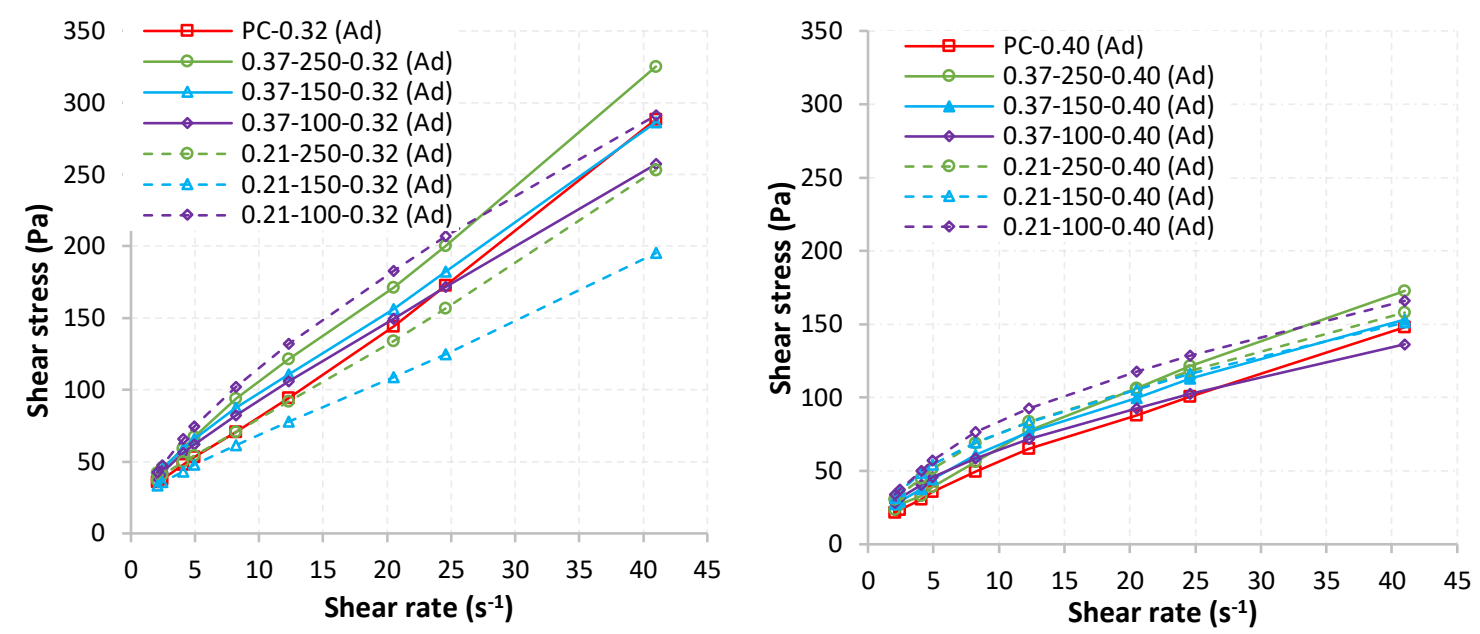

c)

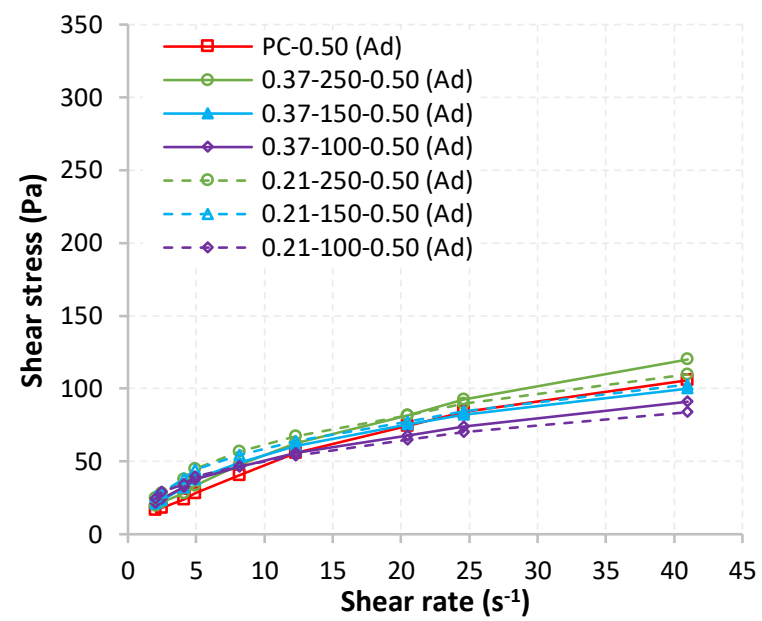

Figure 4-12: Rheological behaviour of pastes proportioned with distinct w/f, a) 0.32 , b) 0.40 and c) 0.50 . Note: The first number of the mixture notation stands for the $\mathrm{q}$ factor, the second is the PC content in $\mathrm{kg} / \mathrm{m}^{3}$ and the third one corresponds to the w/f.

Besides viscosity, it is quite important to understand the impact of LF, distribution factors, and $\mathrm{w} / \mathrm{f}$ ratio on the yield stress of the mixtures (i.e. minimum torque required to enable flow also known as critical torque). In Figure 4-12, mixes 0.21-250-0.32 and 0.21-1500.32 display lower yield stress than the pure PC mix, yet the other four mixes require higher energy to flow. Conversely, all the mixes with $\mathrm{w} / \mathrm{f}=0.40$ and $\mathrm{LF}$ showed higher yield stress than the pure PC mixture. An exception is observed for the $0.37-100-0.40$ mixture. Finally, the replacement of PC by LF in the group with $w / f=0.50$ increased the yield stress of the mixes. 
From the previous descriptions, it becomes evident that PC replacement by LF may provide a flow enhancement in some cases, although LF can also worsen the overall fresh state behavior by increasing the yield stress of the mix. As mentioned before, the inclusion of the right proportions of LF improves the packing density of the system, leading to lower porosity that otherwise would have been filled by water. Hence, this unused water becomes free water volume that might contribute to increase the IPS and thus improve the mix flow properties (Kwan and Chen 2012; Aiqin, Chengzhi, and Ningsheng 1999). In contrast, the inclusion of LF provides the system with larger SSAs, which in turn reduce the IPS (Ferraris, Obla, and Hill 2001) hindering the particle mobility. The resulting balance of these two opposite effects will grant the mixture with either flow improvement (viscosity reduction) or thickening of the paste (viscosity increase). This balance can be controlled by the IPS/dp by selecting combinations of q factors in the PPMs and LF dosages leading to the largest IPS/dp.

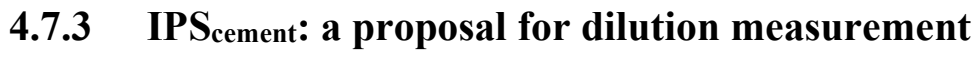

The idea of a fluid that coats and separates solid particles (i.e. IPS or water film thickness) has been applied to understand the fresh state behaviour of cementitious materials (F.S. Ortega et al. 2002; Kwan and Chen 2012; Funk and Dinger 1994). However, this concept might also be adopted to describe or at least better understand other properties such as setting time and or hardened state behaviour (e.g. compressive strength of highly packed systems).

It is well recognized that the $f^{\prime} c$ decreases as the w/c ratio increases as per Abrams' Law (Abrams 1924; Mehta and Monteiro 2006; Mindess, Young, and Darwin 2003). Conversely, the distance between PC particles is raised when w/c increases; therefore $f^{\prime} \mathrm{C}$ 
and the distance among PC particles are indirectly related (Dale P. Bentz and Pierre-Claude Aitcin 2008; Pierre-Claude. Aitcin and Sidney Mindess, n.d.). As previously discussed, the IPS represents the average distance among fine particles within a granular system; however, adapting this concept to display the distance among PC particles might also be of interest to understand setting time or compressive strength results. Therefore, a modified

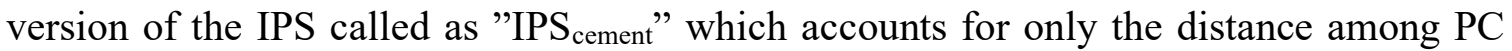
grains is proposed herein (Equation 4-6). One may consider this equation as a measurement of dilution effects induced by LF. Larger distance amongst PC particles implies larger dilution that may impact on the setting behaviour (Bentz et al. 2017) and hardened

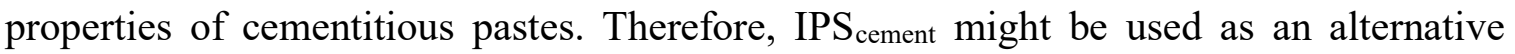
parameter to appraise the influence of dilution on the properties of low PC systems incorporating high LF dosages.

$$
I P S_{\text {cement }}=\frac{2}{V S A_{\text {cement }}} *\left(\frac{1}{V_{S(\text { cement })}} * \frac{1}{1-P_{O f(\text { cement })}}\right)
$$

\section{Equation 4-6}

where: IPS $\mathrm{sement}_{\text {is }}$ the distance among cement particles; Vscement is the volume solid fraction of the cement and $\mathrm{P}_{\text {of (cement) }}$ the dry porosity for pure cement. The volume unity accounts

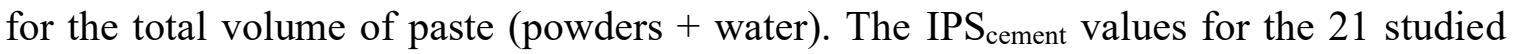
mixes are found in Table 4-4.

Table 4-4: Values of IPS $_{\text {cement }}$

\begin{tabular}{rl|rl|rl}
\hline Mix Name & IPS $_{\text {cement }}$ & Mix Name & IPS cement $_{\text {IP }}$ & Mix Name & IPS cement \\
\hline PC-0.32 & 0.54 & PC-0.40 & 0.70 & PC-0.50 & 0.90 \\
$0.37-250-0.32$ & 0.91 & $0.37-250-0.40$ & 1.06 & $0.37-250-0.50$ & 1.25 \\
$0.37-150-0.32$ & 1.98 & $0.37-150-0.40$ & 2.23 & $0.37-150-0.50$ & 2.53 \\
$0.37-100-0.32$ & 3.32 & $0.37-100-0.40$ & 3.69 & $0.37-100-0.50$ & 4.14 \\
$0.21-250-0.32$ & 2.17 & $0.21-250-0.40$ & 2.38 & $0.21-250-0.50$ & 2.62 \\
$0.21-150-0.32$ & 4.09 & $0.21-150-0.40$ & 4.44 & $0.21-150-0.50$ & 4.83 \\
$0.21-100-0.32$ & 6.49 & $0.21-100-0.40$ & 7.01 & $0.21-100-0.50$ & 7.60 \\
\hline
\end{tabular}




\subsubsection{Setting time and influence of IPS $_{\text {cement }}$}

Significant evidence found in the literature has proven that one of the major effects of LF in cement pastes is the acceleration of hydration rates (Oey et al. 2013; Tikkanen, Cwirzen, and Penttala 2014; Hawkins, Tennis, and Detwiler 2005; Bonavetti et al. 2003); therefore, reduction in setting times should be expected. Multiple results showed in Figure 4-7 agree with previous studies, especially for mixes with $\mathrm{w} / \mathrm{f}=0.32$ and $\mathrm{w} / \mathrm{f}=0.40$, where all the paste

combinations presented faster initial setting times than control PC mixes. However, not all the $w / f=0.50$ mixes behaved the same, and four out of the six LF-made mixes yielded delayed setting time.

It is known that the higher SSA of particles finer than PC increases the number of nucleation sites in the mixture, which promotes the precipitation of hydration products at higher rates (Villagran-Zaccardi, Falcone, and Benito. 2015; P. Thongsanitgarn et al. 2011). Therefore, the higher the SSA of the PC-LF mix, the lower the setting time. Yet, a combined mechanism (i.e. SSA + packing) might have a distinct impact on the resulting setting behaviour of cementitious mixtures than just the SSA of the particles. Knop and Peled (2016b) verified that higher packing densities enhanced the hydration rates, reducing the setting times of the mixtures. Conversely, the authors also found that loose packing conditions might delay the paste hardening, becoming a dominant factor in the resulting balance of SSA and packing.

The aforementioned combined mechanism provides an interesting insight on the understanding of the setting time patterns gathered in this research, where some mixtures incorporating LF reached the fastest setting times (i.e.0.37-250-0.50 and 0.21-250-0.50), while others with larger LF amounts displayed longer setting times, sometimes even longer 
than mixes with pure PC. The works from Knop and Peled (2016b) only studied the influence of fillers up to $35 \%$ of replacement. Yet, in the present work, much higher amounts of filler were used; the latter gives the opportunity to appraise Knop and Peled (2016b) outcomes for high filler contents but also to include a third mechanism in the system: IPS cement.

According to Scherer et al. (2012), PC particles distributed within the granular system need to keep growing (i.e. hydrating) until bonds are established between them, forming a continuous network of hydrated products (i.e. setting point). Therefore, excessive distance in the initial arrangement of PC grains (i.e. IPS $_{\text {cement }}$ ) will likely induce longer times to bind all particles together.

a)

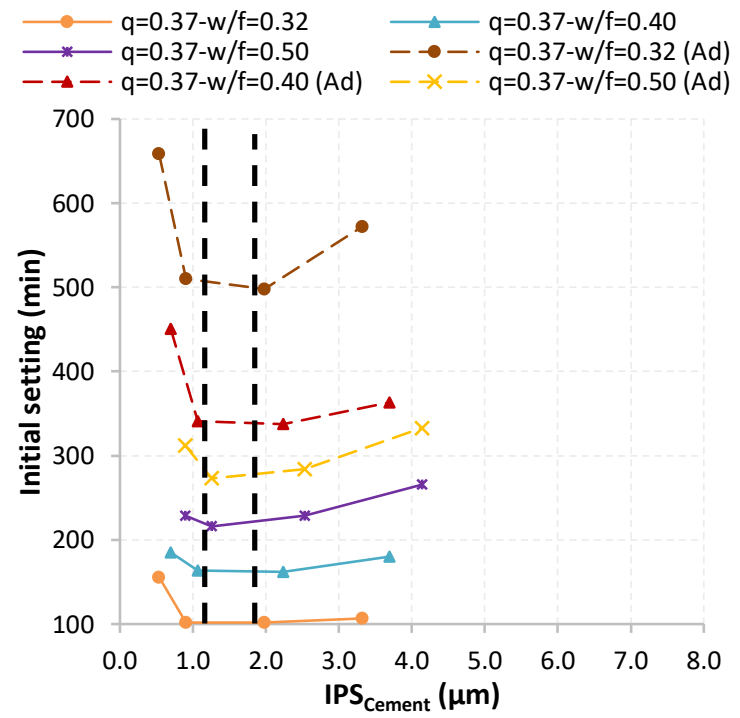

b)

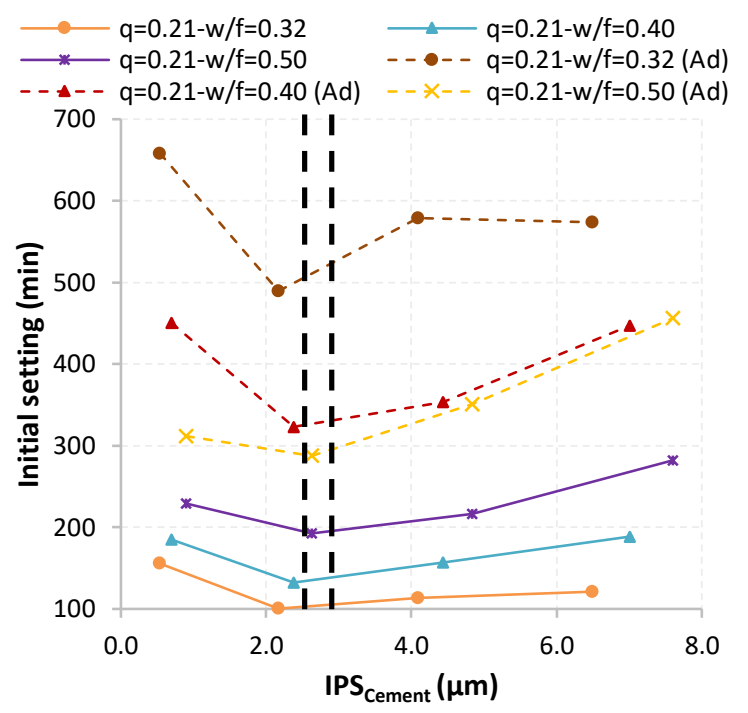

Figure 4-13: Initial setting time versus IPS cement. $_{\text {a) Pastes }} \mathrm{q}=0.37$, b) Pastes $q=0.21$

Figure 4-13a and $\mathrm{b}$ show the setting time of mixtures designed with distribution factors of 0.37 and 0.21 (respectively), as a function of the IPS $_{\text {cement. For mixtures with the highest }}$ packing density (i.e. $q=0.37$ ), a decrease in setting time is observed up until the point where IPS $_{\text {cement }}$ reaches values close to $1.25 \mu \mathrm{m}$. For these mixtures, LF particles are deemed to 
introduce further nucleation sites to the system, promoting an improved distribution of hydration products. Between 1.25 and $2.0 \mu \mathrm{m}$, the initial setting time seems to be roughly constant (based on the available data); yet, above and beyond this value, the initial setting starts increasing again, likely because the distance amongst PC particles becomes too large and thus limits the hydration products formation at the same rate.

Similarly, mixtures with larger amount of fines (i.e. $\mathrm{q}=0.21$ - Figure 4-13b) display a decrease in setting time, yet the IPS cement $_{\text {threshold is slightly increased this time (i.e. } 2.25}$ to $2.5 \mu \mathrm{m})$. Above and beyond this value, dilution effects overcome the filler effects. The difference in the IPS $S_{\text {cement }}$ threshold obtained for mixes with q of 0.37 and 0.21 may take place due to the number of fine particles present in the system; larger fine particles bring larger amounts of precipitation sites which enables a larger distance between PC grains

until the dilution effect becomes predominant. The latter suggests that the packing condition (i.e. distribution factor) influences on the setting time of cementitious materials, as previously mentioned by other authors.

\subsubsection{Compressive Strength}

\section{Correlation between compressive strength and w/f}

It has been found that Abrams' law in densely packed mixtures incorporating low PC content and high LF dosages might be different from conventional cementitious systems (M.T. de Grazia et al. 2019; Mayra T. de Grazia, Sanchez, and Pileggi 2018). Furthermore, recent research identified the potential adoption of $w / f$ as the parameter governing the hardened state properties of such eco-efficient systems (John et al. 2018a). Figure 4-14 gives a plot on the relationship between $f^{\prime} c$ and $\mathrm{w} / \mathrm{f}$ for all cement paste mixtures studied in this work. Analyzing the data, one notices that the higher the w/f, the lower the 28-day 
compressive strength results obtained. Yet, relationships are only possible for mixtures presenting similar distribution factors and PC contents (for instance, 0.37-150 - blue triangles), which emphasizes the unsuitability of the $\mathrm{w} / \mathrm{f}$ to be the sole and main parameter describing the mechanical performance of those mixtures.

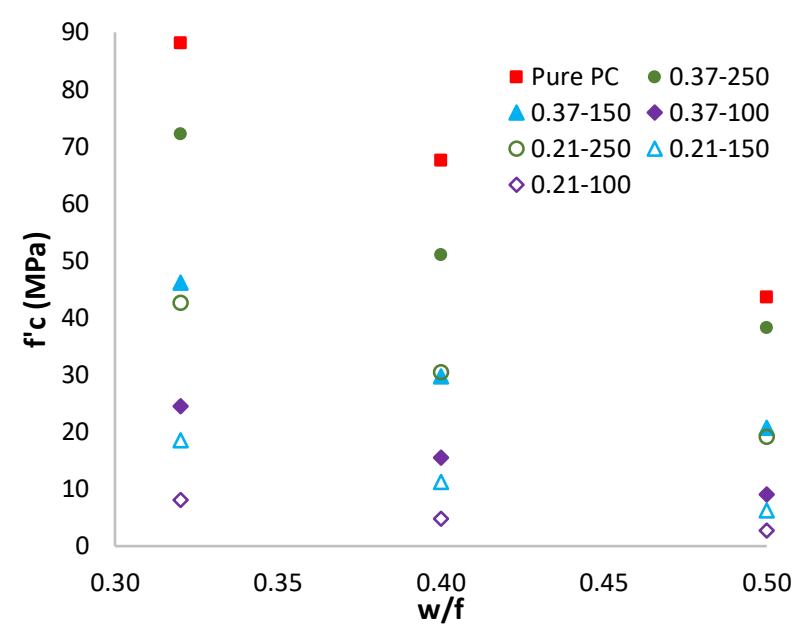

Figure 4-14: Compressive strength as function of water to fines ratio of densely packed cementitious systems incorporating distinct PC and LF contents

Note: The first number of the mixture notation stands for the $\mathrm{q}$ factor and the second one is the PC content in $\mathrm{kg} / \mathrm{m}^{3}$.

\section{Modified version of Abrams law}

Aiming to better describe the compressive strength of the mixtures studied, Figure 4-15a gives a plot on the relationship between $f^{\prime} \mathrm{c}$ and $\mathrm{w} / \mathrm{c}$ for all mixtures appraised in this work. From the plot below, one notices a clear decreasing trend for all mixes, regardless of their $\mathrm{w} / \mathrm{f}$ and PC content, which indicates that the $\mathrm{w} / \mathrm{c}$ is still the main parameter leading the compressive strength of densely packed mixtures incorporating low PC and high LF dosages. The shape of the curve can be compared to the traditional Abrams' law for conventional cementitious materials (e.g. pure PC pastes). Yet, the sole use of w/c ratio does not seem to be sufficient to fully explain the mechanical responses obtained in this work since different compressive strength results were gathered from mixes presenting the same w/c and distinct packing densities and amounts of LF. For instance, mixture 0.37- 
250-0.32 with $\mathrm{w} / \mathrm{c}=0.40$ presents higher compressive strength than pure cement paste PC0.40 with no LF replacement neither optimized through PPM.
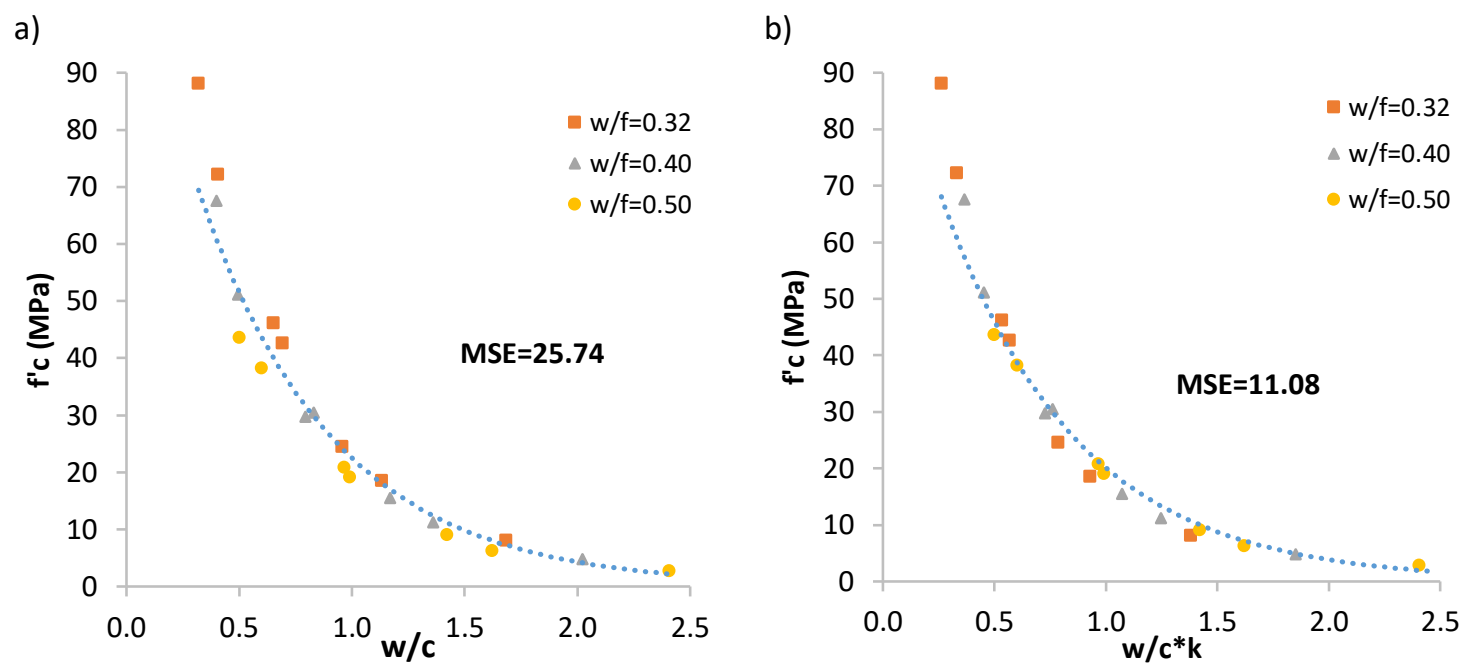

Figure 4-15: Influence of water to cement and water to fines ratio in compressive strength of blended mixes with $\mathrm{LF}$

$$
\begin{gathered}
k=\left(2.1 * \frac{w}{f}\right)^{0.5} \\
f^{\prime} c=147.64 / 8.72^{\left(\frac{w}{c} * k\right)}
\end{gathered}
$$

Equation 4-7

Equation 4-8

The discussion above indicates that improvements could be made on the conventional Abrams' law, likely incorporating the amount of fines in the system to analyze a highly packed system with a high amount of LF. In this work, a modified version of Abrams' law is proposed, accounting for both $\mathrm{w} / \mathrm{c}$ and $\mathrm{w} / \mathrm{f}$ and based on the mechanical behaviour obtained from 21 mixtures investigated. A $k$ factor, which is a function of $\mathrm{w} / \mathrm{f}$ (Equation 4-7), is incorporated into the conventional Abrams' equation to describe the amount of fines in the granular system. The proposed model is displayed in Equation 4-8 and illustrated in Figure 4-15b.

Evaluating the minimum square error (MSE) for a traditional relationship $f^{\prime} c$ versus w/c (presented in Figure 4-15), one may clearly see a reduction in the error of the prediction 
model for compressive strength when $\mathrm{w} / \mathrm{f}$ is accounted as an adjustment factor. The latter attests a significant improvement achieved by the new model.

\section{Correlation between compressive strength and IPS cement}

As an alternative to predict the compressive strength of highly packed cementitious pastes

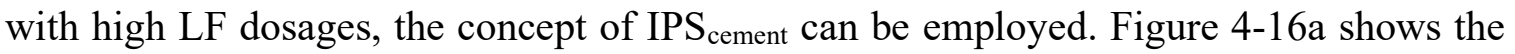
exponential relationship between the IPS $\mathrm{S}_{\text {cement }}$ and the compressive strength of mixtures presenting distinct w/f. Results show that lower w/f is related to higher compressive

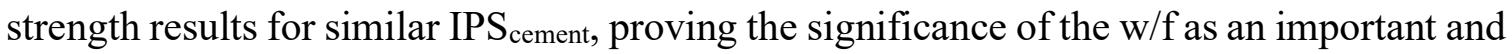
secondary factor to describe the compressive strength of eco-efficient mixes. Nevertheless,

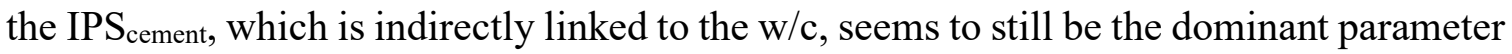
controlling the mechanical results of these cement paste mixtures. Equation 4-9 and Figure

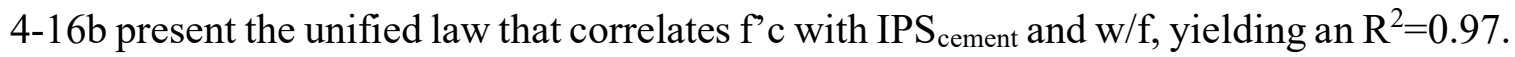
This equation may be used to predict the compressive strength of eco-efficient cementitious mixes, regardless of their cement and filler contents, and w/c.

a)

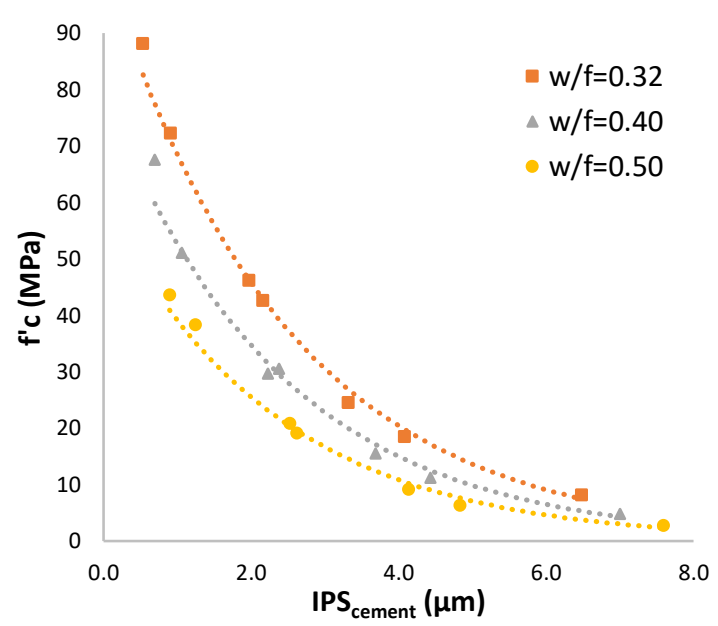

b)

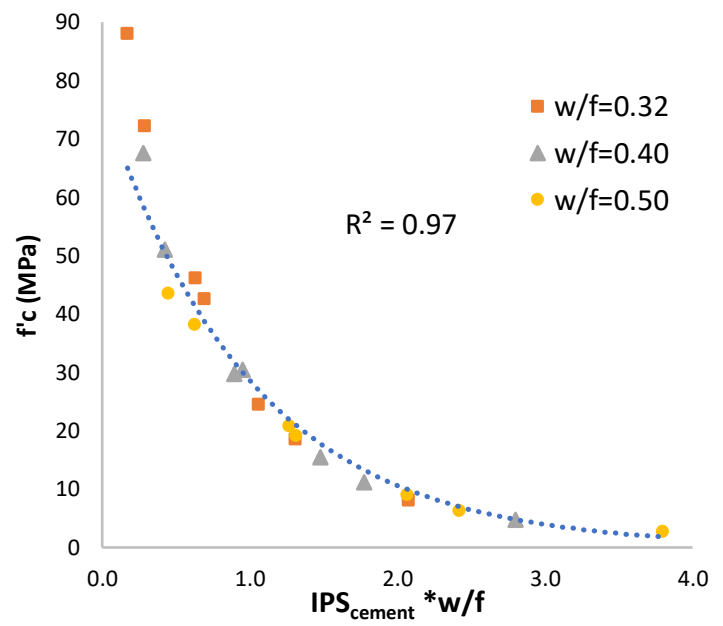

Figure 4-16: Influence IPS ${ }_{\text {cement }}$ on compressive strength of blended mixes with LF. 


$$
f^{\prime} c=100 / 3.75\left(I P S_{\text {cement }} * \frac{w}{f}\right)
$$

Equation 4-9

It is worth noting that numerous studies (Wang, Shi, Farzadnia, Shi, and Jia 2018; Palm et al. 2016; P. Thongsanitgarn et al. 2011) have found reductions in compressive strength when PC was directly replaced by LF, without considering the fillers dilution effect (Bonavetti et al. 2003; John et al. 2018a). However, results presented herein suggest that cementitious mixes incorporating important LF dosages may display higher compressive strengths than pure PC mixes at the same $\mathrm{w} / \mathrm{c}$; the latter can be attributed to the increase in packing density and porosity lessening of these mixtures (Wang, Shi, Farzadnia, Shi, and Jia 2018). Therefore, although the $\mathrm{w} / \mathrm{c}$ can still be considered the main factor leading the compressive strength of these mixtures, the implementation of the amount of fines in the granular system (i.e. w/f) may significantly improve the prediction of the hardened state properties (i.e. compressive strength) of low binder content mixtures incorporating high LF dosages.

\subsection{Conclusions}

The present work studied the influence of IPS on the fresh and hardened state properties of densely packed cement paste mixtures with and without chemical admixtures (i.e. combination of high and mid-range plasticizers) and incorporating low binder and high LF dosages. The main findings of the current research are presented hereafter:

- Plasticizers were seen to reduce the viscosity of pastes regardless of the torque regime. Pastes with admixtures presented smother rheological behaviours that were better described by established rheological models;

- The IPS concept accounts directly and indirectly for multiple mechanisms affecting the viscosity of cementitious pastes such as the volume surface area, packing density, etc. 
Yet, it was found that the IPS $/ \mathrm{d}_{\mathrm{o}}$ ratio provides a better and more precise viscosity of these mixtures. Thus, knowing the torque regime as per a given application, cementitious materials can be proportioned accounting for IPS/dp to reach targeted viscosity values;

- The cement paste mixtures evaluated in this research could be classified either as Bingham or shear-thinning fluids;

- The inclusion of LF to cement paste mixtures negatively influenced their slump retention. Lower water contents also evidenced faster slump losses than mixtures with higher amounts of water;

- The use of plasticizers delayed in the setting times of cement paste mixtures, as expected. The admixture dosage was found to be proportional to the delay in setting initiation;

- The setting behavior of densely packed systems incorporating high LF dosages depends

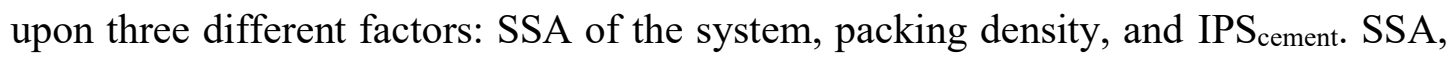
accelerates hydration rates, thus a decrease in setting time is observed. Likewise, the higher the packing density, the faster the initial setting times. Finally, excessive dilution

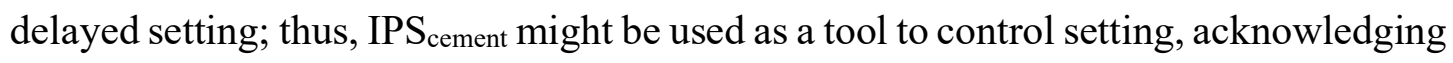

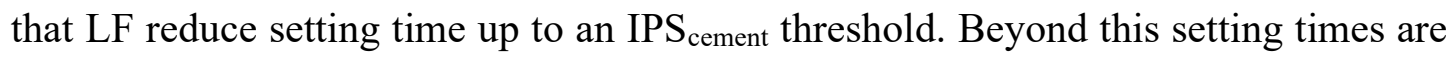
delayed;

- Densely packed systems with important LF dosages can yield better compressive strength results than pure PC mixtures, especially when the dilution effects are accounted and the $\mathrm{w} / \mathrm{c}$ of the blend $(\mathrm{PC}+\mathrm{LF})$ is close to the pure $\mathrm{PC}$ mixture. Adequate proportioning of LF may lessen porosity and enhance the packing density of the system; 
- It has been demonstrated that $\mathrm{w} / \mathrm{c}$ is the leading parameter to set the compressive strength of eco-efficient systems. Yet, the sole use of w/c is not enough to properly describe the influence of the fines and packing density within the system. Therefore, the w/f (i.e. in mass) was successfully observed and used as a secondary important parameter to better predict the compressive strength performance of these mixtures;

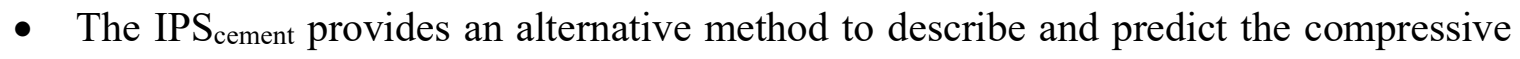
strength of cementitious mixtures with significant dosages of LF and reduced PC

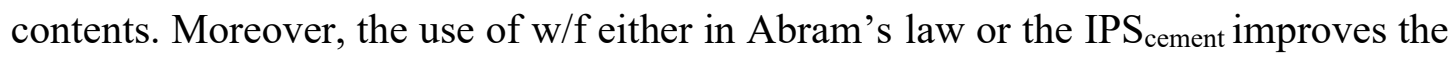
accuracy of the f'c prediction. Thus, a target compressive strength of a highly packed system with high LF dosages can be achieved by selecting w/c and w/f or IPS cement $_{\text {and }}$ $\mathrm{w} / \mathrm{f}$. 


\subsection{References}

Abrams, Duff. A. 1924. "Design of Concrete Mixtures." Lewis Institute. Lewis Institute, Structutal Materials Research Laboratoty, Chicago.

http://www2.cement.org/pdf_files/ls001.pdf.

Aiqin, Wang, Zhang Chengzhi, and Zhang Ningsheng. 1999. "The Theoretic Analysis of the Influence of the Particle Size Distribution of Cement System on the Property of Cement" 29: 1721-26.

Ametek, Brookfield. n.d. "Brookfield DVE Digital Viscometer Operating Instructions."

Andreasen, A. H. M. 1930. "Ueber Die Beziehung Zwischen Kornabstufung Und Zwischenraum in Produkten Aus Losen Körnern (Mit Einigen Experimenten)." Colloid and Polimer Science 50 (3): 217-28.

Andrew, Robbie M. 2018. "Global CO2 Emissions from Cement Production, 19282017.” Earth System Science Data 10 (4): 2213-39. https://doi.org/10.5194/essd-102213-2018.

ASTM International. 2018a. "ASTM C191-18a, Standard Test Methods for Time of Setting of Hydraulic Cement by Vicat Needle." ASTM International, 1-8. https://doi.org/10.1520/C0191-18A.2.

_. 2018b. "ASTM C39-18: Standard Test Method for Compressive Strength of Cylindrical Concrete Specimens." ASTM International, 1-8. https://doi.org/10.1520/C0039.

Banfill, P F G. 2014. Rheology of Fresh Cement and Concrete. https://doi.org/10.4324/9780203473290.

Bentz, Dale P, Chiara F Ferraris, Scott Z Jones, Didier Lootens, and Franco Zunino. 2017. "Limestone and Silica Powder Replacements for Cement : Early-Age Performance" 78: 43-56.

Bonavetti, V., H Donza, G. Menéndez, O. Cabrera, and E. F. Irassar. 2003. "Limestone Filler Cement in Low w/c Concrete: A Rational Use of Energy." Cement and Concrete Research 33 (6): 865-71. https://doi.org/10.1016/S0008-8846(02)01087-6. Brookfield Ametek. 2008. "Spindles." www.brookfield engineering.com.

- 2017. "More Solutions to Sticky Problems."

Dale P. Bentz, and Pierre-Claude Aitcin. 2008. "The Hidden Meaning of Water- Cement Ratio Distance between Cement Particles Is Fundamental." Concrete International, no. May: 51-54.

Damineli, Bruno L., Vanderley M. John, Björn Lagerblad, and Rafael G. Pileggi. 2016. "Viscosity Prediction of Cement-Filler Suspensions Using Interference Model: A Route for Binder Efficiency Enhancement." Cement and Concrete Research 84: 819. https://doi.org/10.1016/j.cemconres.2016.02.012.

Dinger, Dennis R., and James E. Funk. 1997. "Particle-Packing Phenomena and Their Application in Materials Processing." MRS Bulletin 22 (12): 19-23. https://doi.org/10.1557/S0883769400034692.

F.S. Ortega, R.G. Pileggi, A.R. Studart, and V.C. Pandofelli. 2002. "IPS A Viscosity Predictive Parameter." American Ceramic Society Bulletin 81 (1): 44-52.

Farris, R J. 1968. "Prediction of the Viscosity of Multimodal Suspensions from Unimodal Viscosity Data." The Society of Rheology 12 (2): 281-301. https://doi.org/10.1122/1.549109. 
Fennis, S.A.A.M. 2011. "Design of Ecological Concrete by Particle Packing Optimization.” Delft University of Technology.

Fennis, Sonja A.A.M., and J. C. Walraven. 2012. "Using Particle Packing Technology for Sustainable Concrete Mixture Design." Heron 57 (2): 73-101.

Ferraris, Chiara F. 1999. "Measurement of the Rheological Properties of High Performance Concrete : State of the Art Report" 104 (5).

Ferraris, Chiara F, Karthik H Obla, and Russell Hill. 2001. "The Influence of Mineral Admixtures on the Rheology of Cement Paste and Concrete" 31: 245-55.

Feys, Dimitri, Ronny Verhoeven, and Geert De Schutter. 2009. "Why Is Fresh SelfCompacting Concrete Shear Thickening?" Cement and Concrete Research 39 (6): 510-23. https://doi.org/10.1016/j.cemconres.2009.03.004.

Fuller, William B, and S.E. Thompson. 1907. "The Laws of Proportioning Concrete." American Society of Civil Engineers 33: 223-98.

Funk, James E., and Dennis R. Dinger. 1994. Predictive Process Control of Crowded Particulate Suspensions. https://doi.org/10.1007/978-1-4615-3118-0.

Furnas, C.C. 1931. "Grading Aggregates I - Mathematical Relations for Beds of Broken Solids of Maximum Density." U.S. Bureau of Mines 23 (9): 1052-58. https://doi.org/10.1021/ie50261a017.

Gartner, Ellis, and Hiroshi Hirao. 2015. "A Review of Alternative Approaches to the Reduction of CO 2 Emissions Associated with the Manufacture of the Binder Phase in Concrete." Cement and Concrete Research 78: 126-42. https://doi.org/10.1016/j.cemconres.2015.04.012.

Grazia, M.T. de, L.F.M. Sanchez, R.C.O. Romano, and R.G. Pileggi. 2019. "Investigation of the Use of Continuous Particle Packing Models (PPMs) on the Fresh and Hardened Properties of Low-Cement Concrete (LCC) Systems." Construction and Building Materials 195: 524-36. https://doi.org/10.1016/j.conbuildmat.2018.11.051.

- 2020. "Evaluation of the Fresh and Hardened State Properties of Low Cement Content Systems." Magazine of Concrete Research 72 (5): 232-45.

Hao, Tian, and Richard E Riman. 2006. "Calculation of Interparticle Spacing in Colloidal Systems”V: 374-77. https://doi.org/10.1016/j.jcis.2004.10.014.

Hawkins, P, P D Tennis, and R J Detwiler. 2005. The Use of Limestone in Portland Cement : A State-of-the-Art Review. Stokie, Illinois, US: Portland Cement Association.

Hernandez-Rubio, F-J. 2018. "Rheological Behavior of Fresh Cement Pastes." Fluids 3. https://doi.org/10.3390/fluids3040106.

Hooton, R. D., M Nokken, and M D A Thomas. 2007. "Portland Limestone Cement: State of the Art Report and Gap Analysis For CSA A 3000.” Toronto.

International, ASTM. 2014. "ASTM C305-14 Standard Practice for Mechanical Mixing of Hydraulic Cement Pastes and Mortars of Plastic Consistency," 1-3. https://doi.org/10.1520/C0305-14.2.

John, Vanderley M., Bruno L. Damineli, Marco Quattrone, and Rafael G. Pileggi. 2018. "Fillers in Cementitious Materials - Experience, Recent Advances and Future Potential." Cement and Concrete Research 114 (September 2017): 65-78. https://doi.org/10.1016/j.cemconres.2017.09.013.

Knop, Yaniv, and Alva Peled. 2016a. "Packing Density Modeling of Blended Cement 
with Limestone Having Different Particle Sizes" 102: 44-50.

- 2016b. "Setting Behavior of Blended Cement with Limestone : Influence of Particle Size and Content," 439-52. https://doi.org/10.1617/s11527-014-0509-y.

Kronlöf, Anna. 1997. "Filler Effect of Inert Mineral Powder in Concrete." Espoo: VTT Technical Research Centre of Findland.

Kumar, Senthil V., and Manu Santhanam. 2003. "Particle Packing Theories and Their Application in Concrete Mixture Proportioning: A Review." Indian Concrete Journal 77 (9): 1324-31.

Kwan, A.K.H., and H.H.C. Wong. 2008. "Effects of Packing Density, Excess Water and Solid Surface Area on Flowability of Cement Paste." Advances in Cement Research 20 (1): 1-11. https://doi.org/10.1680/adcr.2008.20.1.1.

Kwan, Albert K.H., and Jia Jian Chen. 2012. "Roles of Packing Density and Water Film Thickness in Rheology and Strength of Cement Paste." Journal of Advance Concrete Technology 10: 332-44. https://doi.org/10.3151/jact.10.332.

Kwan, Albert K.H., and H.H.C. Wong. 2008. "Packing Density of Cementitious Materials : Part 2 - Packing and Flow of OPC + PFA + CSF." Materials and Structures 41: 773-84. https://doi.org/10.1617/s11527-007-9281-6.

Lagerblad, B, and E Forssberg. 2004. "The Function of Fillers in Concrete." Materials and Structures 37 (March): 74-81.

Larrard, F. 1999. Concrete Mixture Proportioning: A Scientific Approach. E \& FN Spo. London.

Ling, S K, and Albert K.H. Kwan. 2016. "Adding Limestone Fines as Cementitious Paste Replacement to Lower Carbon Footprint of SCC." Construction and Building Materials 111: 326-36. https://doi.org/10.1016/j.conbuildmat.2016.02.072.

LIU, Shuhua, and PeiyU YAN. 2010. "Effect of Limestone Powder on Microstructure of Concrete" 25 (2): 328-31. https://doi.org/10.1007/s11595-010-2328-5.

Lothenbach, Barbara, Karen Scrivener, and R. D. Hooton. 2011a. "Supplementary Cementitious Materials." Cement and Concrete Research 41 (12): 1244-56. https://doi.org/10.1016/j.cemconres.2010.12.001.

Lothenbach, Barbara, Karen Scrivener, and R D Hooton. 2011b. "Cement and Concrete Research Supplementary Cementitious Materials." Cement and Concrete Research 41 (12): 1244-56. https://doi.org/10.1016/j.cemconres.2010.12.001.

M. C. G. Juenger, and R. Siddique. 2015. "Recent Advances in Understanding the Role of Supplementary Cementitious Materials in Concrete." Cement and Concrete Research 78: 71-80. https://doi.org/10.1016/j.cemconres.2015.03.018.

Mangulkar, Mn, and Ss Jamkar. 2013. "Review of Particle Packing Theories Used For Concrete Mix Proportioning." International Journal Of Scientific \& Engineering Research 4 (5): 143-48.

Mehta, Kumar P. 2002. "Greening of the Concrete Industry for Sustainable Development." Concrete International 24 (7): 23-28.

Mehta, Kumar P., and Paulo J.M. Monteiro. 2006. CONCRETE Microstructure, Properties Ans Materials. McGraw Hill. https://doi.org/10.1036/0071462899.

Mindess, Sidney, Francis J Young, and David Darwin. 2003. Concrete. 2nd Edition. Edited by Inc Pearson Educatioon. New jersey: Prentice Hall.

Mitschka, P. 1982. "Simple Conversion of Brookfield R.V.T. Readings into Viscosity Functions." Rheologica Acta 21 (2): 207-9. 
Nehdi, M., and M. A. Rahman. 2004. "Estimating Rheological Properties of Cement Pastes Using Various Rheological Models for Different Test Geometry, Gap and Surface Friction." Cement and Concrete Research 34 (11): 1993-2007. https://doi.org/10.1016/j.cemconres.2004.02.020.

Noël, Martin, Leandro Sanchez, and Gholamreza Fathifazl. 2016. "Recent Advances in Sustainable Concrete for Structural Applications.” Sustainable Construction Materials \& Technologies 42050 (CAC 2009): 10.

Oey, Tandré, Aditya Kumar, Jeffrey W. Bullard, Narayanan Neithalath, and Gaurav Sant. 2013. "The Filler Effect: The Influence of Filler Content and Surface Area on Cementitious Reaction Rates.” Journal of the American Ceramic Society 96 (6): 1978-90. https://doi.org/10.1111/jace.12264.

Oliveira, I.R. de, A.R. Studart, R.G. Pileggi, and V.C. Pandolfelli. 2000. Dispersão e Empacotamento de Partículas: Princípios e Aplicações Em Processamento Cerâmico. Sao Paulo: Fazendo Arte.

Palm, Sebastian, Tilo Proske, Moien Rezvani, Stefan Hainer, Christoph Müller, and Carl Alexander Graubner. 2016. "Cements with a High Limestone Content - Mechanical Properties , Durability and Ecological Characteristics of the Concrete." Construction and Building Materials 119: 308-18.

Pierre-Claude. Aitcin, and Sidney Mindess. n.d. Sustainability of Concrete. 2011 th ed. Taylor and francis.

Pileggi, R G, A R Studart, V C Pandolfelli, Universidade Federal, De S Carlos Ufscar, Rod Washington, Luiz Km, and S Carlos. 2000. "Um Modelo Para Previsão Da Viscosidade Mínima de Suspensões Cerâmicas ( A New Model to Predict the Minimum Viscosity of Ceramic Suspensions )" 46 (299): 160-65.

Proske, Tilo, Stefan Hainer, Moien Rezvani, and Carl-alexander Graubner. 2013. "EcoFriendly Concretes with Reduced Water and Cement Contents - Mix Design Principles and Laboratory Tests." Cement and Concrete Research 51: 38-46. https://doi.org/10.1016/j.cemconres.2013.04.011.

Proske, Tilo, Stefan Hainer, Moien Rezvani, and Carl Alexander Graubner. 2014. "EcoFriendly Concretes with Reduced Water and Cement Content - Mix Design Principles and Application in Practice." Construction and Building Materials 67 (PART C): 413-21. https://doi.org/10.1016/j.conbuildmat.2013.12.066.

Raucci, J S, R T Cecel, R C O Romano, R G Pileggi, and V M John. 2018. "Effect of Mixing Method on the Mini-Slump Spread of Portland Cement Pastes." Ibracom Structures and Materials 11 (2): 410-20.

Scrivener, Karen L, Vanderley M John, and Ellis Gartner. 2018. "Eco-Efficient Cements : Potential Economically Viable Solutions for a Low-CO 2 Cement-Based Materials Industry." Cement and Concrete Research 114 (February): 2-26. https://doi.org/10.1016/j.cemconres.2018.03.015.

Shaughnessy, Richard, and Peter E. Clark. 1988. "THE RHEOLOGICAL BEHAVIOR OF FRESH CEMENT PASTES." Cement and Concrete Research 18: 327-41.

Snellings, Ruben. 2016. "Assessing, Understanding and Unlocking Supplementary Cementitious Materials.” RILEM Technical Letters 1: 50. https://doi.org/10.21809/rilemtechlett.2016.12.

Tan, Zhijun, Susan A Bernal, and John L Provis. 2017. "Reproducible Mini-Slump Test Procedure for Measuring the Yield Stress of Cementitious Pastes." Materials and 
Structures 50 (6): 1-12. https://doi.org/10.1617/s11527-017-1103-x.

Thongsanitgarn, P., W. Wongkeo, S. Sinthupinyo, and A. Chaipanich. 2011. "Effect of Limestone Powders on Compressive Strength and Setting Time of PortlandLimestone Cement Pastes." In TIChE International Conference 2011. Songkhla, Thailand. https://doi.org/10.4028/www.scientific.net/AMR.343-344.322.

Tikkanen, Johanna, Andrzej Cwirzen, and Vesa Penttala. 2014. "Effects of Mineral Powders on Hydration Process and Hydration Products in Normal Strength Concrete." Construction and Building Materials 72: 7-14. https://doi.org/10.1016/j.conbuildmat.2014.08.066.

United Nations. 2015. "Paris Agreement." United Nations Framework Convention on Climate Change, 27-52. http://bigpicture.unfccc.int/\#content-the-paris-agreemen.

Villagran-Zaccardi, Y. A., D.D. Falcone, and D.E. Benito. 2015. "Influence of Limestone Powder in the Setting and Hydration of Cement Paste in the Fresh State." In XIII Conference on Durability of Building Materials and Components, edited by Marco Quattrone, 359-66.

Wang, Dehui, Caijun Shi, Nima Farzadnia, Zhenguo Shi, and Huangfei Jia. 2018. "A Review on Effects of Limestone Powder on the Properties of Concrete." Construction and Building Materials 192: 153-66. https://doi.org/10.1016/j.conbuildmat.2018.10.119.

Westman, A. E R, and H. R. Hugill. 1930. "The Packing of Particles." Journal of the American Ceramic Society 13 (10): 767-79. https://doi.org/10.1111/j.11512916.1930.tb16222.x.

Wong, H H C, and Albert K.H. Kwan. 2008a. "Packing Density of Cementitious Materials : Measurement and Modelling," no. 3: 165-75. https://doi.org/10.1680/macr.2007.00004.

- 2008b. "Rheology of Cemen Paste: Role of Excess Water to Solid Surface Area Ratio." Journal of Materials in Civil Engineering 20 (2): 189-97. https://doi.org/10.1061/(ASCE)0899-1561(2008)20.

Worrell, Ernst, Lynn Price, Nathan Martin, Chris Hendriks, and Leticia Ozawa Meida. 2002. "Carbon Dioxide Emissions From the Global Cement Industry." Annual Review of Energy and the Environment 26 (1): 303-29. https://doi.org/10.1146/annurev.energy.26.1.303.

Yahia, A, and K H Khayat. 2001. "Analytical Models for Estimating Yield Stress of High-Performance Pseudoplastic Grout." Cement and Concrete Research 31: 73138.

Yanrong, Zhang, Kong Xiangming, G A O Liang, and Wang Jiaxin. n.d. "Rheological Behaviors of Fresh Cement Pastes with Polycarboxylate Superplasticizer" 31 (2): 286-99. https://doi.org/10.1007/s11595-016-1366-z.

Yousuf, S., L.F.M. Sanchez, and S.A. Shammeh. 2019. "The Use of Particle Packing Models (PPMs) to Design Structural Low Cement Concrete as an Alternative for Construction Industry." Journal of Building Engineering 25 (October 2018): 100815. https://doi.org/10.1016/j.jobe.2019.100815. 


\section{Chapter 5: Summary and Conclusion}

Production of materials with a low environmental footprint is crucial to stop global warming and to ensure economic growths framed within the context of sustainable development. Concrete is the second-most consumed material worldwide, but it represents an important burden to the atmosphere as the production of Portland cement (PC) is responsible for almost $8 \%$ of total $\mathrm{CO}_{2}$ emitted worldwide. Several strategies to reduce PC content in concrete have been studied in the past decades. Amongst those, advanced mixdesign techniques such as particle packing models (PPMs) along with the use of limestone fillers (LF) seem promising due to the enhancement of material properties in the fresh and hardened states.

Both techniques can be applied simultaneously, achieving significant reductions in PC content. Nevertheless, the fresh and hardened state performance of these low cement content cementitious mixtures with high amounts of LF should be further investigated. In this context, adopting theories of particle motion in suspensions such as the Interparticle Separation Distance (IPS) may be of help, providing insights on the fresh state behaviour of cementitious mixtures as well as on the development of prediction models.

This thesis focused on the assessment of cement paste mixtures presenting low cement content $\left(250,150\right.$, and $\left.100 \mathrm{~kg} / \mathrm{m}^{3}\right)$, high amounts of LF, and designed through a continuous PPM (i.e. Alfred model - using two q factors 0.21 and 0.37 ). The performance of a wide range of mixes in the fresh (i.e. slump flow and retention, rheological behaviour, and setting time) and hardened states (i.e. compressive strength) was appraised and compared to their specific IPS values (Chapter 3). Then, the concept of IPS was further explored and used to understand and forecast the fresh and hardened state behaviours obtained. 
Moreover, the influence of plasticizers was also evaluated (Chapter 4). The main conclusion that can be drawn from this research are presented hereafter:

\section{- Eco-efficiency}

Despite code regulations for minimum PC content in structural applications, the results of the current research suggest that low cement content cementitious mixtures (i.e. $<$ $250 \mathrm{~kg} / \mathrm{m}^{3}$ ) might present suitable performance in the fresh and hardened state. It has been found that the w/c, packing density, and IPS are key factors to achieve ecofriendly mixtures with a suitable performance for structural purposes.

- Slump retention

Limestone fillers reduce the slump retention properties of cement pastes, therefore special attention should be taken in this regard.

\section{- Rheological behaviour}

The viscosity of highly packed low cement content pastes incorporating high amounts of LF rely upon mainly two factors: a) packing density enhancement leading to better flow and b) increase of the specific surface area (SSA) of the particles. These two opposite effects can be accounted for by the IPS/dp ratio. The latter provides a prediction tool for evaluating the viscosity of cementitious materials at different torque regimes. Moreover, it is worth noting that all cement pastes evaluated in this research showed a shear-thinning behaviour (i.e. decrease of viscosity as a function of the torque applied), regardless of the cement content. This behaviour is quite suitable for vibrated and/or pumped mixes. 


\section{- $\quad$ Setting time}

The use of LF shortens the setting time of cementitious pates due to filler effects (enhancement of nucleation sites for hydrates growth). Conversely, moderate to high LF content may delay setting time due to dilution effects. The use of the interparticle separation distance between only PC grains (i.e. IPS $\mathrm{Sement}_{\text {) }}$ enables the prediction of the threshold where dilution effects exceed filler effects, which can be adopted while the material's mix-proportioning.

\section{- Compressive strength}

The improvement of packing density through the use of LF can enhance the compressive strength $\left(f^{\prime} c\right)$ of the material. Hence, the sole use of $\mathrm{w} / \mathrm{c}$ to forecast $f^{\prime} c$ is no longer suitable. Better predictions are made using a combination of $w / c$ and $w / f$ ratios, which indirectly accounts for the packing improvements due to LF.

\section{Chapter 6: Recommendations for future research}

A major goal of this research was to increase the body of knowledge of low cement content mixtures with high levels of LF for structural applications. Although it is considered that this work brings new insights and understanding of the fresh and hardened state behaviours of these mixtures, further investigation is still required in the field. The most important aspects as per the author are the following:

- It is important to scale up and appraise the achievements obtained in this research on mortar and/or concrete mixtures. Furthermore, further and similar studies should be conducted on the influence of the Maximum Paste Thickness (MPT) on the fresh and hardened properties of densely packed low cement content mixtures incorporating high LF dosages. Finally, the interaction between IPS and MPT should be investigated. 


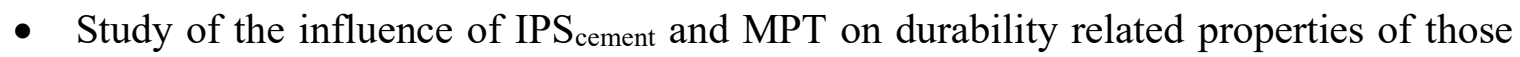
eco-friendly mixtures incorporating high LF dosages.

- Development of a formal concrete mix-design protocol using mobility parameters (i.e. IPS and MPT) coupled with PPMs to set, upon proportioning, targeted fresh, hardened, and durability related properties. 